E.A.Vagner Perm State Medical University

\title{
UTERINE MYOMA GUIDELINES
}

Study guide for students of the medical faculty

Perm 2021 


\begin{abstract}
Reviewers:
Head of the Department of Obstetrics and Gynecology of Kirov State Medical University, Doctor of Medical Sciences, Professor S.A. Dvorianskii;

Head of the Department of Obstetrics and Gynecology of the Faculty of Advanced Training and Professional Training of Izhevsk State Medical Academy, Doctor of Medical Sciences, Professor F.K. Tetelyutina
\end{abstract}

U92 UTERINE MYOMA GUIDELINES: Study guide for students of the medical faculty / N.V. Statnykh, M.M. Padrul, A.A. Olina, G.K. Sadykova, T.N. Chugaeva, E.V. Shirinkina.Perm, 2021. - $115 \mathrm{p}$.

ISBN 978-5-398-02513-2

The textbook covers the classification, diagnosis and treatment of uterine fibroids. The significance of the problem is due to the high frequency of this pathology. The publication fully describes the academic discipline, covers the issues of etiology, pathogenesis and morphology of uterine fibroids, features of the clinical picture, methods of diagnosis and therapy from a modern point of view.

It is intended for students, residents, and postgraduates of medical universities.

UDC 618

ISBN 978-5-398-02513-2

(C) E.A. Vagner Perm State Medical University, 2021 


\section{INTRODUCTION}

The significance of problem represented in this tutorial is due to the high incidence of uterine fibroids.

The practitioner shall update the knowledge of pathology and modern technologies constantly and, based on the achievements of evidence-based medicine, shall improve the individual (personalized) approach to the supervision of patients with uterine fibroids.

Despite the prevalence of uterine fibroids and a large quantity of surveys and publications devoted to this pathology, many issues concerning its etiology and pathogenesis remain unclear, which makes it difficult to establish treatment methods. Nevertheless, the success of molecular genetic surveys and studies within recent years allows us to look into the future with optimism and to predict the emergence of targeted and personalized therapies regarding this common disease in the upcoming years.

The tutorial describes the academic discipline entirely, as from a modern perspective, the issues of etiopathogenesis of uterine fibroids, the features of morphological and disease pattern, and methods of diagnosis and therapy as well.

The principles of diagnosis and treatment of uterine fibroids are updated constantly as new scientific knowledge is accumulated. Certainly, some scope of provisions may provide plenty to be discussed. In this regard, any opinions, comments and suggestions will be appreciated by the authors. 


\section{TERMINOLOGY, EPIDEMIOLOGY AND RISK FACTORS}

Shall be known: definition, concepts, prevalence and risk factors of uterine fibroids.

Uterine fibroid (synonyms: leiomyoma, fibromyoma) is a benign monoclonal hormone-dependent, smooth muscle tumor of a uterine wall, one of the most common human mesenchymal tumors. Hypotheses on the non-tumor, hyperplastic and reactive nature of uterine fibroids were not confirmed.

The disease was first described by Hippocrates in the IV century BC and was named as "uterine stones". In the 1840 s, the founder of modern pathological anatomy, R. Virchov S. Ashwell and J. Bennett proved the smooth muscle origin of the tumor and first used the term "fibroids". Later T. Billroth proposed to define such neoplasms as myofibromas, and in the middle of the XX century, American pathologist G. Mallory - as leiomyomas, and the latter term is fixed in the morphological literature mainly.

However, as early as 1860 , C. von Rokitansky and in 1863 J.J. Klob, based on the frequent predominance of the stromal component of the tumor, proposed the term of "fibroid", which is used in modern English literature widely.

The incidence of uterine fibroids in women of reproductive age is as $25-40 \%$, and in the premenopausal period reaches up to $50-70 \%$. The true prevalence of the tumor is unknown, which is associated with an asymptomatic course of the disease in $25 \%$ of women. Its share among gynecological diseases have become a reason for hysterectomies, reaches $30 \%$, ranking second past cesarean section operations.

Uterine fibroids do not occur at prepubescent age, but may be developed in adolescents.

The risk of malignancy of uterine fibroids is extremely low. Whether leiomyosarcomas may be developed from leiomyoma or 
occur independently (de novo) is unknown. It is generally assumed that approximately one in 400 women operated on for fibroids $(0.25 \%)$ is at risk of leiomyosarcoma developing. In the subpopulation of women with rapid growth of fibroids, the prevalence of leiomyosarcoma is of $0.27 \%$ only, but the growth of fibroids or its symptoms expression in postmenopause shall cause caution in terms of suspicion of malignancy of the tumor.

The incidence of leiomyosarcoma is estimated within the population in the range of 0.22 to $0.49 \%$, although in women above 50 -year-old, its detection in the operating material past hysterectomy may reach $1 \%$.

\section{Risk Factors for Uterine Fibroids}

The causes of uterine fibroids are under discussion currently. It is considered that uterine fibroids are a multi-factorial disease, which pathogenesis is based onto the combined impact of gene and environmental factors.

It is proved that every tumor node is monoclonal, regardless of their quantity. Within cells of $40 \%$ of myomas, various chromosomal aberrations and mutations are detected, and similar ones are typical for leiomyosarcomas.

Factors that increase the risk of uterine fibroids developing are as following:

1. Race. The incidence of uterine fibroids is 23 -fold higher in blacks than in white women. In addition, uterine fibroids in black women may be developed 4-6 years earlier than in the population of white ones, and do not tend to decrease in growth rates past 35-year-old. In patients of Latin American origin, there is an increase in the risk of uterine fibroids developing by 1.3 -fold. The etiology of this fact remains unknown.

2. Menarche at the age of 10-year-old is associated with an increased risk of uterine fibroids developing.

3. Parity. Having an anamnesis of one or more pregnancies lasting above 20 weeks reduces the likelihood of fibroids. Birth of a 
child at an early reproductive age reduces the risk of uterine fibroids developing, and a long interval between births increases it.

4. Hormonal Contraception. The use of low-dose oral contraceptives does not cause the growth of myomatous nodes, so the use of these remedies in women with myoma is not contraindicated. Long term use of progestin contraceptives reduces the risk of uterine fibroids developing, but when used by women with uterine fibroids, the quantity of figures of mitosis and tumor myocytes atypia increases, up to the development of mitotic active leiomyoma and leiomyoma with fanciful nuclei (synonyms are as follows: symplastic, fanciful, outdated - atypical leiomyoma), as well as apoplexy leiomyoma (synonyms are as follows: leiomyoma with apoplexy changes, hemorrhagic leiomyoma) with multiple hemorrhagic infarcts and hemorrhages. In the postpartum period, when taking hormonal contraceptives, there is a decrease in the rate of regression of myomatous nodes extent.

5. The induction of ovulation with clomiphene citrate increases the risk of uterine fibroids.

6. Obesity. The risk of uterine fibroids developing increases by $21 \%$ for every $10 \%$ increase in body weight.

7. Nutrition. Eating beef increases the risk of uterine fibroids developing by 1.7 -fold. Vitamin D deficiency is associated with an increased risk of fibroids.

8. Smoking and alcohol drinking, especially beer, increase the risk of uterine fibroids developing.

9 . Heredity. The availability of a family predisposition to the development of uterine fibroids was revealed.

10. Instrumental intervention on the uterus (abortions, diagnostic scraping).

11. Chronic inflammatory diseases of the female reproductive system.

12. Endocrine diseases (diabetes mellitus, thyroid pathology).

13. Somatic diseases (arterial hypertension and other diseases of the cardiovascular system, liver diseases, gastrointestinal organs).

14. Psychosomatic factor. It has been demonstrated that uterine fibroids occur on average 1-2 years past severe stressful situations. 


\section{CLASSIFICATION}

Shall be known: modern classifications of uterine fibroids.

The classification of uterine fibroids is based on its most diverse features, from the localization and the extent of tumor node to histological and molecular genetic features. So, according to the extent of nodes, it is customary to allocate minor (up to $4 \mathrm{~cm}$ ), medium-sized $(4-5 \mathrm{~cm})$ and large $(6-8 \mathrm{~cm}$ or more) tumors or, according to another scheme, minor (node diameter up to $5 \mathrm{~cm}$ ) and large uterine fibroids (node diameter above $5 \mathrm{~cm}$ ).

In $75 \%$ of cases, fibroids are multiple, and the quantity of tumor nodes is quite large, which requires differential diagnosis of leiomyomas with variants of leiomyomatosis in such patients.

The extent of myoma nodes may grow at the expense of true growth - as hypertrophy and hyperplasia of smooth muscle tumor cells, increased stromal component and due to the false growth caused by expressed secondary changes in tumors (primarily edema or infarcts with hemorrhage) due to malnutrition in the host. Uterine fibroids may not only grow, but also tend to regress or disappear completely.

According to the clinical course, asymptomatic (50-80\%) and symptomatic uterine fibroids (20-50\% - with hemorrhagic, painful, dysuric and/or constipation syndromes, as well as (infertility) are revealed.

Depending on the growth rate of the node/nodes of uterine fibroids, fast-growing tumors are isolated (an increase in the extent of uterus per 4 weeks of conditional pregnancy per 6 months or above). Clinical symptoms determine medical tactics and influence the choice of treatment method. When the extent of the uterus exceeds

12 weeks of conditional pregnancy (large fibroids), this is an indication for surgery intervention. 
Classification of Uterine Fibroids by Anatomical Localization

- Corporate fibroids $(90 \%)$.

- Isthmic fibroids (10\%.)

- Cervical fibroids (3\%).

- Rare variants: intraligamentous (delaminating) and "parasitic" fibroids.

Classification of Fibroids by the Nature of Growth in Relation to the Muscle Layer of Uterine Wall (Myometrium)

A. Sub-serous (peritoneal) fibroids-located slightly below (deeper) the serous surface. It may grow exophytically, within the abdominal cavity, while it is on a wide base or on a "stem" of different thickness. Myoma nodes on the stem may be attached to adjacent structures (walls and pelvic organs, intestines, omentum, mesentery) and when the stem is lost (torsion, necrosis), develop secondary blood supply from the pelvic organs or omentum, losing primary blood supply from the uterus, - "parasitic" leiomyoma. Sub-serous fibroids may also grow between broad ligaments-intraligamental (delaminating) fibroids.

B. Sub-mucous fibroids are located under the endometrium. With an exophytic character, growth into the uterine cavity may be on a wide base and on a stem. Fibroids on the stem may be "born" throughout the cervical canal, are subject to twisting of the stem and infection.

C. Intramural (intermuscular) myoma as developed in the thickness of muscle wall (myometrium).

International Statistical Classification of Diseases and Health-Related Problems, Tenth Revision (ICD-10)

According to (ICD-10), depending on the location of tumor, four variants of uterine fibroids are identified as follows.

- D25.0 Submucous uterine leiomyoma.

- D25.1 Intramural leiomyoma.

- D25.2 Subserous leiomyoma.

- D25.9 Unspecified Leiomyoma (code used for primary gynecological examination). 
When fibroids are localized within cervix and its ligaments, the ICD code D26.0 will be recommended

\section{Classification of Uterine Fibroids \\ European Association of Gynecologists and Endoscopists (ESGE, 1995)}

The classification proposed concerns the submucous localization of fibroids, and is based onto hysteroscopic examination and magnetic resonance imaging data, and determines the type of tumor node depending on its intramural component. The classification includes the types (T) as following:

1. Submucous tumors (onto stem) without intramural component (T:0).

2. Submucous tumors onto a broad base with an intramural component of below $50 \%$ (T:I).

3. Submucous tumors with an intramural component of $50 \%$ or above (T:II).

4. There is no myometrium layer available between the tissues of the tumor node and the endometrium (T:III, according to magnetic resonance imaging).

\section{Classification of Uterine Fibroids}

International Federation of Gynecologists and Endoscopists (ESGE, 19995)

According to the FIGO classification system PALM-COEIN (2011), first proposed in 1993, uterine fibroids are divided into four main variants and eight types (table 1, Fig. 1, 2) as follows:

1. Intramural fibroids (types $3,4,5$ ) - with localization within the muscle layer, as well as partially subserosal or reaching the borders with the endometrium.

2. Submucosal fibroids (types $0,1,2$ ) - nodes originate from the muscle layer directly above the endometrium.

3. Subserous fibroids (type 6,7) - nodes are located subserosally mainly, or onto a wide base, or intraligamentally.

4. Cervical and other uterine fibroids outside the body (type 8). 
The Classification of Uterine Fibroids by the International Federation Obstetricians and Gynecologists-PALM-COEIN System (FIGO, 2011)

\begin{tabular}{|c|c|l|}
\hline \multirow{3}{*}{$\begin{array}{c}\text { Submucous } \\
\text { myoma }\end{array}$} & 0 & Completely within the uterine cavity \\
\cline { 2 - 3 } (Submucosal - SM-) & 1 & $\leq 50 \%$ intramural \\
\cline { 2 - 3 } & 2 & $\geq 50 \%$ intramural \\
\cline { 2 - 3 } & 3 & Contact with the endometrium, $100 \%$ intramural \\
\cline { 2 - 3 } $\begin{array}{c}\text { Other options } \\
\text { (Others - O-) }\end{array}$ & 4 & Intramural \\
\cline { 2 - 3 } & 6 & Subserosal-intramural $(\geq 50 \%$ intramural) \\
\cline { 2 - 3 } & 7 & Subserosal $(\leq 50 \%$ intramural) \\
\cline { 2 - 3 } & 8 & Cervical Fibroids \\
\hline
\end{tabular}

Note. Fibroids are classified into two categories: SM - or $\mathrm{O}$ - and 0 to 8 (for example, SM-2). Thus, in the first place the relation towards the endometrium is indicated, and in the second - towards the serous membrane.

Category 8 is reserved for fibroids located outside the myometrium, and includes not only cervical (cervical), but also located within the thickness of round or wide ligaments (intra-ligamentous or delaminating fibroids), including without attachment to the uterus, and other so-called parasitic fibroids as well.

"Hybrid" fibroids involving both the endometrium and serosa indicate a combination of numbers from 1 to 8 (for example, 2-5) only.

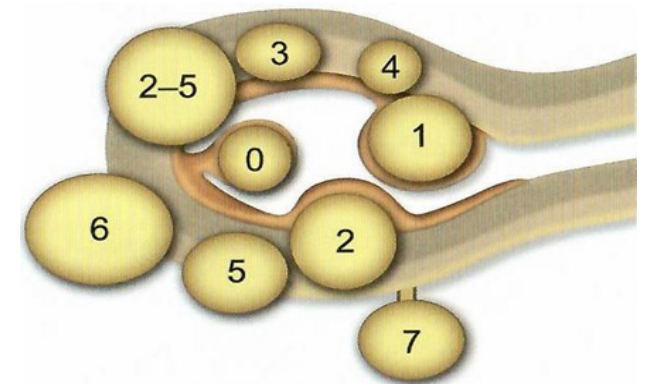

Fig. 1. The Classification of Uterine Fibroids by the International Federation Obstetricians and Gynaecologists (FIGO, 2011). For the value of numbers refer to table 1 


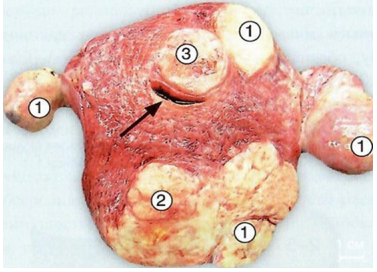

A

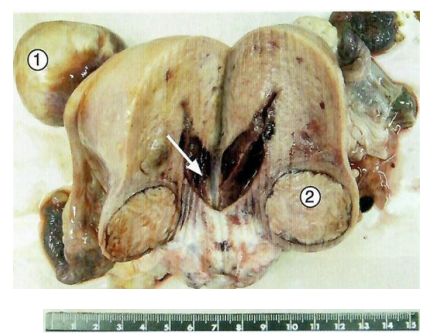

$\mathrm{C}$

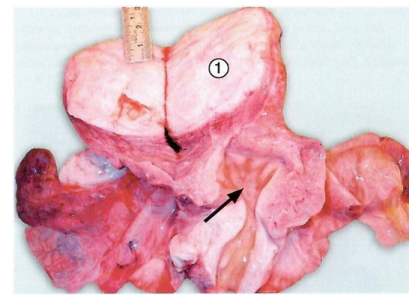

$\mathrm{E}$

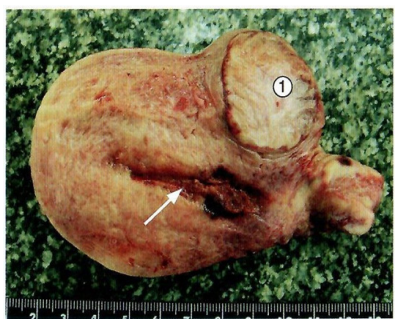

G

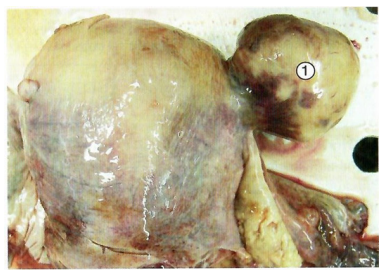

B

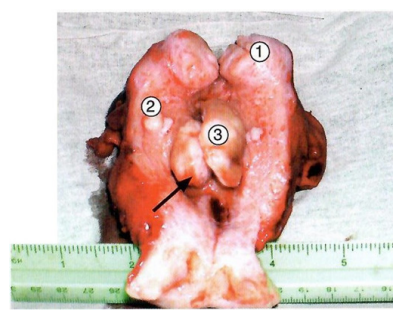

$\mathrm{D}$

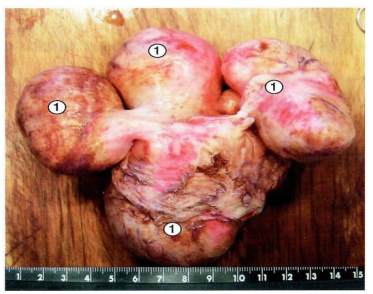

F

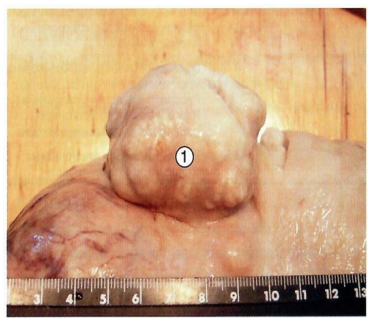

$\mathrm{H}$

Fig. 2. A-3. Subserous (1), intramural (2) and submucous (3) leiomyomas of uterus with secondary changes as foci of edema, necrosis, hemorrhage, sclerosis, hyalinosis and calcification; the uterine cavity is deformed (arrow). A - gross specimen by N.O. Kryukov, D - by E.V. Fedotov 
Based on the classification of International Federation Obstetricians and Gynecologists (FIGO, 1993) and the European Society of Gynecologists and Endoscopists (ESGE, 1995), was proposed a classification of submucous uterine fibroids (STEPW classification, 2005) from the point of view of possible further tactics of surgical treatment. Four main criteria were used: size (S), topography (location) (T), width of the base relative to the uterine wall (E), and the degree of penetration into the myometrium (PW) - STEPW (table 2).

Table 2

Preoperative Classification of Submucous Uterine Fibroids (STEPW Classification, 2005)

\begin{tabular}{|c|c|c|c|c|c|c|}
\hline Points & $\begin{array}{l}\text { Extent (largest } \\
\text { diametre) of } \\
\text { fibroids, cm }\end{array}$ & $\begin{array}{l}\text { Topography } \\
\text { (location in the } \\
\text { wall of the } \\
\text { uterus), third }\end{array}$ & $\begin{array}{l}\text { Width of base } \\
\text { (relative to the } \\
\text { wall of the } \\
\text { uterus) }\end{array}$ & $\begin{array}{l}\text { Penetration } \\
\text { (penetration } \\
\text { into the myo- } \\
\text { metrium) }\end{array}$ & $\begin{array}{l}\text { Side } \\
\text { wall }\end{array}$ & Total \\
\hline 0 & $<2$ & Lower & $<1 / 3$ & 0 & \multirow{3}{*}{+1 point } & \\
\hline 1 & $2-5 \mathrm{~cm}$ & Medium & $<1 / 3-2 / 3$ & $<50 \%$ & & \\
\hline 2 & $>5 \mathrm{~cm}$ & Upper & $>2 / 3$ & $>50 \%$ & & \\
\hline $\begin{array}{c}\text { Score } \\
\text { in points }\end{array}$ & & & & & & \\
\hline
\end{tabular}

\begin{tabular}{|c|c|l|}
\hline $\begin{array}{c}\text { Rating } \\
\text { (in points) }\end{array}$ & Group & \multicolumn{1}{c|}{ Complexity of hysteroscopic surgery } \\
\hline $0-4$ & I & Complexity of hysteroscopic myomectomy \\
\hline $5-6$ & II & $\begin{array}{l}\text { High complexity of hysteroscopic myomectomy } \\
\text { The use of GnRH (gonadotropin-releasing hormone) is considered } \\
\text { Two-stage hysteroscopic myomectomy is considered }\end{array}$ \\
\hline $7-9$ & III & Alternatives to hysteroscopic techniques are considered \\
\hline
\end{tabular}

Histological classification of smooth muscle and mixed (epithelial and mesenchymal) uterine tumors (who, 2014) with morphological codes of the International Classification of Diseases in Oncology (ICD-O, 2013)

Benign tumor

- Leiomyoma (simple, common) 8890/0.

- Cell leiomyoma 8892/0. 
- Leiomyoma with bizarre nuclei (synonyms: fanciful, outdated: atypical, pleomorphic, with simplasts) 8893/0.

- Mitotic active leiomyoma 8890/0.

- Hydropic leiomyoma (synonym: edematous) 8890/0.

- Apoplexy leiomyoma (synonyms: hemorrhagic, outdated: red) $8890 / 0$.

- Leiomyoma with lipomatosis (synonyms: lipoleiomyoma, leiolipomyoma) 8890/0.

- Epithelioid leiomyoma 8891/0.

- Myxoid leiomyoma 8896/0.

- Delaminating (cotyledonoid) leiomyoma (synonym: intraligamentous) 8890/0.

Edge or with uncertain prognosis of tumor

- Diffuse leiomyomatosis 8890/1.

- Intravenous (intravenous) leiomyomatosis 8890/1.

- Metastatic leiomyoma 8898/1.

- Smooth muscle tumor of unclear malignant potential 8897/1.

Malignant tumor

- Leiomyosarcoma 8890/3.

- Epithelioid leiomyosarcoma 8891/3.

- Myxoid leiomyosarcoma 8896/3.

Mixed epithelial and mesenchymal tumors (benign and malignant)

- Adenomyoma 8932/0.

- Atypical polypoid adenomyoma 8932/0.

- Adenofibroma 9013/0.

- Adenosarcoma 8933/3.

- Carcinosarcoma 8980/3. 


\section{PATHOLOGICAL ANATOMY}

Shall be known: pathological anatomy of uterine fibroids.

\section{Benign Tumors.}

Simple (normal, without additional instructions) leiomyoma (fibromyoma) is diagnosed most often, in $90 \%$ of patients, both with single and multiple tumor nodes. Each node is an independent monoclonal tumor. Over time and with large node sizes, they may be merged into different extents and shapes of conglomerates.

The division of uterine fibroids into subserous, intramural and submucous variants has not only clinical significance, but also a morphogenetic basis.

Smooth muscle cells of the myometrium differ in morphofunctional heterogeneity: in the subserous layer, they have much expressed synthetic activity (production of extracellular matrix), and in the submucous layer - proliferative, which is reflected in the features of leiomyomas. E.M. Vikhlyaeva et al. (1977) found that the tumor node repeats in its extension parenchymal-stromal features of the myometrium layer from which it developed: subserous leiomyomas are prone to sclerosis and hyalinosis, and submucous ones - to increased mitotic activity and rapid growth.

Subserous leiomyomas in most cases have their ratio of parenchyma and stroma of 1:3 or above. In these tumors, connective tissue prevails at the early stages of the development of neoplasm, so they have the structure of a fibromyoma, even fibroids later on.

Submucous leiomyomas frequently differ in the ratio of parenchyma and stroma up to 2:1 and are closer in their histological structure to cellular and mitotic active ones according to the International Histological Classification of Uterine Tumors (WHO, 2014). 
Intramural leiomyomas usually occupy an intermediate position in the ratio of parenchyma and stroma.

Macroscopically, the leiomyoma is a node clearly delimited and surrounded by sclerosed tissue - a pseudocapsule (no true capsule available) (see Fig. 2, A-3). The expansive nature of its growth, as a result of which the tumor does not infiltrate, but pushes the tissues surrounding, explains the clearly defined boundaries of myomatous node and the possibility of "leiomyoma hatching" upon organpreserving surgery. Usually, the leiomyoma has from 1 to 2-4 vascular stems, throughout which it is fed. Often, the tumor retains an anatomical connection with the muscle layer of the vessel wall, and the growth of the node is directed towards the tissues of uterine wall without violating the integrity of its endothelium.

When detached from the stem, the subserous leiomyoma does not always undergo necrosis (later-sclerosis and calcification), but may continue its growth, which is named as "parasitic leiomyoma". Nutrition of such tumor having separated from the uterus is implemented throughout newly established vessels of omentum, and walls or pelvic organs.

Compression of vascular stems of leiomyoma by a growing node of tumor, thrombosis of their vessels and other causes of difficulty in blood supply to the node of leiomyoma lead to a violation of its nutrition along with the development of infarcts (often hemorrhagic) and inflammatory infiltration, up to the complete death of the tumor, which is based onto the method of embolization of uterine vessels upon conservative treatment of fibroids. With a slowly increasing violation of the tumor node nutrition, which is quite common, in leiomyoma there is a decrease in proliferation, dystrophic changes, atrophy and apoptosis of tumor smooth muscle cells, minor infarcts, edema, progressive sclerosis and hyalinosis of the stroma with a gradual transformation of the tumor into fibromyoma and the similarity of fibroma. This "fibroma" (often subserous) usually does not grow and even decreases in its extent, the tumor node calcification is possible. Similar changes may 
be observed in menopause, under the influence of hormonal disorders or certain therapy.

Within "young" growing tumors, the stroma and pseudocapsule, on the contrary, are developed poorly, so they are limited indistinctly, which may provide an impression of infiltrating growth characteristic of a malignant neoplasm.

The consistency and type of leiomyoma in the incision depend on the ratio of tumor parenchyma (tumor smooth muscle cells) and stroma (extracellular matrix - connective tissue), as well as availability and severity of secondary changes - infarcts, often hemorrhagic, hemorrhages, inflammatory infiltration, dystrophy, atrophy and apoptosis of tumor myocytes, edema, myxomatosis, sclerosis and hyalinosis of the stroma, establishment of cysts, calcification foci. In most leiomyomas, the tumor stroma is at least half of its volume (usually up to 60-70\%), so ordinarily the myomatous node is of a dense consistency and grayish-white color onto its incision (see Fig. 2, A-3).

Microscopically, the leiomyoma is represented by intertwining bundles of smooth muscle tumor cells outgoing into different directions among the extracellular matrix - different volumes of stroma (connective tissue). The quantity of vessels is different, typical vessels are sinusoid type and larger, surrounded by clutches of tumor myocytes and cells without markers of smooth muscle differentiation (the so-called perivascular growth areas of leiomyoma). Tumoral myocytes are usually monomorphic, without cellular atypia. Mitosis figures are often almost non-detected, and atypical mitoses are absent (Fig. 3, A-D, Fig. 4, A-D, Fig. 5, A-J). Secondary changes may affect the morphological pattern of leiomyoma significantly (Fig. 6, A-G). Mitotic activity is higher within the second phase of the menstrual cycle than in comparison to the first. The exception is some rare histological variants of leiomyomas (bizarre, mitotic active) with cellular atypia or relatively increased mitotic activity. 


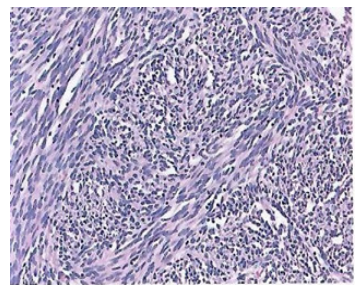

A

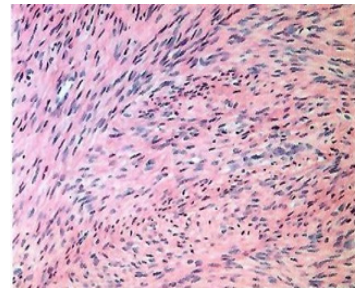

$\mathrm{C}$

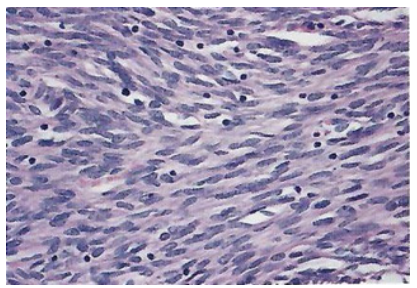

B

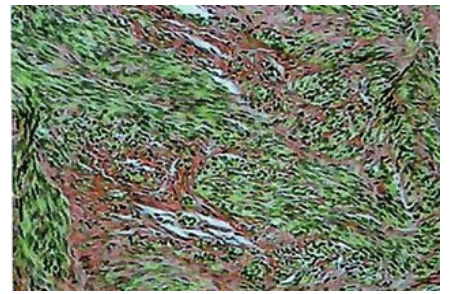

$\mathrm{D}$

Fig. 3. A-D - Leiomyoma of Uterus

(Simple, Normal without Additional Instructions).

Hematoxylin and eosin (A-C) and Picrofuchsin by van Gieson (D). A, C, D $-\times 120, \mathrm{~B}-\times 250$.

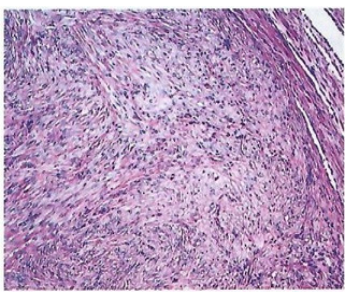

A

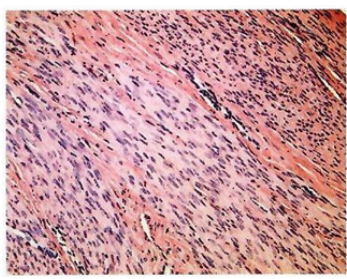

$\mathrm{C}$

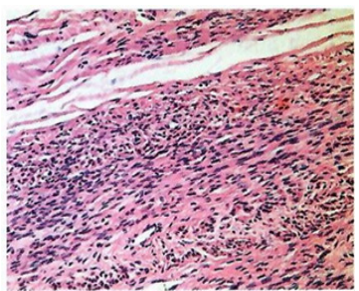

$\mathrm{B}$

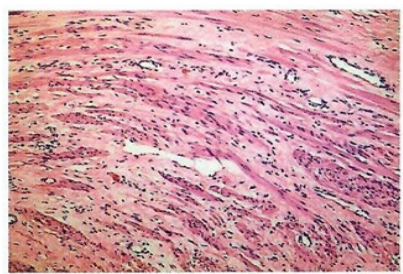

$\mathrm{D}$

Fig. 4. A-D - Pseudocapsule of Uterine Leiomyoma with Varying Degrees of Sclerosis and Hyalinosis.

Coloration with hematoxylin and eosin $\mathrm{A}-\times 60$, B-C $-\times 120$. 


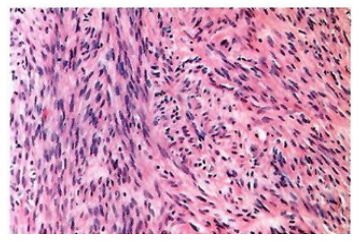

A

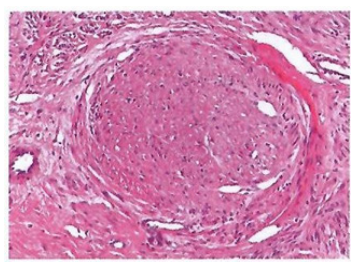

$\mathrm{D}$

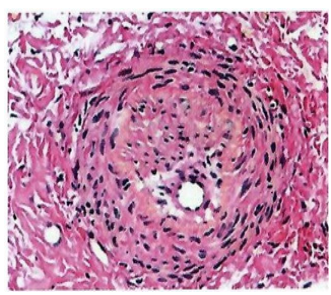

G

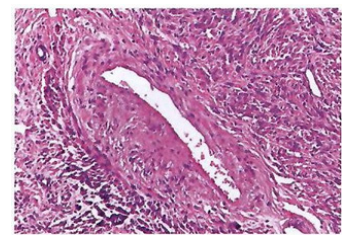

B

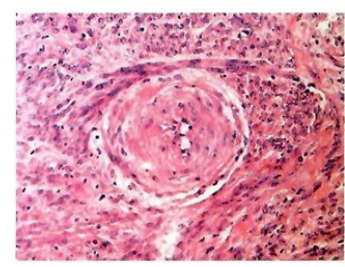

$\mathrm{E}$

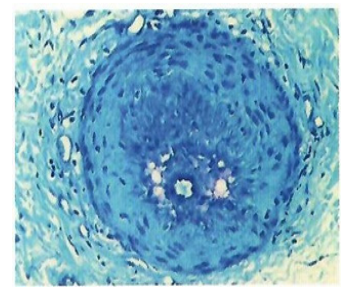

$\mathrm{H}$

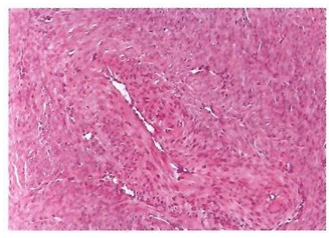

C

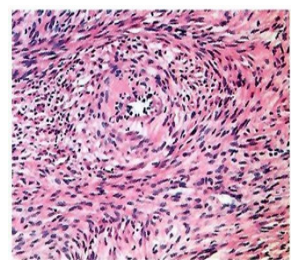

$\mathrm{F}$

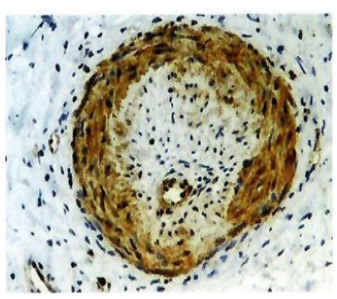

I

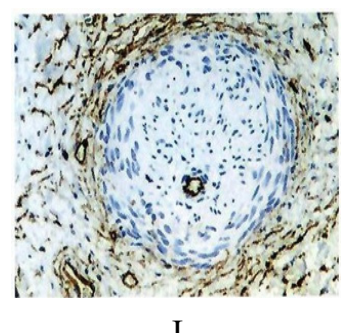

$\mathrm{J}$

Fig. 5. A-J - Leiomyomas perivascular growth areas of varying degrees of activity (hypercellular and with varying degrees of sclerosis and hyalinosis). Colouration with hematoxylin and eosin (A-H), picrofuchsin by van Gieson (I), toluidine blue (J), immunohistochemistry (IHC) reaction with antibodies to TGF $-\beta_{1}(\mathrm{~L})$ and $\mathrm{CD} 34(\mathrm{M})$. A-J $-\times 200, \mathrm{I}-\mathrm{M}-\times 250$ (I-M - changes within perivascular growth areas under the influence of a treatment course with a selective progesterone modulator-ulipristal acetate) 


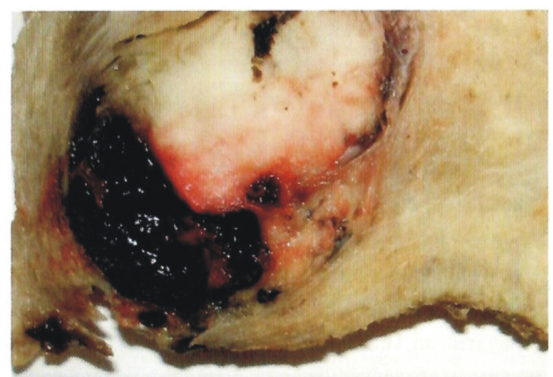

\section{[IIIIIIIIIIIIIIIIIIIIIIIIIIIIIIIIIIIIIII}

A

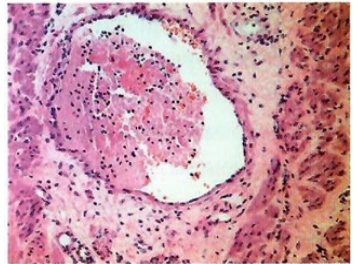

B

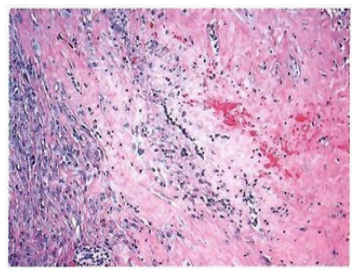

E

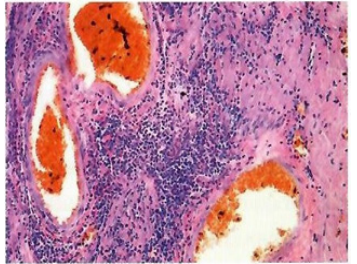

$\mathrm{C}$

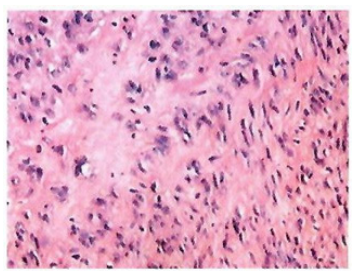

F

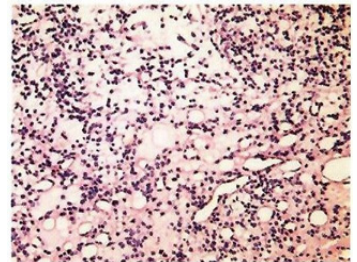

$\mathrm{D}$

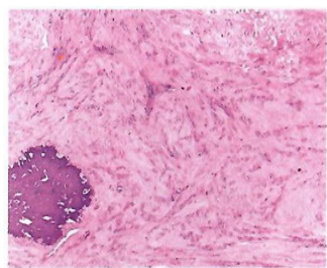

G

Fig. 6. A-G - Secondary Changes in Leiomyoma.

And extensive hemorrhagic infarction along with establishing a pseudocapsule dissecting hematoma; $\mathrm{B}$ - blood clot in a large vessel leiomyoma; $\mathrm{C}$ ischemic infarction with hemorrhagic ring and perifocal inflammatory infiltration; D - stromal edema; E - large-focal sclerosis and hyalinosis stroma with minor hemorrhages, dystrophic and atrophic changes of the tumor parenchyma; F - diffuse sclerosis of stroma (by myofibrosis type) with dystrophic and atrophic changes of the tumor cells; $\mathrm{G}$ - center of calcification in sclerosed and hyalinizated tumor stroma. Coloration with hematoxylin and $\operatorname{eosin}(\mathrm{B}-\mathrm{G}), \mathrm{A}-$ gross specimen, $\mathrm{B}-\mathrm{E}, \mathrm{G}-\times 60, \mathrm{~F}-\times 250$ 
Often leiomyoma sites differ in various histological structure, within one tumor a different ratio of parenchyma and stroma may be found, as well as histological signs of simple (normal) and any of the rarer variants of leiomyomas. In this regard, the diagnosis of a particular histological variant of leiomyoma shall be established upon the predominance of the tumor characteristic structure within most of its areas surveyed.

Like any tumor, leiomyoma is accompanied by the process of neoangiogenesis. Many of its vessels are sinusoid, and the blood flow within these vessels is low-resistive.

As an expression of secondary changes (dystrophic processes), the availability of foci of dystrophic polymorphism and necrosis of the tumor's myocytes is possible, as it simulates a bizarre leiomyoma and even leiomyosarcoma. On the periphery of infarcts, increased proliferation of tumor cells with an increase in the quantity of mitoses and cellular polymorphism is characteristic, which also may cause difficulties upon putting differential diagnosis under leiomyosarcoma.

During pregnancy, leiomyomas may acquire a fleshy appearance ("red degeneration"), mainly due to multiple hemorrhagic infarcts and hemorrhages (up to the establishment of apoplexy leiomyoma pattern, the outdated name is red leiomyoma), but also increased growth of parenchyma. Due to this, some patients are observed as rapid (false, associated with secondary changes) and slower (true) growth of leiomyomas.

Herein, other changes in the tumor are also possible, such as the availability of uneven borders with simulated infiltrating growth, foci of coagulation necrosis of tumor cells as much characteristic of leiomyosarcoma, inflammatory infiltrates, etc. The same variety of changes in leiomyomas are developed under the influence of hormonal disorders, and with hormonal and other conservative therapy regarding these tumors.

Immunohistochemically, within leiomyomas smooth muscle actin and myosin, desmin, h-caldesmon, receptors for estrogens and progesterone, oxytocin, etc. are expressed. In rare histological variants of tumors, the expression of $\mathrm{p} 5 \mathrm{z}$ and $\mathrm{p} 16$ is also much often 
detected (usually in bizarre leiomyomas). However, hitherto, it has not been possible to identify immunohistochemical signs of various histological variants of leiomyomas, or to differentiate them with leiomyosarcomas. In this regard, immunohistochemical research is useful under the differential diagnosis of some variants of leiomyomas, for example, with endometrial stromal tumors and PEC.

Different histological variants of leiomyomas different from a simple (normal) tumor are found within $10 \%$ of cases. A reliable clinical and morphological correlation between histological variants of leiomyomas and the features of their clinical manifestations has not been identified yet. Some histological variants of leiomyomas may probably be phases (stages) of their development or may be transformed into each other primarily under the influence of hormonal changes. Other variants are rather conditionally distinguished, due to the predominance of secondary changes (for example, apoplexy leiomyoma) or due to the growth features (intraligamentous leiomyoma), but some, apparently, differ molecularly and genetically, and are independent types of leiomyomas.

Cellular leiomyoma (synonym: hypercellular leiomyoma) is much often detected submucosally and at a younger age.

Macroscopically, the tumor is characterized by a soft or soft elastic consistency, with incisions of yellow and brownish color due to the secondary changes.

Microscopic signs include increased cellularity, and poor development of stroma, for example in comparison with the surrounding myometrium, and normal uterine leiomyomas. The pseudocapsule is not expressed, so the edges of the tumor may be indistinct, despite the absence of infiltrative growth. A characteristic combination of vessels with a slit-like lumen and thickened walls.

Tumor cells, although often larger, but typical for leiomyoma species, without cellular and nuclear atypia, mitosis figures are rare (usually below five within 10 visual fields at $\times 400$ ). The grouping of cells into bundles may be lost, which sometimes imitates an endometrial stromal tumor (endometrial stromal nodule). 
About $40 \%$ of cell leoimiomas express CD10, just like endometrial stromal tumor does. The lack of expression of smooth muscle markers, desmin and h-caldesmon by endometrial stromal tumor assists to put a differential diagnosis.

Leiomyoma with bizarre nuclei (synonyms: fanciful, outdated: atypical leiomyoma, with simplasts) was considered previously as normal with expressed dystrophic changes in tumor cells. Foci of such dystrophic polymorphism along with the availability of tumor myocytes with ugly nuclei and accumulation of apoptotic bodies may actually be observed within any leiomyomas, which is not a reason to name these tumors bizarre.

Leiomyomas with bizarre nuclei are characterized by the predominance of atypical tumor myocytes with expressed nuclear polymorphism. Genetic analysis allowed to prove the availability of cell atypia unrelated to dystrophy and apoptosis, and revealed a certain similarity in the molecular genetic profile of bizarre leiomyomas with leiomyosarcomas (Fig. 7, A-C).

In the anamnesis of patients with such leiomyomas, long-term use of hormonal contraceptives is often noted.

Macroscopically, the tumor usually does not differ from simple leiomyomas, although it may be of a soft consistency on incision with yellowish areas caused by secondary changes.

Microscopically, all areas of the tumor are characterized by sporadic cells or their groups with large hyperchromic bizarre shape of one or above nuclei, sometimes with intracellular cytoplasmic inclusions.

Mitoses are rare, but the morphology of part of the nuclei as a result of apoptosis and karyorrhexis may imitate the figures of atypical mitoses. Under mitotic activity of above five mitoses within 10 fields of vision at $\times 400$, it is recommended to diagnose "leiomyosarcoma" even in the absence of other signs of malignancy (necrosis of tumor cells, not infarcts, infiltrating growth, etc.). In the previous International Histological Classification of uterine leiomyomas (WHO, 2003) two variants of a bizarre leiomyoma were pointed out as follows: a pleomorphic and symplast, but usually these changes are combined into the same tumor. 


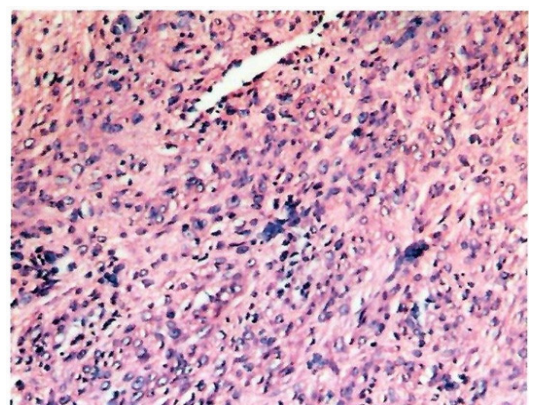

A

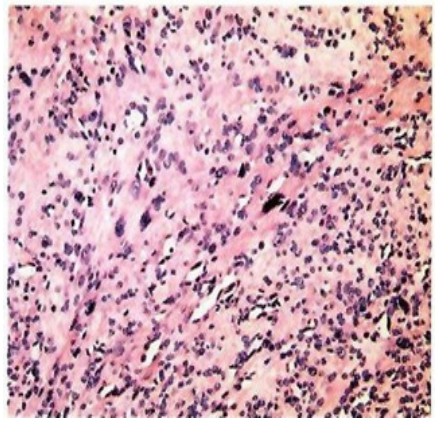

B

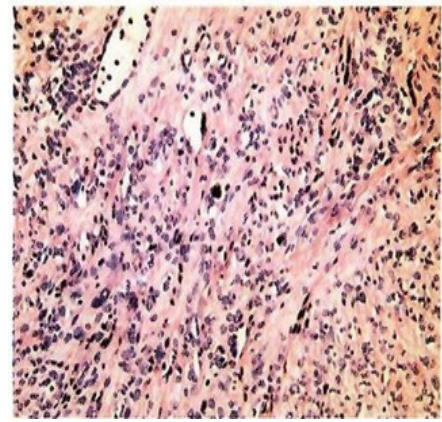

$\mathrm{C}$

Fig. 7. A-C - Leiomyoma with Bizzare Nuclei (Fanciful, Atypical Leiomyoma) Colouration with Hematoxylin and Eosin, $\times 200$

Increased expression of Ki-67 and P16 are characterized immunohistochemically, which does not allow to distinguish the bizarre leiomyoma from leiomyosarcoma and therefore may not serve as a criterion for differential diagnosis.

In the postoperative period past conservative myomectomy, monitoring of patients is recommended, since the risk of relapse is not excluded.

Mitotic active leiomyoma is typical for patients of reproductive age (especially when the tumor is removed in the second phase of menstrual cycle) and submucous localization. Sometimes observed under hormone therapy, in particular - by gestagens. 
Macroscopically, the tumor does not differ from normal leiomyomas, the extent usually does not exceed $6-10 \mathrm{~cm}$.

The diagnostic criterion is the detection of above 10 mitosis figures (according to other authors, above five) in 10 fields of view at magnification of microscope $\times 400$. Herewith, there is no atypia of tumor cells and their necrosis available. In the mitotic active myoma, it is possible to identify areas with hypercellularity and individual tumor myocytes with bizzare nuclei (Fig. 8, A, B).

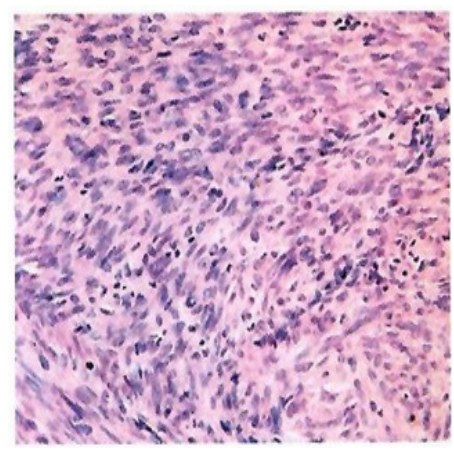

A

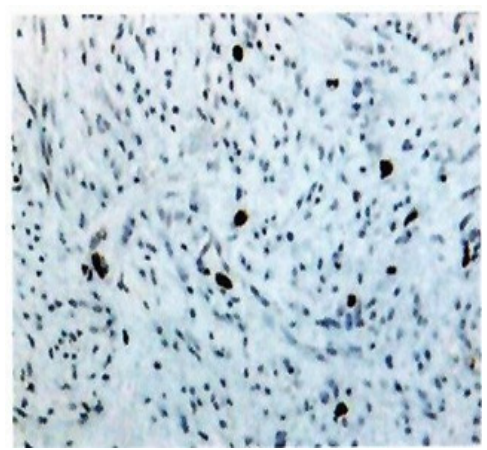

B

Fig. 8. A, B. Mitotically Active Leiomyoma. A - Colouration with hematoxylin and eosin, $\times 200$; B - Mitosis in leiomyoma, IHC (immunohistochemistry) reaction with antibodies to phosphogystone $\mathrm{H} 3, \times 400$

In such cases, a differential diagnosis shall be made with leiomyosarcoma, for which it shall be necessary to survey as many areas of tumor as possible. If the quantity of mitoses in 10 visual fields at $\times 400$ exceeds 20 , the patient shall be monitored past surgery.

Hydropic leiomyoma (synonym: edematous leiomyoma) may be a result of severe edema of a normal leiomyoma stroma or represents an independent variant of the tumor.

Macroscopically much often with uneven consistency and dense, soft areas, greyish-white colour, sometimes with yellowbrown foci and many cystic cavities of different extent are filled with clear liquid that flows out upon the incision. 
It shall be noted that the same, but sporadic cysts filled with either blood or clear liquid are found in all variants of leiomyomas, and bloody content ones are characteristic of adenomyomas. The shape of the tumor may be irregular, rather than round and oval, as in other leiomyomas.

Microscopically, the tumor is dominated by a stroma with expressed edema, sclerosis and hyalinosis, in which many cystic cavities are established without a lining. The edematous stroma and the contents of cysts do not contain mucus (they are not stained with alcian blue). The parenchyma of hydropic leiomyoma is represented by narrow bundles of tumor myocytes without cellular atypia and an increased quantity of mitosis figures. There is also a typical abundance of vessels of different calibers, often with thickened hyalinized walls (Fig. 9, A-C).

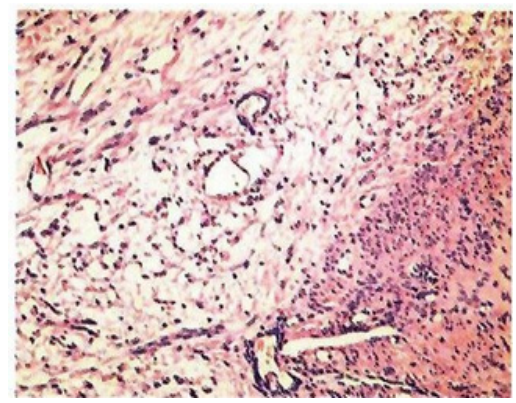

A

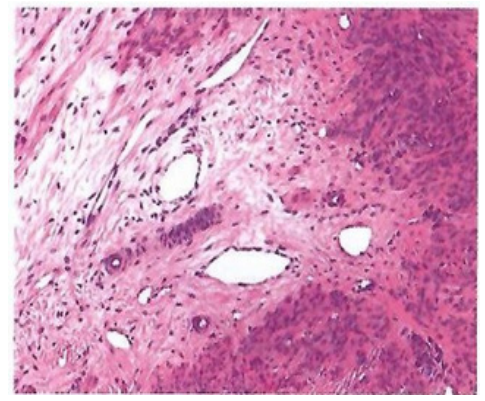

B

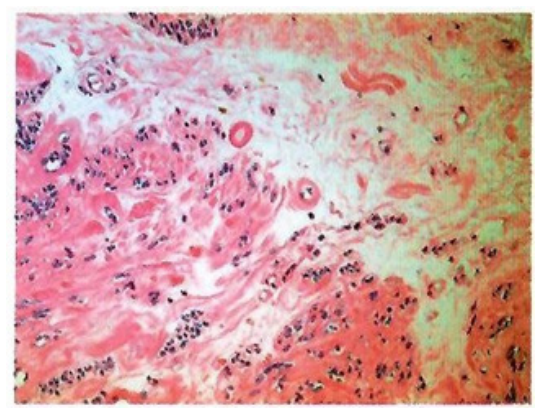

$\mathrm{C}$

Fig. 9. A-C - Hydropic (edematous) Leiomyoma.

Coloration with hematoxylin and eosin, $\times 120$ 
Apoplexy leiomyoma (synonyms: leiomyoma with apoplexy changes, hemorrhagic leiomyoma-according under WHO classification of 2003, outdated - "red myoma") is usually diagnosed during pregnancy, within the postpartum period, with progestin therapy, taking hormonal contraceptives. In this case, rapid growth of tumor may be observed.

It is more likely that apoplexy leiomyoma is not an independent histogenetic variant, but represents different variants of leiomyomas with expressed secondary changes, introduced by draining hemorrhagic infarcts with hemorrhages and swelling of the tumor tissue.

Macroscopically, apoplexy leiomyoma is characterized by a "fleshy" appearance, soft-elastic consistency, and extensive areas of red and brown colour.

Microscopically revealed drain hemorrhagic infarcts, areas of fresh hemorrhages and hemosiderosis with perifocal inflammatory infiltration. These areas are usually surrounded by areas with hypercellularity, in which the quantity of mitoses is increased, and myxoid changes within stroma. In addition, necrosis and apoptosis of individual tumor myocytes may be observed, and all these signs require sometimes differential diagnosis with leiomyosarcoma. In the outcome of hemorrhagic infarcts, large foci of sclerosis and hyalinosis are established in the leiomyoma with the stroma collapse and the loss of the tumor parenchyma (Fig. 10, A-D).

Leiomyoma with lipomatosis (synonyms: lipoleiomyoma, leiomyolipoma) is diagnosed only when a significant quantity of mature lipocytes or their groups are detected among the bundles of tumor myocytes (Fig. 11).

Individual lipocytes may occur in the stroma of any leiomyoma. Sometimes lipocytes are similar to hibernoma cells. They are more often detected within pre- and postmenopausal patients.

Macroscopically, lipoleiomyoma often does not have specific features, except for areas of yellow colour in tumors along with expressed development of adipose tissue. 


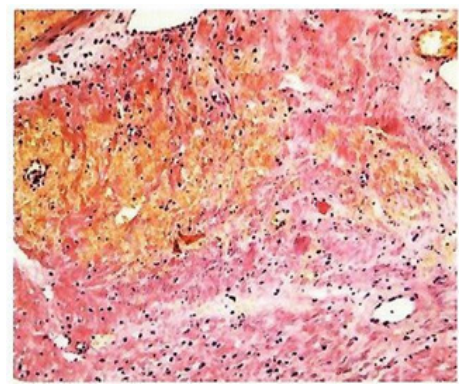

A

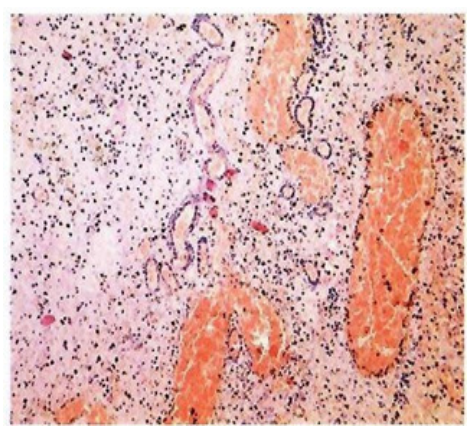

$\mathrm{C}$

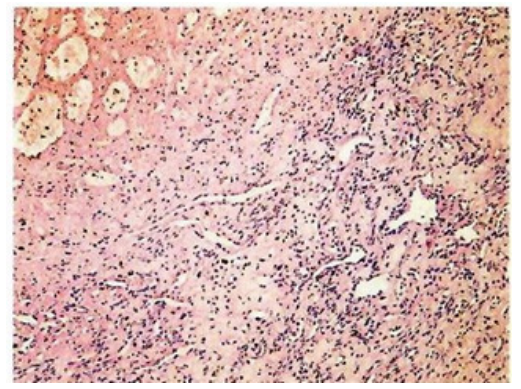

B

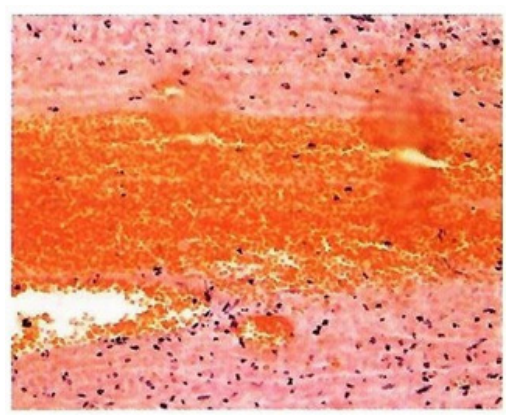

$\mathrm{D}$

Fig. 10. A-D. Apoplexy Leiomyoma (leiomyoma with apoplexy changes, hemorrhagic leiomyoma, "red fibroids").

Colouration with hematoxylin and eosin. A, D $-\times 120, \mathrm{~B}, \mathrm{C}-\times 60$

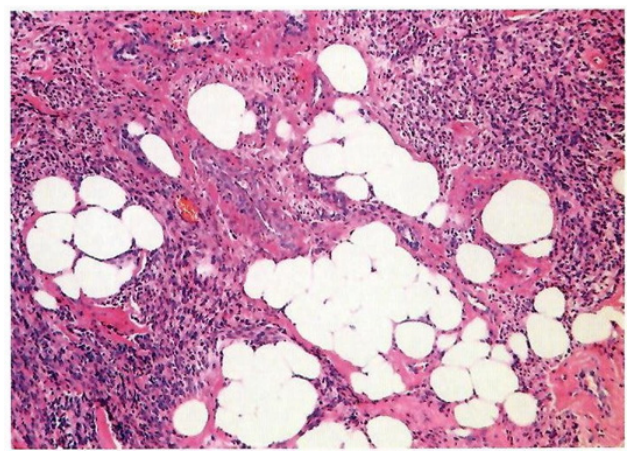

Fig. 11. Lipoleiomyoma (Leiomyoma with Lipomatosis, Leiomyoma). Colouration with hematoxylin and eosin, $\times 120$ 
Lipoleiomyoma histogenesis is not clear, even discussed the possibility of adipose metaplasia of neoplastic smooth muscle or stromal cells. Described tumor having the structure of angiomyolipoma and adenolipomatosis which histogenesis is also unclear.

It is important to note that in various leiomyomas, the areas of cartilage, bone tissue establishing may be found, as well as skeletal muscles, foci of hematopoiesis, and lymphoid tissue with lymphoid follicles formation (sometimes this requires differential diagnosis with tumors of corresponding histogenesis, from soft tissue to hematopoietic and lymphoid tissue).

Epithelioid leiomyoma was isolated based on the similarity of tumor myocytes with epithelioid cells and frequent loss of bundle structure.

Macroscopic tumor of a soft consistency, greyish-white, with areas of yellow and brown, sometimes with single cysts on incision.

Microscopic epithelioid leiomyoma is represented by epithelioid cells - round or polygonal shape with eosinophilic or light (due to the accumulation of glycogen and lipids) cytoplasm. Tumor myocytes form bundles, trabeculae, or "nests". The similarity of tumor myocytes with fetal myocytes is discussed (Fig. 12).

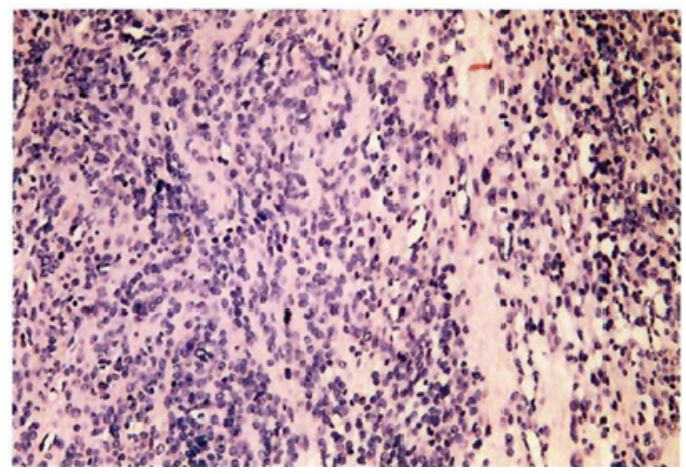

Fig. 12. Epithelioid Leiomyoma.

Colouration with hematoxylin and eosin, $\times 120$ 
The previous International Histological Classification of uterine leiomyomas (who, 2003) are identified three variants of epithelioid leiomyomas: leiomyoblastoma, clear cell leiomyoma and the reticular turmorlet.

Nevertheless, practice has demonstrated that usually changes typical for a particular variant (for example, vacuolated weakly basophilic in leiomyoblastoma) are combined within a single tumor. However, tumors with a network-like growth pattern of tumor myocytes and their diameter below $1 \mathrm{~cm}$ are still regarded as "plexiform tumours" ("plexiform tumourlets").

When detecting cellular atypia of myocytes of epithelial leiomyoma, even without an increase in the quantity of mitoses, it is recommended to establish the diagnosis of "smooth muscle tumor of unclear (undefined) malignant potential" (smooth muscle tumour of uncertain malignant potential - STUMP).

Epithelioid leiomyomas of medium and large extents, with cellular atypia, increased quantity of mitoses (above five within 10 fields of view at magnification of the microscope $\times 400$ ), foci of necrosis of tumor cells shall be regarded as potentially malignant.

Immunohistochemical survey helps to differentiate epithelioid leiomyomas with tumors of other histogenesis - not smooth muscle one.

Myxoid leiomyoma is either an independent histogenetic variant, or the result of predominance of secondary changes in the shape of myxoid (mucosal) edema of stroma, in which amorphous material is accumulated, positive when alcyan blue coloured. Such leiomyomas are more common during pregnancy, taking progestins.

Macroscopic tumor of a soft consistency, greyish-white, with yellow and brown areas, with cysts on incision.

Microscopically, along with the common myxomatosis of stroma and the cysts establishment (focal myxomatosis may be detected within any leiomyomas) characterized by hypercellularity, the absence of cellular atypia and a minimum quantity of mitoses. There may be an infiltrating growth of tumor, which is not a sign of malignancy (Fig. 13, A-B). 


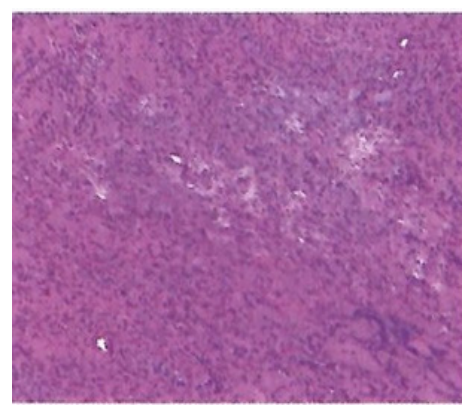

A

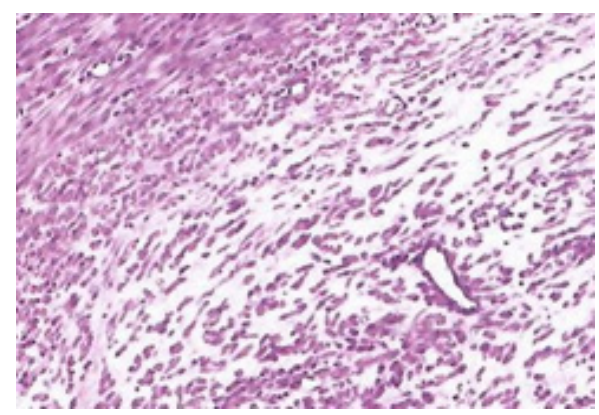

B

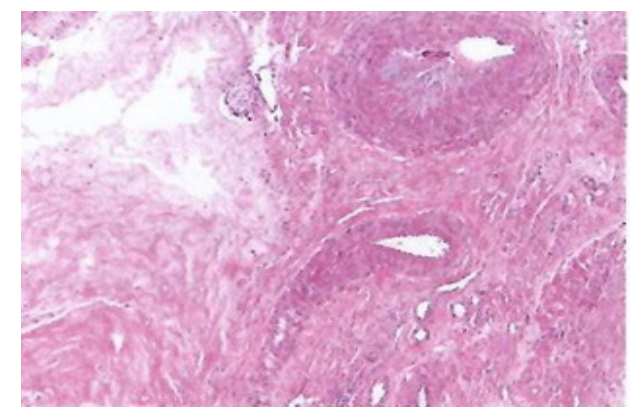

C

Fig. 13. A-C - Myxoid Leiomyoma. Coloration with hematoxylin and eosin. A, B $-\times 120,8-\times 60$

In the postoperative period past conservative myomectomy, monitoring of patients is recommended, since the risk of relapse is not excluded.

Dissecting, or intraligamentary, leiomyoma (synonym: cotyledonoid leiomyoma) allocated in connection with the localization and character of growth. The tumor is either subserous, along with expressed exophytic growth, or it grows out of connection with myometrium and spreads within wide or round ligaments of uterus. Leiomyoma often reaches large extents. Histologically, hydropic (edematous) changes in the stroma are typical; tumor myocytes stablish narrow bundles among the connective tissue. 
The modern International Histological Classification of uterine leiomyomas (WHO, 2014) does not include the neoplasms as following.

- Leiomyoma with lymphoid infiltration: simple leiomyoma with expressed infiltration by lymphocytes, sometimes with plasmoblasts and plasmocytes, the establishment of lymphoid follicles, sometimes with an admixture of eosinophils in the infiltrate (Fig. 14). The severity of lymphoid infiltration causes sometimes suspicion regarding development of lymphoma. The influence of various therapies in the pathogenesis of these changes is discussed.

- Strikingly schwannian pattern leiomyoma: a simple leiomyoma with areas where tumor myocytes establish schwannian structures, possibly due to the reaction towards secondary changes (often in apoplexy leiomyoma on the periphery of the infarction zone). Identification of such structures may require differential diagnosis with schwannoma.

- Vascular (hemangioendothelioma) leiomyoma: simple leiomyoma with a significant predominance of the vascular component (numerous dilated vessels, probably as a result of secondary changes with collapse and stroma sclerosis, Fig. 15). Differential diagnosis shall be performed with hemangioma or arteriovenous malformations, which are extremely rare in myometry.

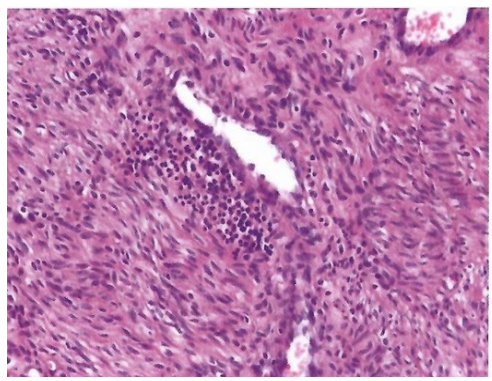

Fig. 14. Leiomyoma with Lymphoid Infiltration. Colouration with hematoxylin and eosin, $-\times 120$

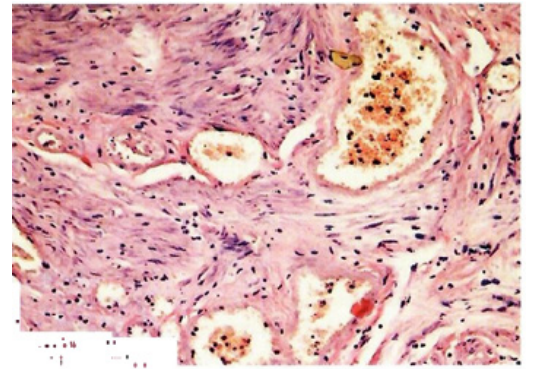

Fig. 15. Vascular (Hemangioendothelioma) Leiomyoma. Coloration with hematoxylin and eosin, $-\times 120$ 


\section{Edge or with uncertain prognosis of tumor}

Diffuse leiomyomatosis is a very rare pathology in women of reproductive age. In myometry, multiple hypercellular tumors are detected, many with a diametre above $1 \mathrm{~cm}$, merging with one another. As a result, the walls of the uterus are thickened, and it is enlarged in extent itself. Genetic surveys have demonstrated that each myomatous node is an independent monoclonal tumor. Histologically, tumors are represented by simple or cellular leiomyomas without cellular atypia, a minor quantity of mitoses and secondary changes expressed weakly. With organ-preserving operations, the risk of relapses is high.

Leiomyomatosis and renal cell carcinoma syndrome is a hereditary syndrome in young women with an autosomal dominant type of inheritance, which is based on a mutation of fumarate hydratase gene. It is characterized by diffuse leiomyomatosis with hypercellularity of tumors, atypia of tumor myocytes (with characteristic nucleoli with a light halo) and vessels similar to those observed in hemangiopericitomas.

Intravenous leiomyomatosis is a rare pathology observed in women above $40-50$ year old. The diagnosis is macroscopic mainly, upon the detection of expressed intra-vascular spread, since focal growth of leiomyoma in the lumen of the veins is noted within various leiomyomas. It is characteristic of spreading usual histological structure tumors for leiomyomas along the veins of uterus, its broad ligament, and also the pelvis. The tumor tissue is either located freely within the lumen of veins, or attached to their walls (the phenomenon of tumor permeation, usually described in renal cell carcinoma). Sometimes endometrial glands and cysts with blood are detected. Although the tumor has no signs of malignancy, with intravenous leiomyomatosis, approximately $5 \%$ patients are diagnosed with leiomyomas in the inferior vena cava and heart within 15 years past hysterectomy.

Metastatic leiomyoma is a common leiomyoma found in the lungs or lymph nodes of women having undergone hysterectomy surgery regarding uterine leiomyoma many years ago. Genetic 
analysis has proved metastatic histogenesis of myomatous nodes in the lungs and lymph nodes, and the unavailability of multifocal smooth muscle proliferation. Histologically, the myomatous nodes in the lungs are often found as "captured" epithelium of bronchi and alveoli. Differential diagnosis is performed with endometrial stromal sarcoma with smooth muscle or myofibroblastic differentiation.

Smooth muscle tumour of uncertain malignant potential STUMP (synonym: atypical smooth muscle tumour). The term was first introduced in the WHO International Histological Classification in 2003. This diagnosis, which shall be extremely rare, is put when a smooth muscle tumor of the uterus has definitive signs neither of leiomyosarcoma or leiomyoma. Usually there is a different combination of these tumors signs, such as a large quantity of mitoses, but insufficient regarding the diagnosis of leiomyosarcoma, the unclear nature of necrosis foci, etc. There are no immunohistochemical differential diagnostic signs represented. The observation within the postoperative period past organ-preserving myomectomies has revealed rare relapses of such tumors.

The WHO International Histological Classification 2014 regarding uterine leiomyomas does not include disseminated peritoneal leiomyomatosis. This rare disease is described in women of reproductive age during pregnancy, and the postpartum period is characterized by regression of changes. On the serous membrane of the pelvic organs and omentum, nodules of leiomyomas with their diametre of $1-3 \mathrm{~cm}$ or above are found. In leiomyomas, there may be foci of endometriosis.

Perivascular epithelioid cell tumour (PEC) is much common in the tissues of the kidneys, lungs, liver, but may also be in uterus. This group concept includes such tumors as epithelioid angiomyolipoma, lymphangioleiomyomatosis and light cell ("sugar") tumor. Usually, the neoplasm is solitary, histologically tumor cells of epithelioid type, spindle-shaped, with abundant eosinophilic smallgranular cytoplasm, are groupped around the vessels. To provide diagnostics and differential diagnostics, an immunohistochemical sur- 
vey shall be necessary, allowing to detect the characteristic expression of both smooth muscle (smooth muscle actin, desmin) and melanocyte markers (NMV-45, Melan-A, transcription factor MITF). It shall be kept in mind that the expression of NMV-45 is observed in leiomyosarcoma sometimes.

On the basis of generally accepted histological signs, there are benign, unclear malignant potential and malignant (regarded as leiomyosarcoma) perivascular epithelial cell tumors (PECs).

\section{Clinical and Morphological Types of Uterine Fibroids (by I.S. Sidorova et al., 2000)}

The great practical significance is identification of two clinical and morphological types or stages of fibroids (variants of their biological behaviour, under different clinical manifestations and morphological structure): simple and proliferating uterine fibroids. These terms are not related to the names of uterine leiomyomas variants according to the WHO International Histological Classification $(2003,2014)$ and do not apply to smooth muscle tumors of uterus with an unclear potential for malignancy and potentially malignant.

Histological classification of leiomyomas is not informative enough for choosing treatment tactics and determining prognosis, so domestic researchers, in particular morphologists, made attempts long ago to identify their morphological types or phases of development as of practical interest to the clinic with weak and relatively expressed proliferative activity, regardless their histological structure of tumors (I.A. Yakovleva, B.G. Kukute, 1979). O.K. Khmelnitsky (1994) emphasized in his works the practical significance for the clinic of isolation of simple, proliferating and pre-sarcomatous uterine leiomyoma, which remains relevant to this day, although the criteria and methods of diagnosis have been changed significantly.

For the first time, the division of uterine fibroids into two clinical and morphological types-simple (inactive) and proliferating (active) was proposed and justified by professor I.S. Sidorova et al. in 2000. 
Simple uterine fibroids are diagnosed most often (70-80 \%), frequently as a single node. Tumors are mainly subserous and intramural, macroscopically represented by a clearly delimited node of dense consistency, surrounded by expressed pseudocapsule, greyish-white in color on incision. Secondary changes in the tumor provide its areas a yellowish or brown color, the establishment of cysts, calcification foci is possible.

Histologically, this type corresponds to most simple or common leiomyomas (without additional instructions) and very rarely some other, rarer variants of leimyomas (only cellular, mitotic active and epithelioid ones are uncommon) according to the WHO International Histological Classification (2014). These are slow-growing tumors with low-activity, sclerosed perivascular growth areas. Such tumors are characterized by particularly low activity of proliferation and angiogenesis, but often increased synthetic activity with excessive production of extracellular matrix components. The predominance of stroma, which is usually sclerosed and hyalinized, allows to name such tumors fibromyomas. For simple leiomyoma, a combination with adenomyosis, hyperplastic and neoplastic processes in the endometrium and ovaries is not typical.

Proliferating uterine fibroids are localized submucosally and intramurally mainly, and are characterized by faster growth. Histologically, it corresponds to some common leiomyomas, but much often to cellular, mitotic active or epithelioid leiomyomas according to the WHO International Histological Classification (2014), and also differs in the clinical course and prognosis significantly. Multiple active large perivascular growth areas are typical. They are characterized by increased activity of proliferation and angiogenesis (the latter may be diagnosed not only morphologically, but also by colour Doppler mapping) and low synthetic activity with weakly expressed production of extracellular matrix components. Often such tumors are multiple. Proliferating myomas, regardless their histological variant, are characterized by 
a combination with adenomyosis, hyperplastic and neoplastic processes in the endometrium and ovaries. Due to these circumstances, proliferating leiomyomas cause reasonable oncological alertness.

Table 3 summarizes the clinical and morphological features of simple and proliferating uterine fibroids.

Differential diagnostic clinical and morphological signs

of simple and proliferating uterine fibroids

\begin{tabular}{|c|c|c|}
\hline Main Features & Simple Fibroids & $\begin{array}{c}\text { Proliferating } \\
\text { Myoma }\end{array}$ \\
\hline The predominant age & $30-35$ years old & $18-25$ or $35-45$ years old \\
\hline Hereditary burden & Rare frequency $(5-7 \%)$ & High frequency $-37 \%$ \\
\hline \multicolumn{3}{|c|}{ Frequency per the Age Aspect } \\
\hline Reproductive & $5-7 \%$ & $2-3 \%$ \\
\hline Late reproductive & $17-20 \%$ & $10-15 \%$ \\
\hline Premenopausal & $20-33 \%$ & $8-12 \%$ \\
\hline $\begin{array}{l}\text { Menopausal (first } 2 \text { years of } \\
\text { postmenopause) }\end{array}$ & $\begin{array}{c}2-3 \% \\
\text { (it regresses much often) }\end{array}$ & $5-8 \%$ \\
\hline Anamnesis & $\begin{array}{l}\text { Burdened: abortions, } \\
\text { inflammation of uterus and } \\
\text { appendages, combination } \\
\text { with endometriosis, } \\
\text { secondary infertility }\end{array}$ & $\begin{array}{l}\text { Burdened: infertility, severe } \\
\text { stress, surgery, high somatic } \\
\text { and gynecological } \\
\text { morbidity }\end{array}$ \\
\hline Reproductive function & Often non-transgressed & $\begin{array}{l}\text { Often transgressed (the first } \\
\text { birth in } 35-40 \text { year old) }\end{array}$ \\
\hline Clinical implications & Usually asymptomatic & $\begin{array}{l}\text { Symptomatic fibroids (pain } \\
\text { syndrome, pathological } \\
\text { bleeding, violation of the } \\
\text { function of adjacent organs, } \\
\text { anemia) }\end{array}$ \\
\hline The course of pregnancy & $\begin{array}{l}\text { As a rule, without complica- } \\
\text { tions, but there is a risk of } \\
\text { secondary changes in the } \\
\text { myoma (edema, necrosis), it } \\
\text { is also possible to transform } \\
\text { into a proliferating myoma }\end{array}$ & $\begin{array}{l}\text { Complicated course of } \\
\text { pregnancy and childbirth } \\
\text { (spontaneous miscarriages } \\
\text { and premature birth, pla- } \\
\text { cental insufficiency, uterine } \\
\text { bleeding). Rapid growth, } \\
\text { secondary changes: edema, } \\
\text { necrosis of nodes }\end{array}$ \\
\hline
\end{tabular}




\section{Continuation of Table 3}

\begin{tabular}{|c|c|c|}
\hline Main Features & Simple Fibroids & $\begin{array}{c}\text { Proliferating } \\
\text { Myoma }\end{array}$ \\
\hline \multicolumn{3}{|c|}{ Characteristics of Myomatous Nodes } \\
\hline Localization & $\begin{array}{l}\text { Mainly peritoneal and } \\
\text { intermuscular-peritoneal }\end{array}$ & $\begin{array}{l}\text { Mostly submucosal and } \\
\text { intermuscular, intermus- } \\
\text { cular with centripital } \\
\text { growth }\end{array}$ \\
\hline Location & $\begin{array}{l}\text { Mainly is the bottom and } \\
\text { body of uterus, rarely the } \\
\text { cervix }\end{array}$ & $\begin{array}{l}\text { Mainly tubal angles, body, } \\
\text { uterine ribs, cervical-isth- } \\
\text { mus area, between the } \\
\text { leaves of uterus broad } \\
\text { ligaments }\end{array}$ \\
\hline $\begin{array}{l}\text { The quantity of myomatous } \\
\text { nodes }\end{array}$ & Often sporadic $(1-4)$ & $\begin{array}{l}\text { Mostly often multiple } \\
(5 \text { or above })\end{array}$ \\
\hline Extents (largest diametre, $\mathrm{cm}$ ) & $\begin{array}{l}\text { Usually minor }(3-4 \mathrm{~cm}) \text { or } \\
\text { medium }(5-6 \mathrm{~cm})\end{array}$ & $\begin{array}{l}\text { Usually large ( } 7 \mathrm{~cm} \text { or } \\
\text { above) }\end{array}$ \\
\hline Growth rate & Slow (years) & $\begin{array}{l}\text { Rapid (months) growth } \\
\text { spurt (1-3 months) }\end{array}$ \\
\hline $\begin{array}{l}\text { Features of myomatous } \\
\text { nodes growth }\end{array}$ & $\begin{array}{l}\text { The increase in the extent } \\
\text { of myomatous node is } \\
\text { largely due to the accumu- } \\
\text { lation of stroma as tissue } \\
\text { connective component } \\
\text { (extracellular matrix), with } \\
\text { its sclerosis and hyalinosis, } \\
\text { as well as due to secondary } \\
\text { changes in the nodes of } \\
\text { tumor (ischemic } \\
\text { and dystrophic character: } \\
\text { edema, heart attacks, } \\
\text { formation of cysts) }\end{array}$ & $\begin{array}{l}\text { Increase in the extent of } \\
\text { myomatous node occurs } \\
\text { largely due to the growth of } \\
\text { parenchyma: proliferation } \\
\text { of tumor myocytes. The } \\
\text { relationship between the } \\
\text { processes of apoptosis and } \\
\text { proliferation (the phenome- } \\
\text { non of relative insufficien- } \\
\text { cy of apoptosis) is trans- } \\
\text { gressed. Active growth of } \\
\text { vessels with low-resistance } \\
\text { blood flow. Secondary } \\
\text { changes are less frequent }\end{array}$ \\
\hline Mitotic activity & $\begin{array}{l}\text { Low (0-2 mitosis per } \\
1,000 \text { myocytes), } \\
\text { No pathological mitoses }\end{array}$ & $\begin{array}{l}\text { Low (0-3 mitosis } \\
\text { per } 1,000 \text { myocytes, with the } \\
\text { exception of mitotic active } \\
\text { leiomyomas), no } \\
\text { pathological mitoses }\end{array}$ \\
\hline $\begin{array}{l}\text { The morphology of myoma } \\
\text { node }\end{array}$ & $\begin{array}{l}\text { Foci of perivasular pro- } \\
\text { liferation of tumor myo- } \\
\text { cytes are not expressed } \\
\text { or sclerosed. The pre- } \\
\text { dominant myocytes are } \\
\text { minor and medium-sized }\end{array}$ & $\begin{array}{l}\text { Expressed perivascular foci } \\
\text { of proliferation of tumor } \\
\text { myocytes. Tumor myocytes } \\
\text { are large, their nuclei are } \\
\text { large, rod-shaped or oval. } \\
\text { Typical areas of }\end{array}$ \\
\hline
\end{tabular}




\section{Continuation of Table 3}

\begin{tabular}{|c|c|c|}
\hline Main Features & Simple Fibroids & $\begin{array}{l}\text { Proliferating } \\
\text { Myoma }\end{array}$ \\
\hline & $\begin{array}{l}\text { tumors, their nuclei are } \\
\text { petty, rod-shaped or } \\
\text { wrinkled. Expressed } \\
\text { sclerosis and hyalinosis } \\
\text { of stroma and vascular } \\
\text { walls. Usually, stroma } \\
\text { prevails. Sinusoid ves- } \\
\text { sels are developed } \\
\text { poorly. Secondary } \\
\text { changes are typical }\end{array}$ & $\begin{array}{l}\text { hypercellularity. Active } \\
\text { growth of sinusoid type } \\
\text { vessels. Less often, secon- } \\
\text { dary changes are observed, } \\
\text { but there may be edema, } \\
\text { myxomatosis of stroma and } \\
\text { hemorrhagic infarcts }\end{array}$ \\
\hline \multicolumn{3}{|c|}{ Evaluation of the Processes of Proliferation and Apoptosis of Tumor Myocytes } \\
\hline Ploidy & Polyploidy & Polyploidy \\
\hline $\begin{array}{l}\text { Proliferative activity of tu- } \\
\text { mor myocytes (expression } \\
\text { Ki-67) }\end{array}$ & Low & $\begin{array}{l}\text { May be increased (relatively } \\
\text { regarding the weak prolife- } \\
\text { rative activity of tumor myo- } \\
\text { cytes in any leiomyomas) }\end{array}$ \\
\hline $\begin{array}{l}\text { Expression of growth factors } \\
\text { and angiogenesis, proteins } \\
\text { and genes - markers of } \\
\text { apoptosis processes. }\end{array}$ & $\begin{array}{l}\text { Low expression of growth } \\
\text { factors and angiogenesis, } \\
\text { high expression of proteins } \\
\text { and genes, inducers of } \\
\text { apoptosis. }\end{array}$ & $\begin{array}{l}\text { Increased expression of } \\
\text { growth factors and angio- } \\
\text { genesis, low expression of } \\
\text { proteins and genes, inducers } \\
\text { of apoptosis (the phenome- } \\
\text { non of relative apoptosis } \\
\text { insufficiency) }\end{array}$ \\
\hline $\begin{array}{l}\text { The state of the surrounding } \\
\text { macroscopically unchanged } \\
\text { myometrium }\end{array}$ & Often sclerosis of stroma & $\begin{array}{l}\text { Hypertrophy of the myocy- } \\
\text { tes of myometrium. Activa- } \\
\text { tion of metabolic processes, } \\
\text { increasing the content of } \\
\text { ribonucleotides. Increased } \\
\text { activity of lactate dehydro- } \\
\text { genase (LDH), alkaline } \\
\text { phosphatase (AP) }\end{array}$ \\
\hline The condition of ovaries & $\begin{array}{l}\text { Ovarian cysts are much } \\
\text { common }(11-35 \%)\end{array}$ & $\begin{array}{l}\text { Cysts and benign ovarian } \\
\text { tumors }(50-57 \%)\end{array}$ \\
\hline The state of endometrium & $\begin{array}{l}\text { Reflects age and hormonal } \\
\text { balance in one's body (often } \\
\text { unbalanced estrogen secre- } \\
\text { tion). Pathology of endo- } \\
\text { metrium - } 20-25 \%\end{array}$ & $\begin{array}{l}\text { In postmenopause, the } \\
\text { frequency of non-atypical } \\
\text { and atypical hyperplasia is } \\
\text { increased }(30-42 \%) \text {, the } \\
\text { frequency of endometrioid } \\
\text { adenocarcinoma is } 7-8 \%\end{array}$ \\
\hline
\end{tabular}




\section{Continuation of Table 3}

\begin{tabular}{|c|c|c|}
\hline Main Features & Simple Fibroids & $\begin{array}{l}\text { Proliferating } \\
\text { Myoma }\end{array}$ \\
\hline \multicolumn{3}{|c|}{$\begin{array}{c}\text { The state of endometrium is an important factor determining the treatment } \\
\text { strategy of patients with uterine fibroids }\end{array}$} \\
\hline $\begin{array}{l}\text { Clinical Manifestations of } \\
\text { Uterine Fibroids in the Age } \\
\text { Aspect }\end{array}$ & \multicolumn{2}{|c|}{$\begin{array}{l}\text { The onset of disease is often unknown. The peak of pri- } \\
\text { mary detection of uterine fibroids is } 30-35 \text { year old }\end{array}$} \\
\hline $\begin{array}{l}\text { Reproductive } \\
(18-34 \text { year old })\end{array}$ & $\begin{array}{l}\text { Usually asymptomatic. } \\
\text { Secondary infertility. In- } \\
\text { sufficiency of the cycle } \\
\text { luteal phase }\end{array}$ & $\begin{array}{l}\text { Symptomatic fibroids. } \\
\text { Primary infertility. } \\
\text { Insufficiency of the cycle } \\
\text { luteal phase. Long-term } \\
\text { anovulation }\end{array}$ \\
\hline $\begin{array}{l}\text { Late reproductive } \\
(35-45 \text { year old })\end{array}$ & \begin{tabular}{|l|} 
Accidentally occurring un- \\
planned pregnancy causes \\
lots of problems
\end{tabular} & \\
\hline \multirow[t]{2}{*}{$\begin{array}{l}\text { Premenopausal } \\
\text { (45-52 year old) }\end{array}$} & \begin{tabular}{|l|} 
Minor hormone-dependent \\
growth of uterine fibroids; \\
dysfunctional uterine \\
bleeding, endometrial \\
hyperplastic processes \\
\end{tabular} & $\begin{array}{l}\text { Rapid growth of uterine fi- } \\
\text { broids, menometrorrhagia, } \\
\text { acyclic bleeding. Anemia. } \\
\text { Complications from the uri- } \\
\text { nary system }\end{array}$ \\
\hline & $\begin{array}{l}\text { Menopause is } 50-52 \text { year } \\
\text { old }\end{array}$ & $\begin{array}{l}\text { Late onset of menopause } \\
(53-55 \text { year old })\end{array}$ \\
\hline \multirow[t]{2}{*}{$\begin{array}{l}\text { Menopause in } 53 \text { year old } \\
\text { and later. Widespread in- } \\
\text { volution of hormone- } \\
\text { dependent cells and tissues, } \\
\text { including endo-and myo- } \\
\text { metrium }\end{array}$} & $\begin{array}{l}\text { In the first two years of me- } \\
\text { nopause, complete regression } \\
\text { of fibroids (with the excep- } \\
\text { tion of dense, minor-sized } \\
\text { fibromiomas with a pre- } \\
\text { dominance of stroma with } \\
\text { sclerosis and hyalinosis) }\end{array}$ & $\begin{array}{l}\text { Regression of most nodes } \\
\text { occurs in the first 2-3 years } \\
\text { of menopause. In 18-20\% of } \\
\text { cases, myomatous nodes do } \\
\text { not decrease }\end{array}$ \\
\hline & \multicolumn{2}{|c|}{$\begin{array}{l}\text { The availability of non-regressing uterine fibroids in } \\
\text { postmenopause is a marker of endometrial, uterine, ovarian } \\
\text { cancer pathology, etc. }\end{array}$} \\
\hline \multirow[t]{2}{*}{$\begin{array}{l}\text { General Characteristics of } \\
\text { Uterine Fibroids }\end{array}$} & \multicolumn{2}{|c|}{$\begin{array}{l}\text { True benign monoclonal uterine tumor of smooth muscle } \\
\text { cells with varying degrees of connective tissue stroma }\end{array}$} \\
\hline & $\begin{array}{l}\text { Inactive, grows slowly, } \\
\text { often due to an increase in } \\
\text { the volume of the stroma as } \\
\text { tissue connective component }\end{array}$ & $\begin{array}{l}\text { Active, multiple. Fast- } \\
\text { growing, with increased } \\
\text { proliferative potential }\end{array}$ \\
\hline
\end{tabular}




\title{
ETIOLOGY, PATHOGENESIS AND MORPHOGENESIS OF UTERINE FIBROIDS
}

\author{
Shall be known: etiology, pathogenesis and morphogenesis of \\ uterine fibroids
}

Education the rudiments of uterine leiomyoma is likely to occur only during embryogenesis from undifferentiated cells of mesodermal origin of müller duct, which are kept in myometrium and begin growing after menarche on the background of expressed activity of ovaries under the influence of estrogen and progesterone (according to the classical works of K.P. Ulezko-Stroganova, conducted in the 1930s) and postnatal as a result of mutations and neoplastic transformation of stem vascular smooth muscle cells, perivascular areas and, as suggested, muscle lining of blood vessels of uterus.

Myometrium has unique properties allowing it to increase in volume significantly within pregnancy or under certain pathological processes (for example, in adenomyosis) due to hyperplasia and hypertrophy of smooth muscle cells. Thus, the ploidy of the nuclei of about $10 \%$ of myocytes is equal to $3 \mathrm{~s}$ (in other tissues of such triploid cells below $1 \%$ ). Wherein, under physiological conditions, the proliferative activity of myometrium is very low and below $0.1 \%$ of myocyte nuclei express a marker of proliferative activity, the nonhistone nuclear protein Ki-67 (and mainly within the submucous layer). As already mentioned, myometrial myocytes are also characterized by structural and functional heterogeneity depending on their localization in different layers of uterine wall. These features of myometrium, on one hand, affect morphological and biological properties of leiomyomas, and on the other - have influenced the concepts of their pathogenesis and morphogenesis.

Previously, the hypothesis of reactive, hyperplastic pathogenesis of uterine leiomyomas was discussed, which is now abandoned 
past receiving genetic evidence of their tumor nature. So, as a result of survey conducted by A.L. Tikhomirov (1998), it was found that leiomyomas may occur in response to damage to the myometrium caused by inflammatory, mechanical, and other factors. At the same time, the time interval from exposure to a possible etiological factor to the moment of the first detection of leiomyoma is on average of 6 10 years. Bacteriological examination of removed myomatous nodes revealed the availability of associated microbial flora within. Identification of flora upon polymerase chain reaction conducting revealed the availability of Ureaplasma urealyticum, Chalmydia trachomatis, Gardnerella vaginalis, Micoplasma hominis, etc. in leiomyomas, even if they were not represented in the underlying parts of genital tract at the moment of examination. This allowed the authors to consider myomatous nodes as pathological reactive (regenerative) proliferates occuring due to damage to myometrium, for example, around foci of persistent infection. E.M. Vikhlyaeva et al. (1990) also suggested that leiomyomas are focal hyperplasia of smooth muscle cells and in 15-20\% of cases only have signs of true tumor growth. Just modern genetic and molecular biology surveys have proved that leiomyomas are true tumors finally.

Uterine leiomyoma (each node in multiple tumors) is a monoclonal tumor, about $60 \%$ cells of which have an abnormal karyotype, including trisomy 12 , translocations between chromosomes 12 and 14, deletion of 7q, 3q and 1P, and rearrangements of 6P, 10q and 13q. These karyotypic changes, in turn, lead to a disruption of regulation of individual genes at the level or nearby these translocations. The availability of a genetic predisposition to leiomyomas development is confirmed by a large quantity of cytogenetic and epidemiological data. It was found, in particular, that patients with leiomyomas are more likely to have the 1st blood group. Hereditary predisposition to leiomyoma development within the survey of pedigrees is found in every third case. In addition, surveys of twins have reflected a family predisposition to the development of leiomyoma. Some surveys have revealed that leiomyomas are more 
common in African-American women than in white women in the United States, and this may not be explained entirely by differences in body constitution, socio-economic status, their access to medical care, etc. The existence of a hereditary factor in the etiology of leiomyomas is confirmed by family surveys of Reed's syndrome. This hereditary disease is characterized by availability in women of multiple skin leiomyomas or uterine fibroids, and often a combination of both these types of tumors. A potential locus for multiple leiomyomas is mapped on chromosome $18 \mathrm{q} 11,32$, but no candidate genes have yet been identified in this region. Past surveying a large quantity of families with Reed's syndrome, various possible types of inheritance of leiomyoma predisposition were discussed: autosomal dominant, autosomal recessive, or X-linked dominant, but reliable evidence for any of these types of inheritance is not yet available.

Although mitotic activity of leiomyomas is usually low, they, like all tumors, grow and may reach very large sizes (weight up to $3-4 \mathrm{~kg}$, rarely up to $16 \mathrm{~kg}$, diametre of 35-40 $\mathrm{cm}$ or above), which is impossible for the processes of regeneration and focal tissue hyperplasia.

The growth of leiomyomas begins in perivascular areas and, possibly, in the walls of myometrial vessels, where stem cells are localized. Structural areas in the leiomyoma tissue characteristic to active growth areas established around blood vessels, and having a high level of metabolism and increased vascular-tissue permeability, were first described by V.V. Serov et al. in 1973 and described in detail by O.V. Zairatyants et al. (2005-2014).

In the morphogenesis of leiomyomas three consecutive stages are defined as follows:

- establishing of active perivascular area of growth

- (rudiment) in myometrium along with activated cellular metabolism;

- tumor growth without signs of differentiation;

- the growth of tumor with differentiation and maturation. 
Certainly, an important role is played by systemic and local hormonal disorders, primarily an imbalance between estrogens and progesterone, so uterine leiomyomas are referred to as hormonedependent diseases. Leiomyoma tumor cells express significantly more receptors to estrogens and especially to progesterone (isoforms $\mathrm{A}$ and $\mathrm{B}$ ) than myometrium unchanged. In addition, unlike leiomyomas, the nuclei of only about $50 \%$ of myocytes express receptors for estrogen and progesterone. The high concentration of these receptors in myomas and the features of the reaction of tumor myocytes to hormonal stimulation during the menstrual cycle are closer to these indicators of endometrium than myometrium (Fig. 16, A, B; Fig. 17, A, B).

Herewith, it is revealed that $75 \%$ of patients with uterine leiomyomas have hormonal parametres of their menstrual cycle nondiffer from the average indicators. Detected both an increase in the level of estrogens in the blood, and their normal content, and even a decrease as well. It is supposed that the amount of estrogens released matters not so much, as transgress of their excretion and metabolic transformation, as well as disturbance in qualitative ratio between the fractions of estrogens.

Local disorders of hormones content in the uterine blood flow and changes in the hormonal sensitivity of tumor cells play probably a much important role in leiomyomas development and growth. In leiomyoma, an increased content was detected in the bloodstream of uterus, estradiol and progesterone (the phenomenon of local hyperestrogen and progesteronemia), which is the cause of hypertrophy of surrounding myometrium and true growth of leiomyoma itself (a vicious circle of uterine leiomyoma pathogenesis). Compared with unchanged myometrial tissue, lipomatous nodes revealed an increase in the activity of aromatase enzyme. The biological effect of aromatase enzyme (encoded by the SUR19 gene) is to convert androgens into estrogens, which established local hyperestrogenemia. 


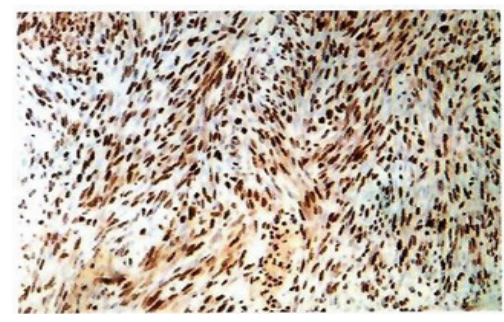

A

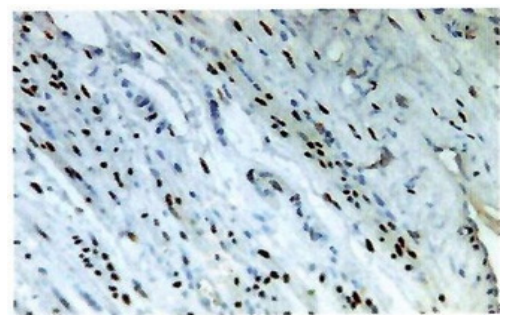

B

Fig. 16. A, B - Increased Expression of Estrogen Receptors in the Nuclei of Leiomyoma Cells (A) Compared to Myometrium (B). IHC reaction with antibodies to estrogen receptors. A $-\times 120, B-\times 200$

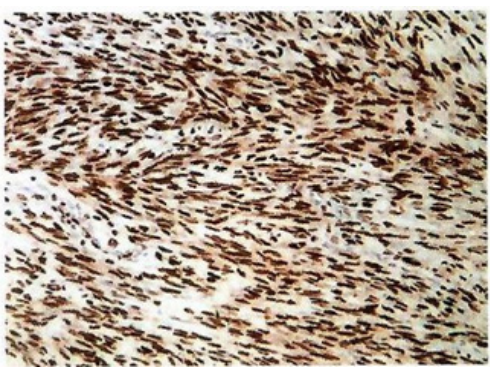

A

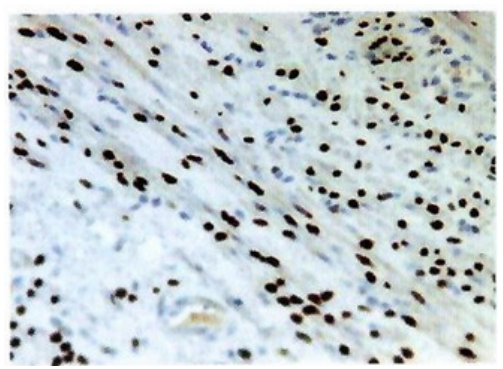

B

Fig. 17. A, B - Increased Expression of Progesterone Receptors in the Nuclei of Leiomyoma Cells (A) Compared to Myometrium (B). IHC reaction with antibodies to progesterone receptor. A $-\times 120, B-\times 200$

Progesterone, to a greater extent than estrogens, stimulates the growth of uterine leiomyomas, but both estrogens and progesterone play an important role in its pathogenesis. In the follicular phase of menstrual cycle, estrogens increase the expression of leiomyoma genes, which are normally activated in the myometrium during pregnancy. An increase in the mass of myometrium may occur both due to smooth muscle cell hyperplasia, which is initiated by estrogens, and due to hypertrophy of these cells. However, the process of hypertrophy of smooth muscle tumor cells, similar to the 
process of their hypertrophy within pregnancy, may occur only when combined with relatively high concentrations of estradiol and progesterone. Within the luteal phase of the cycle, progesterone increases the mitotic activity of leiomyoma cells. In addition, progesterone induces the production of various growth factors and their receptors, inhibits apoptosis by activating the expression of the antiapoptotic Bcl-2 gene, so the proliferative activity of leiomyomas is higher within the secretory phase of menstrual cycle, and mitotic activity index in premenopausal myoma cells is authentically above in comparison to postmenopause. Progesterone is also involved into complex mechanisms of differentiation of smooth muscle cells of leiomyoma tumor.

In the tissue of leiomyomas and normal myometrium receptors of gonadoliberins and pituitary pituitary hormones were found, this indicates the possibility of their direct impact (as well as their agonists) onto the tumor tissue. It is assumed that somatotropin may play the role of one of leiomyoma development initiators, which is confirmed by the high frequency of such tumors in women with acromegaly. It was found that in patients with leiomyoma younger 40 years old, the content of prolactin in blood plasma remains within the normal range, and over 40 years old is significantly higher than said above. In addition, leiomyoma cells may produce prolactin themselves. However, the role of this hormone in the pathogenesis of leiomyoma is not clear yet.

Most hormones exert their impact onto the growth of uterine leiomyoma through various growth factors - epithelial growth factor, insulin-like growth factor-1, transforming growth factor- $\beta$, the main fibroblast growth factor, vascular-endothelial growth factor, etc., the production of which was increased. Growth, stationary course or regression of leiomyomas under the influence of hormones and growth factors depend largely on the relationship between the processes of apoptosis and proliferation of tumor smooth muscle cells. The transgression of proliferation and apoptosis processes regulation is characteristic of tumor growth. The growth of 
leiomyomas, like any other tumor, is determined by the balance between cell proliferation and apoptosis, and such growth may be the result of both activation of proliferative activity and suppression of apoptosis. In addition, an important role is played by lengthening the life cycle of leiomyoma tumor cells at a low level of their apoptosis (Fig. 18, A, B).

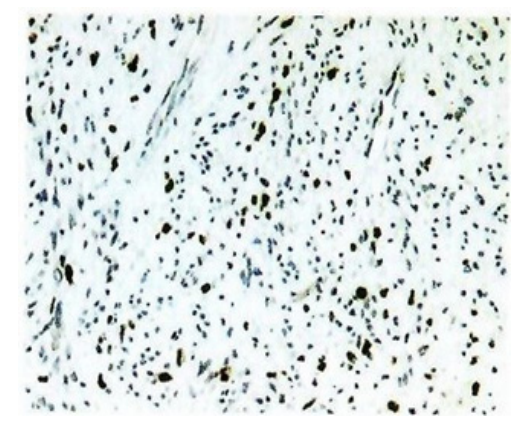

A

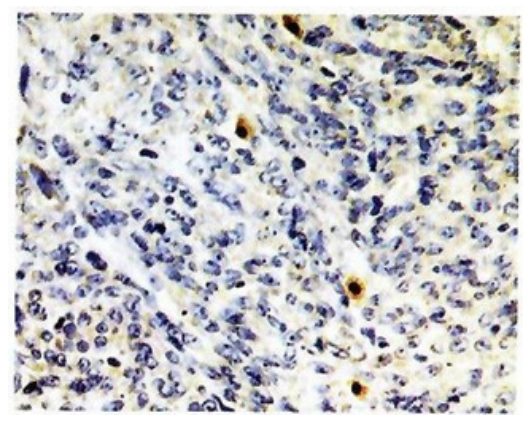

$\mathrm{B}$

Fig. 18. A, B - Proliferation and Apoptosis of Leiomyoma Cells: Expression of Proliferation Marker of Nuclear Non-Histone Protein Ki-67 by Leiomyoma Cells (A), Apoptosis of Tumor Cells (B). A - IHC reaction with antibodies to Ki-67, $\times 120$; B - to activated caspase $\mathrm{Z}, \times 400$

The role of apoptosis in the growth of leiomyomas is ambiguous. Hormone-induced growth of leiomyomas is accompanied by a decrease in the expression of the protein as the product of antioncogene p53 in tumor cells. This may be the result of increased decay due to the instability of p53 molecules in most tumors. Expression of marker proteins is increased as of proliferative activity of PCNA and Ki-67, as well as apoptosis of tumor cells is inhibited due to increased expression of "antiapoptotic" cancer protein Bcl-2, which suppresses apoptosis. Leiomyomas are characterized by a higher content of Bcl-2 compared to myometrium, as well as an increase in its expression under the influence of progesterone and a decrease under the influence of $17 \beta$-estradiol. Higher expression of 
Bcl-2 is observed in cellular and mitotically active leiomyomas. In simple uterine leiomyomas, the level of this oncoprotein is significantly higher in fibroblasts than in the tumor leiomyocyte. The level of Bcl-2 expression in leiomyomas is higher when combined with endometrial hyperplasia, adenomyosis, ovarian pathology (with proliferating clinical and morphological type of leiomyomas). The tendency to increase the level of Bcl-2 expression is also observed in patients with multiple, submucous and intramural leiomyomas.

In leiomyomas, an increased level of angiogenesis processes, an increase in the production of epidermal growth factor and its receptor, insulin-like growth factor-1 and were detected, as well as platelet growth factor. In all histological variants of leiomyomas, a high level of expression of the c-myc cell oncogene was found, which, when growth factors impact onto the cell, induces its division. When co-operating with Bcl-2, even in the absence of growth factors, it promotes cell proliferation, and when Bcl-2 expression is low and growth factor production is reduced, it may induce apoptosis. However, it is likely that in simple leiomyomas, with a relatively low level of $\mathrm{Bcl}-2$, c-myc promotes apoptosis, and in mitotically active and cellular ones, with a high expression of Bcl-2, - cell division. C-myc expression is higher in cellular and mitotically active leiomyomas, especially in combination with adenomyosis. It does not depend on the age of patients with leiomyomas, does not differ in multiple tumors, but is slightly higher within the submucous nodes of the tumor.

Non-histone nuclear protein Ki-67 and PCNA protein are markers of proliferating cells. The proliferative activity of tumor cells in different leiomyomas is very low, but it is higher in cells of all histological types of leiomyomas than in myometry. In cellular and mitotic active tumors, it is observed mainly within perivascular growth areas and its level exceeds this indicator regarding simple leiomyomas. The content of PCNA-positive cells is higher compared to Ki-67-positive cells. This difference reflects the activity of DNA 
repair processes, which are mostly expressed in cellular and mitotic active tumors, and when combined with adenomyosis.

The expression of the" proapoptotic " oncoprotein Bax-inducer of apoptosis is higher in simple leiomyomas than in cellular and mitotic active ones, and especially in their combination with endometrial hyperplasia, adenomyosis and ovarian pathology (in the proliferating clinical and morphological type of leiomyomas). This indicates that for isolated simple leiomyomas the regression of tumor is more likely than in combined pathology, cellular and mitotic active tumors. There are no marked differences in the expression of Bax in patients of reproductive and postmenopausal age. In multiple and submucous leiomyomas, the expression of Bax is higher than in solitary, subserous, and intramural leiomyomas.

The readiness of cells for apoptosis reflects the level of FAS receptors expression. The minimum level of FAS expression is observed within simple and cellular leiomyomas in comparison with mitotically active ones, as well as in patients of older age groups. There were no significant differences in the level of FAS expression in nodes of different anatomical localization. In tumors represented by single nodes, the level of FAS is higher than in multiple neoplasms.

Leiomyoma tumor cells detected by ApopDETEK test or immunohistochemical reaction with antibodies to activated caspase 3 are usually few in their quantity. The highest level of apoptosis is observed in simple and mitotically active leiomyomas, especially when combined with endometrial hyperplasia. The level of apoptosis in postmenopausal patients is higher than in women of reproductive age. There were no marked differences in the level of apoptosis depending on the quantity of leiomyoma nodes.

It may be assumed that different histological variants of leiomyomas are characterized by features of transgression of proliferation and apoptosis processes of tumor cells, which determines the features of such tumors growth mechanisms. Simple leiomyoma is characterized by a relative predominance of apoptosis processes over proliferation. The extent increase of such a tumor is probably the 
result of hypertrophy of tumor leiomyocytes and prolongation of their life span, as well as the growth of stroma and its secondary changes. Cellular leiomyomas are characterized by approximately the same level of proliferation and apoptosis processes, so the increase in the extent of such tumors is associated with both hypertrophy and an increase in the quantity of tumor leiomyocytes, probably due to the lengthening of their life span. Mitotic active leiomyoma is characterized by a predominance of proliferation processes over apoptosis, which is the main condition for the growth of this neoplasm. Stroma establishment, hypertrophy of the tumor leiomyocytes and prolonged their life cycle may also contribute to the increase in the extent of mitotically active leiomyomas. When leiomyoma, adenomyosis and endometrial hyperplasia are combined, there is an increase in the processes of both proliferation and apoptosis in tumor cells. Thus, leiomyomas increase in their extent not due to the proliferation of tumor cells mainly, since their mitotic activity is very low, but due to the lengthening of tumor cells life cycle, a low level of apoptosis and an increase in the volume of connective tissue component.

In different histologic variants of uterine leiomyomas the stromal component is differentiated: in a simple leiomyoma, the most mature stroma with a predominance of fibrocytes and extracellular matrix components is detected, and in cellular and mitotic active tumors, the stroma is less mature, with signs of active angiogenesis (Fig. 19).

Numerous surveys have revealed a variety of immune disorders in women with uterine leiomyomas as differentiation of immunocompetent cells, synthesis of interleukins, interferons, the activity of complement system, etc. However, their pathogenetic role remains unclear.

The survey of leiomyomas relapses past conservative myomectomy operations has revealed that they may be associated with the development of a new tumor from perivascular growth areas in the surrounding myometrium, sometimes in scars past myomectomies, as well as with microscopic leiomyomas non-diagnosed upon preopera- 
tive examination. Usually relapse leiomyomas are characterized by higher proliferative activity compared to tumors newly detected, and among them mitotic active and cellular one's predominate.

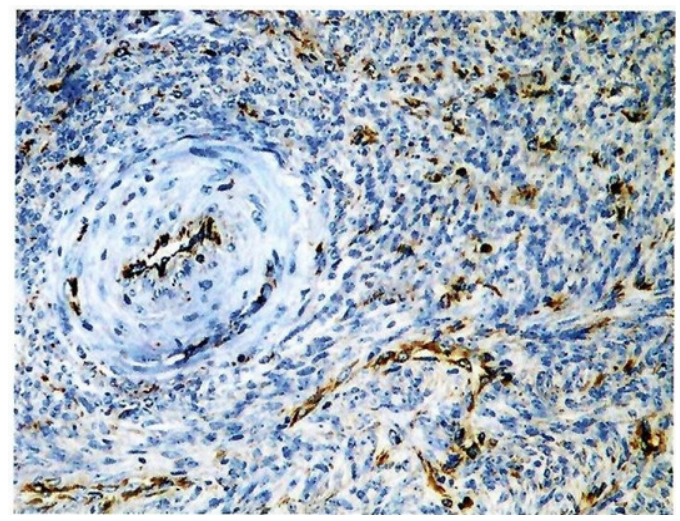

Fig. 19. Perivascular Growth Area and the Surrounding Bundles of Cellular Leiomyoma Tumor Leiomyocytes. The expression by tumor leiomyocytes and vascular endothelia of vascular endothelial growth factor (VEGF).

IHC reaction with antibodies to VEGF, $\times 200$ 


\section{CLINICS OF UTERINE FIBROIDS}

\section{Shall be known: the clinical pattern of uterine fibroids}

Clinical manifestations of uterine fibroids depend on its nodes localization, the age of patients, the tumor extent, concomitant diseases of endometrium, cervix, ovaries and mammary glands.

The main clinical signs of uterine fibroids.

1. Uterine bleeding within the menstruation according to the type of hyperprolinemia.

2. The transgression of menstrual cycle (abnormal uterine bleeding, insufficiency of luteal phase of menstrual cycle).

3. Pain in the lower abdomen and lower back (feeling of heaviness and pressure in the lower abdomen).

4. The transgression of adjacent organs function (constipation, dysuric phenomena).

In $25 \%$ of patients, uterine fibroids are developed slowly and are almost non-accompanied by expressed clinical signs.

With a subserous localization of fibroids on a wide base or on a stem through which the vessels feeding the tumor pass, clinical symptoms are mostly often absent, since the functional activity of the uterus is unchanged.

Upon the location of peritoneal fibroids within the area of the uterus isthmus (isthmic fibroids), pain in the lower abdomen and dysuric phenomena appears. With cervical myoma, infectious complications may be developed, unpleasant sensations in the vagina, difficulties in emptying the bladder. Cervical and isthmian fibroids of uterus cause deformity of its cervix, as are the cause of infertility, spontaneous termination of pregnancy, as well as symptoms of compression of adjacent organs. 
Upon the twisting the stem of peritoneal fibroid, clinics of acute abdominal pain are developed (sharp pain, fever, nausea, vomiting, signs of peritoneal irritation).

When the myomatous node is located along the uterus back wall, the most common clinical symptom is aching pain in the sacrum and lower back, with the development of fibroids, the tumor fills the pelvis retrocervically, shifting the uterus anteriorly, pressing it to the symphysis, squeezing the rectum (causes chronic colitis, hemorrhoids, frequent urges to defecate, a feeling of incomplete emptying of the rectum).

The location of nodes in the cervix or in the isthmus may disrupt blood supply within the pelvic region, cause venous congestion, and thrombosis of pelvic and lower extremities veins.

With intraligamental growth of the tumor, the ureters compression occurs, the outflow of urine is disrupted, and chronic pyelonephritis often joins. In severe cases, hydroureter and hydronephrosis are developed.

Upon secondary changes in myomatous nodes (edema, necrosis, degeneration), there is a pattern of an acute abdomen with a corresponding change in the blood formula (leukocytosis, a shift to the left). Secondary changes may occur upon large myomatous node extents and with myomas of any localization and location.

It is necessary to allocate clinics regarding node necrosis, in which urgent surgical intervention shall be necessary. The process of inflammation, thrombosis of minor vessels and ischemia extends far beyond the myomatous node to remote areas of the myometrium, so when the node necrosis, the uterus is removed.

When palpating a necrotic node, there is not only a sharp local soreness, but also soreness of the entire uterus. The temperature rises, the tongue is dry, furred, the stomach is swollen. Signs of peritoneal irritation and leukocytosis are increasing.

A rare complication occurring past physical activity, during pregnancy, or for no apparent reason, is a rupture of one of the myomatous node vessels. This complication is also accompanied by 
an attack of sharp pain and signs of intra-abdominal bleeding (shock, collapse). The leading signs of this complication are pain and anemia.

In the availability of myomatous nodes of intermuscular localization, there is a deformation of the uterus and / or its cavity contours. The topography of pelvic organs is disturbed (as displacement of the round ligaments, fallopian tubes and ovaries, ureters, and bladder).

Intermuscular fibroids disrupt the functional ability of uterus, reduce its contractile function, increase and deform the uterine cavity and the area of endometrium. Wherein, the middle layer of the myometrium thickens, microcirculation and blood flow in the uterus and neighboring pelvic organs are disrupted. Even if the appropriate transformation of endometrium is maintained during the menstrual cycle, long-term and abundant uterine bleeding is observed during menstruation in patients with uterine fibroids.

Causes of menorrhagia in uterine fibroids.

1. Increase in the extent of uterus and, accordingly, the area of endometrium.

2. Reduced contractility of myomatous altered myometrium.

3. Development of combined pathology (endometrial hyperplastic process, endometriosis).

4. Increasing the quantity of venous plexuses.

5. Changes in the vasculature of myometrium and endometrium (vessels without a sinusoid muscle sheath, the muliplicity of arteriolo-venular anastomoses, increased vascular wall permeability, increased capillary mass during neoangiogenesis, characteristic of large uterine fibroids).

Menorrhagia is typical for active, proliferating, rapidly growing fibroids.

For nodes of intermuscular localization, the development of dysmenorrhea is a frequent symptom. Wherein, if the node grows, the pain may take a permanent character. 
Submucous localization of nodes. Myomatous nodes having centripetal growth are located either on a broad base or on a thin stem, which gradually lengthens until the myomatous node reaches the cervix ("the emerging submucous myomatous node").

Nodes with submucosal localization are characterized by periodically occurring cramping pains in the lower abdomen, uterine bleeding of the type of meno- and metrorrhagia. Liquid bloody discharge with a putrid smell appear from vagina.

Pain and discharge increase during menstruation. Past its ending, when the cervix is partially closed, the clinical manifestations of submucosal fibroids subside.

When vaginal examination, the attention shall be paid to the condition of the cervical canal. Upon the availability of foreign tissue in uterus (myomatous node, polyp), the external and internal uterine pharynx remain ajar.

Thus, the clinical symptoms of myomatous nodes are extremely diverse: from an asymptomatic course to a pattern of an acute abdomen requiring urgent surgical care. 


\section{DIAGNOSTICS METHODS}

Shall be known: modern methods of uterine fibroids diagnosing.

Within the diagnostics, it shall be necessary to make a decision on the patient's supervision tactics, highlighting the absolute and relative indications regarding operative therapy.

\section{The Algorithm of Diagnostic Search}

The examination shall be started with a survey of anamnesis and objective data obtained using routine research methods.

\section{Anamnesis Collection.}

In the anamnesis, a scope of factors characteristic of uterine fibroids shall be identified as follows:

- age of 30-35 year old and the absence of birth by this time;

- burdened obstetric and gynecological anamnesis (abortions, infertility, inflammatory gynecological diseases);

- later menarche;

- heavy menstrual bleeding.

It shall be necessary to pay attention to the possibility of hereditary fibroids in the patient's mother and close relatives. Such fibroids occur mostly often at a younger age (up to 30 year old) in women with stress, frequent diseases in adolescence.

Typical complaints of patients (metrorrhagia, hyperpolymenorrhea, pain in the lower abdomen and lower back, violation of the function of adjacent organs, anemia).

2. Conducting a Bimanual Gynecological Examination

In bimanual examination, the uterus is determined to be enlarged, bumpy, dense. With abdominal localization, the nodes are contoured easily. More often, the uterus is sedentary, especially if the node is large, located intraligamental or retrocervical. 
At nodes of intermuscular localization, there is a deformation of uterus contours.

With submucosal fibroids, the uterus may be of normal extent, with a smooth surface.

3. Ultrasonic Examination of Pelvic Organs.

The main method of screening and primary tool of diagnosis is ultrasonography (US). When performing ultrasonic, it shall be necessary to use transabdominal and transvaginal scanning, complementing the survey with colour Doppler mapping (CDM) of blood flow within vessels.

A reliable ultrasonic sign of uterine fibroids is the detection of hypoechoic solid formation substance in the myometrium. Myomatous nodes of large extents are characterized by the layering of their internal structure, with a more echogenic upper part of the node. Echohysterography (ultrasonic against the background of the fluid installed into the uterine cavity) allows to determine reliably the wall of uterus from which the submucous node originates.

In case of peritoneal localization of myomatous nodes, transvaginal ultrasonic is recommended, which will assist to distinguish myoma from appendage tumors. On the ultrasonic device, fibroids are recognized as a rounded formation, soldered to the uterus, with sonic conductivity increased. Ultrasonic signs of peritoneal fibroids on a wide base are less distinct in comparison to the uterus visibility of fibroids, since subperitoneal tumor absorbs ultrasonic noticeably, reflecting it with a lower intensity.

When ultrasonic of submucosal fibroids, the median echo signal is dislocated and deformed. An enlarged uterine cavity is visible with a rounded neoplasm, fairly smooth contours and medium echogenicity.

Intermuscular fibroids with centripetal growth are recognized by ultrasonic as a uterus-deforming neoplasm in the shape of a crescent with smooth edges.

Ultrasonic examination may reveal signs of secondary changes in the nodes, such as edema, cystic degeneration and calcinosis. 
Edema of myomatous node is manifested by an increase in its extent during dynamic examination, as well as expressed increase in the formation dorsal contour and a decrease in the image echogenicity.

Cystic degeneration of myomatous node looks echographically like the emergence of hypo- and anechoic cavities of different extents in its structure without blood flow.

Calcinosis of myomatous node is visualized as hyperechogenic single or multiple inclusions with clear contours. If the formation diametre exceeds $0.5 \mathrm{~cm}$, an acoustic shadow is always detected behind it.

Ultrasonic examination allows to determine the localization, extent, location, and the structure of myomatous nodes. The sensitivity of the method is $98 \%$, the specificity is $94 \%$, the prognostic value is $81 \%$ for a positive result, and $100 \%$ for a negative one.

According to ultrasonic data depending on the location of the node in relation to the uterus sections shall be detected as follows:

- corporeal myoma (the uterus myoma);

- cervical fibroids;

- isthmian fibroids.

In relation to the layers of uterus wall, it shall be detected as follows:

- subserous uterine fibroids (including intra-ligamentous, subserous-interstitial);

- interstitial fibroids (without or with deformity of uterine cavity);

- submucous fibroids (interstitial-submucous and submucous on the stem).

Depending on their extent, myomatous nodes are divided as follows:

- minor (below $2 \mathrm{~cm}$ in diameter);

- medium (from 2.1 to $6.9 \mathrm{~cm}$ in diameter);

- large (from 7 to $10 \mathrm{~cm}$ in diameter);

- giant (above $10 \mathrm{~cm}$ in diameter). 
According to the quantity of myomatous nodes, fibroids are distinguished as follows:

- sporadic (up to 3 nodes);

- moderate (4 to 6 nodes);

- multiple (from 7 nodes or above).

When performing dynamic ultrasonic control, uterine fibroids are isolated without node growth, with slow and rapid growth.

Along with an echographic picture of the myomatous node structure, colour Doppler mapping shall be performed to assess the qualitative and quantitative parametres of uterine blood flow.

Color Doppler mapping allows to notice the moving fluids of the entire body and analyze this movement in real time. Vascular blood flows of neoplasms have their own characteristics, and the $\mathrm{CDM}$ assists to make a conclusion on the tumor benign or malignant nature.

The CDM method evaluates blood flow by three parameters as follows: velocity, direction, and homogeneity or turbulence. Modern equipment allows to notice the pettiest vessels and to identify them. In myomatous nodes, tumor neovascularization occurs, that is, the establishment of new blood vessels differ in abnormal shapes. Blood flow in them is characterized by increased velocity and multidirectionality, the vascular resistance is very low. With CDM, such vessels are brighter in their color.

In proliferating myoma, nodes are characterized by a diffuse or mixed type of blood flow. In normal myometry, the mosaic type of blood flow is preserved. The blood flow rate in simple and proliferating uterine fibroids is low and ranges from 0.12 to $0.25 \mathrm{~cm} 3 / \mathrm{sec}$, and the resistance index is $0.58-0.69$ and $0.5-0.56$, respectively. A high rate of arterial mosaic blood flow (above $0.4 \mathrm{~cm} 3 / \mathrm{sec}$ ) combined with low resistance index (below 0.4) is an indirect sign of uterine sarcoma (Fig. 20, Fig. 21). 


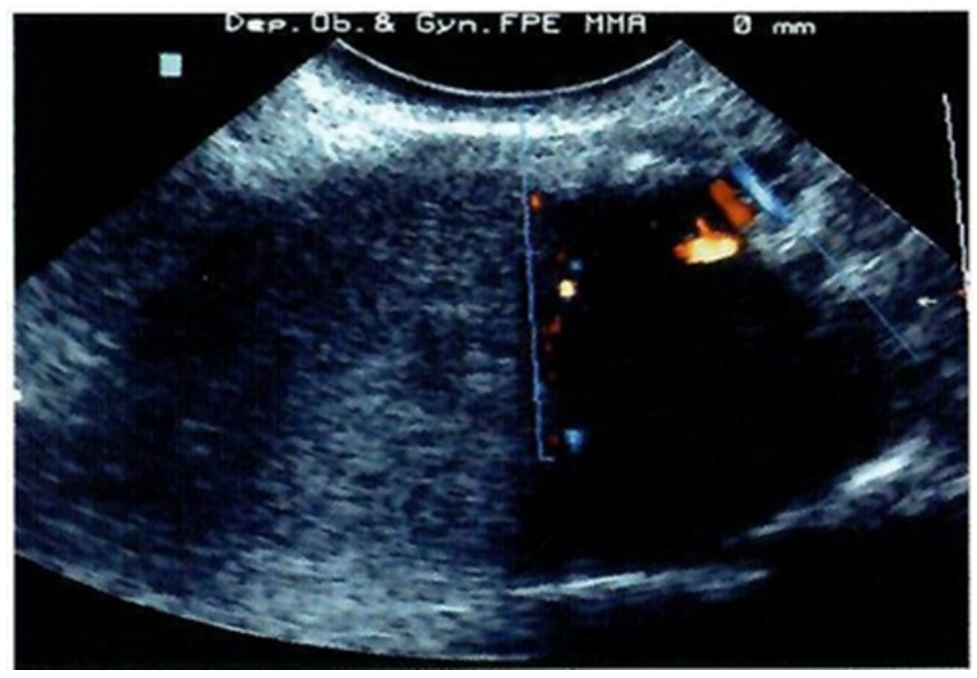

Fig. 20. Ultrasonic with CDM for Simple Uterine Fibroids

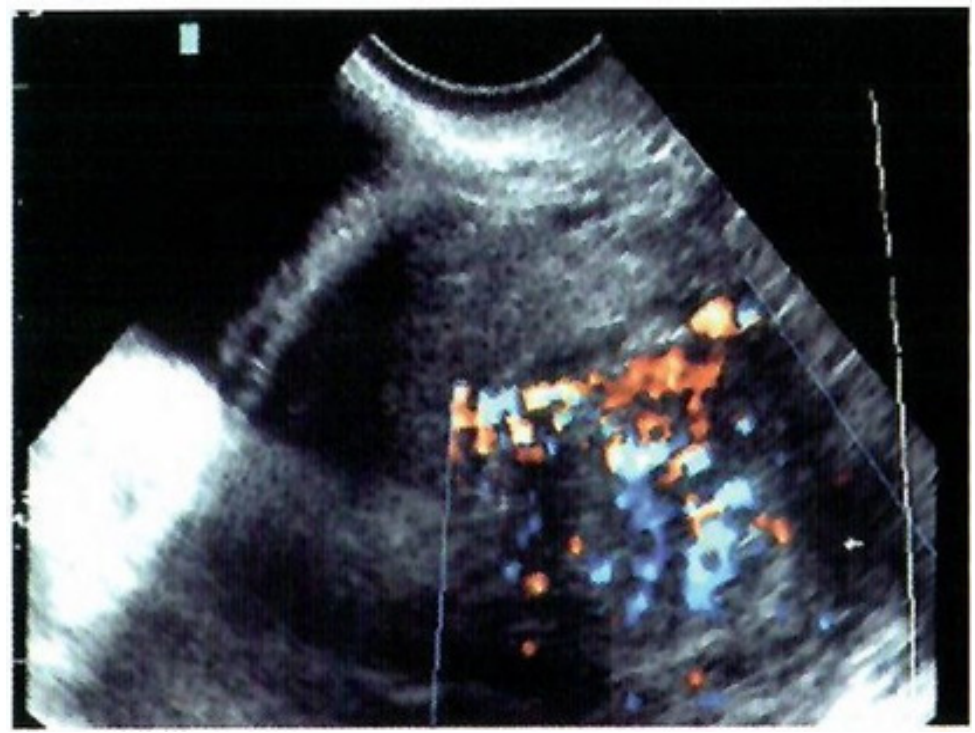

Fig. 21. Ultrasonic with CDM along with Proliferating Uterine Fibroids 


\section{X-Raying.}

Hysterosalpingography (HSG) is a radiological method for evaluating the state of uterus and fallopian tubes. Hysterogrammes demonstrate deformities of uterus inner surface, adenomyosis, intrauterine fusion, submucosal myomatous nodes, and centripetal growth of tumor. In the diagnosis of intrauterine pathology, the sensitivity of HSG is $95 \%$, the specificity is $86 \%$.

Indications for Hysterosalpingography:

- suspicion of submucosal fibroids;

- exclusion of uterine cavity deformities prior to performing myomectomy in women of reproductive age;

- assessment of the patency of fallopian tubes (a combination of uterine fibroids and infertility).

\section{Computer Tomography.}

The use of modern multi-section computed tomography (CT) with artificial contrast allows not only to determine the tumor availability and localization, but also to conduct its differential diagnosis under high resolution.

In $\mathrm{CT}$, myoma is visualized as a soft tissue formation with protruding beyond the outer contour of uterus or deforming its cavity. Fibroids have a well-defined capsule and a uniform structure with a soft-tissue density.

The limitation of the method is radiation load, which is why the method is contraindicated for use in obstetrics and is limited in women of reproductive age.

The method of multispiral computed tomography (MSCT) allows to survey the vascular system of an organism or its individual organ in real time. The continuously generated image makes it possible to establish a three-dimensional computer model of the organ in question and to survey it. MSCT evaluates the optimal filling of abdominal aorta with contrast material and starts scanning automatically as soon as the contrast filling reaches the rate required. 
The level of contrast accumulation in the organ in question assists in putting the diagnosis of tumors and vascular conditions.

MSCT for suspected fibroids reveals the following:

- the extent of the area affected by myomatous nodes and their localization;

- vascular pattern of neoplasms;

- the spread of tumor to nearby organs.

MSCT is a fast and effective way to diagnose myometrial diseases. It has a much-extended resolution than conventional CT, which makes it possible to see the pettiest changes in uterus and to prescribe treatment timely and correct.

\section{Magnetic Resonance Imaging.}

Magnetic resonance imaging (MRI) allows to determine the type of fibroids, the quantity of nodes, their secondary changes and localization. MRI scans the uterus in three projections-sagital, frontal and transverse, which displays its contours and availability of their deformation clearly. A characteristic MRI pattern in myoma is a change in the uterine contour and a sharp (capsular) separation of nodes from the usual myometrium.

Magnetic resonance imaging allows to establish the correct diagnosis in almost $99 \%$ of cases.

When MRI of pelvic organs, regardless the phase of menstrual cycle, there are 5 types of myomatous nodes as follows.

1. With a uniform hypointensive MR-signal (similar to skeletal muscles).

2. With a heterogeneous, mostly hypointensive structure, but with areas of hyperintensive inclusions (due to degeneration with the establishment of hyalinosis edema).

3. With isointensive MR-signal, analogue to the myometrium tissue, due to the low content of collagen.

4. With a high MR-signal, due to cystic degeneration.

5. With a varying MR-signal. 


\section{Histeroscopy.}

This method of survey is recommended upon suspected uterine fibroids with submucosal localization or with centripetal growth of nodes. Using a hysteroscope, a magnified image of the internal uterine surface is transmitted to the monitor, which allows to define the myomatous nodes in great detail, to put a more accurate diagnosis and to recommend the necessary treatment. 


\title{
TREATMENT OF PATIENTS WITH UTERINE FIBROIDS
}

\author{
Shall be known: modern principles of treatment of uterine \\ fibroids
}

The supervision of patients with uterine fibroids depends on the location, extent, rate and nature of growth of myomatous nodes, the tumor clinical and morphological variant, the age of women, the state of their reproductive system, hormonal status and some other factors.

Absolute indications for surgical treatment are as follows:

- submucous localization of myomatous node;

- large extent of myomatous altered uterus (the organ is enlarged to the extent noted at the 12th week of pregnancy);

- abnormal uterine bleeding causing chronic anemia nonresponding to conservative therapy;

- rapid growth of myomatous node (increase in the extent up to typical per the 4th week of pregnancy within 1 year);

- acute nutrition disorders of fibroids;

- expressed secondary changes of an ischemic or degenerative nature (torsion of the node stem, necrosis, establishing of cavities in myoma);

- combination of uterine fibroids with recurrent endometrial hyperplasia, atypical endometrial hyperplasia, ovarian tumor;

- compression of ureter, bladder, rectum (intraligamental, retrocervical fibroids, node located within the pre-vesicular tissue);

- the availability of a myomatous node within the area of uterus tubal angle, which is the cause of infertility in a woman of reproductive age;

- cervical and cervical-isthmus localization of myomatous node;

- non-regressing and growing uterine fibroids in postmenopause.

The scope of surgery is determined by the age of the woman largely. The operation shall be performed on the 5th-14th day of the 
menstrual cycle. In patients under 40 year old, if there are indications for surgical treatment, if technical capabilities allow, myomectomy shall be performed, except in cases of a combination of fibroids with oncological pathology of reproductive system.

In women over 40 year old, it is preferable to perform removal of uterus: supravaginal amputation (in the normal state of its neck) or extirpation, if pathological changes are detected on the cervix.

In postmenopausal age, the uterus is removed with both appendages, since within this period, the ovaries participate in the hormonal background of a woman's body establishing is minimal, and the cancer risk is high.

The choice of operation method (endoscopic, laparoscopic, laparotomic, transvaginal) shall be determined individually.

Conservative treatment allows to avoid removal of uterus in some cases, since within the first 2 years of postmenopause, fibroids usually regress or even disappear completely.

Conservative supervision of patients with uterine fibroids shall be possible under the conditions as following.

1. Young (reproductive) age of a patient

2. Minor extent of myomatous uterus (up to 10-12 weeks of pregnancy).

3. Mainly intermuscular arrangement of myomatous nodes.

4. Relatively slow growth of fibroids.

5. No deformation of uterine cavity.

When treating patients with uterine fibroids, the principles shall be observed as following.

1. At one's young and late reproductive age, it shall be necessary to maintain a woman's reproductive function (to normalize the menstrual cycle disturbed, to treat infertility, to preserve pregnancy).

2. When deciding on myomectomy, it shall be necessary to take into account the tumor morphohistotype (simple, proliferating, pre-sarcomatous). Upon proliferating fibroids, undetected multiple 
microscopic nodes continue to grow, so the tumor recurrence shall be expected. This requires hormonal correction past conservative plastic surgery.

3. Regarding patients within peri - and postmenopausal age, there shall be reasonable oncological caution in relation to possible malignant transformation of endometrium, ovarian tumor, uterine sarcoma. The availability of non-regressing or growing uterine fibroids past 2 years of postmenopausal period is a marker of cancer.

4. The effectiveness of hormone therapy may be different, as it depends on the content and nature of hormonal receptors in the uterine myoma and myometrium.

\section{PHARMACOTHERAPY}

Most pharmaceuticals registered for the treatment of uterine fibroids have their therapeutic effect only against the background of their use with rapid progression of the disease after withdrawal.

With an asymptomatic course of the disease, a wait-and-see tactic is acceptable without prescribing medications. Conducting preventive therapy for the purpose of exclusion of possible future complications shall not be recommended. The exception is submucous node localization for women planning pregnancy, and subserous node localization of large extents, as it may disrupt urodynamics and contribute to the development of hydronephrosis. In these cases, preventive treatment may avert miscarriage and development of obturation of the urinary tract.

Relieving the symptoms of uterine fibroids (abnormal uterine bleeding, pain, pressure) is the main objective of the therapy. The nature of treatment is determined by the severity of clinical symptoms, the extent and location of myomatous nodes, the age of the patient, as well as her reproductive plans. Taking into account the possibility of spontaneous regression of myomas in the postpartum 
and postmenopausal periods, a wait-and-see approach is acceptable for these groups of patients.

Pharmacotherapy is effective in $75 \%$ of patients with metrorrhagia.

Hormonal Therapy. The use of combined hormonal contraceptives (CHC) and progesterone-containing drugs has its limited effectiveness within the treatment of uterine fibroids. These remedies may be used in patients with severe menstrual bleeding and dysmenorrhea.

Estrogen-Progestin Contraceptives. Drugs are not officially registered to provide the treatment of uterine fibroids, but upon the availability of severe menstrual bleeding, they may achieve significant clinical improvement.

Gestagens. The main objective of prescribing gestagens within the treatment of patients with uterine fibroids is to normalize the menstrual cycle and the mineralocorticoid function of adrenal cortex. Gestagens are prescribed 5-10 $\mathrm{mg}$ in the second phase of the menstrual cycle (from the 16th to the 25th day) per 10 days or in continuous mode from the 5 th to the 26th day of the cycle per 6-9 months.

Levonorgestrel-releasing intrauterine system. Against the background of the use of the intrauterine spiral (IUD) of Miren, there is a decrease in the uterus extent and the volume of menstrual blood loss.

Progesterone-containing implants, injections and pills, as well as $\mathrm{CHC}$, may be prescribed to patients with uterine fibroids, but it shall be considered that progesterone is a possible factor in the growth of this tumor. Progesterone-containing contraceptives cause the development of endometrial atrophy and thus reduce the volume of menstrual bleeding. They may be used to treat mild symptoms of uterine fibroids, especially in women need contraception.

Agonists of gonadotropin-releasing hormone (AGn-RH) are one of the most effective remedies regarding the treatment of uterine fibroids. The pharmaceuticals of this group at the initial stage cause an increase in the release of gonadotropins with subsequent desensitization and inhibition of sensitivity towards gonad- 
otropins, leading to the development of hypogonadotropic hypogonadism. Against the background of their use, in most patients amenorrhea is developed, and there is a significant decrease (from 35 to $60 \%$ ) in the uterus extent within 3 months from the start of therapy. Past ceasing the course of treatment, there is a rapid resumption of menstruation.

Against the background of AGn-RH use, drug-induced menopause is developed along with all the manifestations of climacteric syndrome. The most common side effects are hot flashes and increased sweating, associated with medication "shutdown" of ovarian function. Amongst the rare side effects irritability and increased headaches, dryness of the vaginal mucosa, decreased libido shall be noted. These symptoms usually disappear past $2-3$ months past the therapy ceasing. Serious side effects associated with the use of $\mathrm{AGnRH}$ are due to the decrease in the level of circulating estrogens. As a result, the risk of early development of osteoporosis and cardiovascular diseases increases, which prevents the long-term use of these drugs, so AGnRH are mainly used as preoperative therapy per 4-6 months. Reducing the size of uterus reduces the volume of intraoperative blood loss, and also expands the possibilities for minimally invasive surgical interventions, including the use of vaginal access. If there is no reduction in the extent of uterine fibroids against the background of 3 months of AGn-RH use, further use of the drug is ineffective. Similarly, it shall not be advisable to treat uterine fibroids below $3 \mathrm{~cm}$ in their extent prior to surgery.

We conducted a 6-month course of AGnRH treatment (buserelin-depo $3.75 \mathrm{mg}$, "Pharm-Sintez") in 68 patients with a combination of uterine fibroids, adenomyosis and endometrial hyperplasia. The average age of women was $43.1 \pm 1.7$ year old (from 32 to 53), and the duration of their uterine fibroids and adenomyosis was from 1.5 to 12 years (on average, $7.4 \pm 1.2$ years). The extent of uterus pathologically altered in patients prior to treatment corresponded to the extent of 9-17-week pregnancy $\left(280-950 \mathrm{~cm}^{3}\right.$, on average $\left.682.4 \pm 61.1 \mathrm{~cm}^{3}\right)$. Most of the women examined had a combination 
of adenomyosis with multiple uterine myoma and different localization of nodes. During the survey, we used the usual method of administration of buserelin-depot: $3.75 \mathrm{mg}$ of the drug was administered onto the 1st-5th day of the cycle intramuscularly, then the injections were repeated every 28 days per 6 months. 2-3 weeks past AGnRH therapy starting, $61.2 \%$ of patients had bloody discharge from the genital tract, which disappeared past 2 months. $82.1 \%$ of patients had amenorrhea past 1 month and all of them past 2 months. Reducing the size of myomatosis nodes and the uterus itself in all patients, there were no changes observed during the treatment. In 2 months, against the background of menopause onset, there was a fairly significant ( $32 \%$ of the initial value) decrease in the volume of the uterus - up to $464.0 \pm 42.1 \mathrm{~cm} 3$. In the future, during the $3 \mathrm{rd}$, $4 \mathrm{th}$, and 5 th months of treatment, the volume of pathologically altered uterus continued to decrease actively - up to $56.8 \%, 45.2 \%$, and $44.2 \%$ of the initial volume, respectively. The minimum volume $\left(200.6 \pm 23.5 \mathrm{~cm}^{3}\right)$ of uterus has been reached by the end of the treatment course. The volume of proliferating myoma nodes, which were large $(>6 \mathrm{~cm})$ in the majority of patients $(81 \%)$, decreased significantly and much actively upon AGnRH therapy than the volume of simple myoma minor nodes. The changes described were accompanied by a marked decrease in blood flow in the uterine artery and changes in vascularization within myomatous nodes, foci of adenomyosis and myometria, detected upon CDM. Peripheral resistance in the uterine artery prior to treatment corresponded to $0.55 \pm 0.06$, and past hormone therapy, this indicator increased to $0.86 \pm 0.07$. Herewith, in the nodes of proliferating fibroids, there was a significant decrease in the brightness of colour signals and their quantity (on average, up to 3-8 with an initial indicator of $>25-30$ ). In addition, there was a decrease in blood flow in the vessels of proliferating nodes.

In the course of therapy with buserelin-depot, important changes were observed in the areas of myometrium affected by diffuse adenomyosis, as well as in the foci and nodes of adenomyosis. Based 
on the measurement of the thickness of activity affected (along with expressed vascularization) by adenomyosis of uterine wall, we found an average decrease of $28 \%$ (from $33 \pm 2.9$ to $24 \pm 2.6 \mathrm{~mm}$ ). In parallel with the decrease in the size of adenomyotic lesions, a decrease in the activity of vascularization of myometrial areas affected by adenomyosis was registered in the CDM: the quantity of colour signals decreased by an average of $44 \%$.

Thus, the decrease in the total volume of uterus occurred upon buserelin-depo therapy was due to both a decrease in the extent of individual myomatous nodes and a decrease in the extent of sections of myometrium affected by adenomyosis, due, among other things, to a decrease in their vascularization. These data indicate an important role of angiogenesis processes in the pathogenesis of a combination of proliferating fibroids and adenomyosis, since the hormone therapy of $\mathrm{AGnRH}$ reduces the vascularization of fibroids, and this process is expressed to a greater extent in the nodes of proliferating fibroids.

AGnRH reduces the extent of myomas, reduces their vascularization, and suppresses the activity of neoangiogenesis and tumor growth areas along with the development of these areas sclerosis.

It shall be noted that past the end of hormone therapy per 2 months, the volume of uterus and the dominant myomatous node were not changed practically. Nevertheless, within the next 4-6 months, the majority of women (94.1\%), against the background of restoration of menstrual function (on average, past 43 days), revealed a resumption of fibroids growth and an increase in the volume of uterus. Herewith, intensive vascularization of proliferating myomatous nodes occurred in parallel, and their growth activity was significantly higher than that of simple myoma nodes. This was the basis for conducting surgical treatment in patients with combined uterine pathology within $1-1.5$ years past hormone therapy.

To sum up, we may say that AGnRH may be used for shortterm therapy in patients within the perimenopausal period upon the 
availability of contraindications to surgical treatment, as well as preand postoperative therapy in patients with uterine fibroids, including in the combined pathology of endometrium and myometrium, which is considered to be an additional advantage of these drugs. Therapeutically equivalent options are drugs as follows: leuprolide acetate depot (intramuscularly $3.75 \mathrm{mg}$-month or $11.25 \mathrm{mg}-3 \mathrm{months}$ ), gozerelin acetate (3.6 mg-month subcutaneously or 1.0, $6 \mathrm{mg}$ subcutaneous implantation every 3 months) or nafarelin acetate (2-fold a day, spray for intranasal administration).

Gonadotropin-releasing hormone antagonists. The effectiveness of gonadotropin-releasing hormone antagonists (orgalutran, cetrotide) is associated with their competition with endogenous gonadotropin-releasing hormone with binding sites in the pituitary gland. The advantage of antagonists over agonists is a faster onset of clinical effect without the characteristic initial surge of hormonal activity, however, these medicals are mainly available on the market in doses used for ovulation induction. There are no prolonged pharmaceuticals which requires daily injection of the remedy.

The progesterone receptor modulators (PRM) family is a new promising group of pharmaceuticals, predominantly steroids, intended for targeted therapy of pathological processes developing within progesterone - sensitive tissues, such as uterine leiomyoma and endometrium.

They are represented by various ligands of progesterone receptors and include as follows: 1) progesterone agonists (progesterone itself and progestins), 2) substances with a mixed impact of progesterone agonists and antagonists (selective progesterone receptor modulators-SPRMs) and 3) progesterone antagonists (antiprogestins or antigestagens, such as mifepristone) (Fig. 22). 


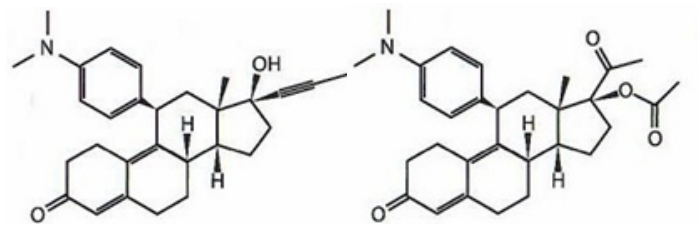

Mifepristone

Ulipristal

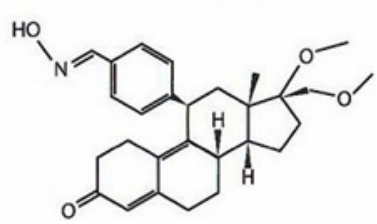

Asoprisnil

Fig. 22. The PRM Family (Pharmacol Rev., 2013)

In modern classifications, all three groups of substances are combined into one family of SPRM. The difference between antigestagens and SPRMs is the ability of the former to terminate pregnancy in certain doses. SPRMs do not cause pregnancy termination due to their tissue specific mixed effect as progesterone antagonists and agonists

Leiomyoma is an example of a progesterone-dependent pathological process.

It is usually developed upon the ovulatory menstrual cycle, and progesterone is a strong inducer of its growth due to increased proliferative activity and suppression of apoptosis of tumor cells. About $90 \%$ of leiomyoma cells express progesterone A and B receptors, which stimulates its cells to produce various growth factors and an apoptosis inhibitor of proto-oncogene Bcl-2. As a result, within the luteal phase of the cycle, the expression of proliferation markers in uterine leiomyoma cells increases, and the activity of apoptosis decreases.

There are two isoforms of progesterone receptors RP-A and RP-B distinguished. Their expression in cell nuclei is encoded by the same gene. The RP-B isoform differs from RP-A by having an $\mathrm{N}$-terminal fragment of 164 amino acids in its molecule, which is absent in RP-A. Using gene knockout models, it has been proved that progesterone receptor isoforms may play different roles in different tissues and the effect of their ligands, including SPRM, depends on the ratio of RP-A and RP-B expression within cell nuclei, 
with RP-B activation giving a much more expressed effect. Under certain conditions, in response to binding to progesterone agonists or antagonists, RP-A is activated as a ligand-dependent transdominant repressor of other steroid receptors, including RP - B, estrogen, androgen, gluco- and mineralocorticoid receptors. Activation of RP-B increases, and RP-A, on the contrary, reduces the susceptibility of tissues to estradiol. For example, selective ablation of RP-A leads to increased proliferative activity of endometrial cells mediated by RP-b activation.

Mifepristone (RU-486) is a synthetic steroid antihestagenic remedy blocking the impact of progesterone at the receptor level and does not have any gestagenic activity. This pharmaceutical is used for conservative treatment of minor uterine fibroids (up to 12 weeks of conditional pregnancy) successfully, as well as past myomectomy (as it promotes reducing the frequency of recurrent fibroids by 4.25 -fold). Pharmacotherapy with mifepristone as preoperative preparation (prior myomectomy) contributes to the regression of clinical symptoms, reduces the extent of myomatous nodes, reduces the duration of surgery and the volume of intraoperative blood loss (T.E. Samoilova, 2011). The central link in the pathogenesis of uterine leiomyoma is determined by sex hormones, especially progesterone. Mifepristone blocks progesterone receptors selectively, which assists to inhibit tumor growth and to reduce the extent of myomatous nodes. Against this background, there is a decrease in the volume of fibroids in $26-74 \%$ of women, which is comparable to the effectiveness of AGnRH. Herewith, it shall be noted that the use of AGnRH in women of reproductive age is significantly limited, since this group of pharmaceuticals has side effects associated with estrogen deficiency. Antigestagens (in particular, mifepristone) are substances to suppress the impact of progesterone at the receptor level, but there are no changes in the level of estrogens available. Past discontinuation of therapy, there is a slow and insignificant growth of fibroids. The frequency of amenorrhea onset is comparable with the results of AGnRH apply- 
ing. The vast majority of patients have amenorrhea, which usually occurs within 4-5 days past the therapy starting (S. Seth, 2011), which is a favourable effect of mifepristone in women suffering from menorrhagia: pelvic pain is stopped. In a survey by M. Engman (2009), it was demonstrated for the first time that taking mifepristone contributed to an increase in hemoglobin levels: its indicators significantly improved $(p=0,003)-$ from $121 \pm 5 \mathrm{~g} / 1$ to $133 \pm 3 \mathrm{~g} / \mathrm{l}$. The recovery of menstruation usually occurs within the first month past discontinuation of mifepristone therapy (S. Seth, 2011). Even long-term use of mifepristone does not affect the state of bone mineral density and does not cause other estrogenrelated adverse events as hot flushes, dryness of the mucous membranes, etc., and possible changes in the endometrium associated with the pharmaceutical are benign and reversible, not requiring measures and are resolved independently past the course of treatment. The therapeutic regimen of the pharmaceutical is $50 \mathrm{mg}$ per day within 3 months.

Ulipristal acetate. Since 2012, the arsenal of pharmaceuticals to provide preoperative treatment of fibroids prior to organpreserving operations of myomectomy, and in some cases their conservative therapy was replenished with peroral synthetic SPRM as ulipristal acetate. This selective progesterone receptor modulator inhibits ovulation, but does not affect serum estradiol levels significantly.

Take ulipristal acetate starting from the 1st day of the menstrual cycle, 1 pill per day in a continuous mode per 12 weeks.

On the 6th day from the beginning of ulipristal therapy, the volume of menstrual blood loss decreases, past a 3-month course, in $79 \%$ of women amenorrhea is developed, in $11 \%$ of cases, there are manifestations of menopausal syndrome.

Histological, immunomorphological and morphometric surveys of uterine leiomyomas past a 3-month course of ulipristal therapy has revealed that it causes a decrease in the extent of leiomyo- 
mas due to a 2.2-fold decrease in proliferative and 6-fold decrease in mitotic activity in combination with the induction of apoptosis and, possibly, a decrease in the degree of hypertrophy of tumor cells (L.V. Adamyan, O.V. Zayratyants, I.B. Manukhin, 2014; L.V. Adamyan, O.V. Zayratyants, A.L. Tikhomirov, 2014). However, despite a 4-fold increase in the activity of apoptosis processes in leiomyoma cells, only a slight and statistically unreliable decrease in the expression of the apoptosis inhibitor bcl-2 and an increase in the apoptosis inducer Bax was found. As a result, the Bax/ bcl-2 index increases minimally, so further research is needed to clarify the mechanisms of expressed induction of apoptosis by ulipristal. The detected tendency to increase the expression of progesterone receptors by tumor cells is probably a compensatory process. In addition to the negative effect onto the leiomyoma parenchyma, ulipristal inhibition of angiogenesis upon reduction of the microcirculatory bed and suppression of the production of growth factors such as VEGF, EGF, FGF-2 and TGF- $\beta 1$, which decreased by $2-3$-fold, was revealed. In addition, a significant 3-4-fold increase in leiomyoma production of matrix metalloproteinases (MMR-2, MMR-10, MMR-12) was found upon simultaneous suppression of the production of their tissue inhibitors (TIMR1, TIMR-2, TIMR-3), which also leads to enzyme lysis of the extracellular matrix and stroma remodelling upon a decrease in the volume of their stromal component as a result. The histological feature of leiomyomas in patients treated with ulipristal acetate is also the suppression of the activity of perivascular growth areas with their sclerosis and narrowing of the gap of the arteries and the transformation of the proliferating clinical and morphological type of fibroids into simple, often with expressed myofibrosis.

Changes within the endometrium developing under the influence of ulipristal acetate and often other SPRM (mifpristone, etc.) are named PAEC - Progesterone receptor modulators Associated Endometrial Changes (changes in the endometrium associated with the 
progesterone receptor modulator) as a new and class-specific type of its reversible changes (O.V. Zayratyants et al. 2014)

$10-15 \%$ of patients with uterine leiomyomas upon SPRM therapy, endometrial thickening is developed (according to ultrasonic data or MRI), which regresses within 6 months past the termination of treatment. The detection of endometrial thickening often causes the referral of aspirates or cuttered from the uterine cavity upon pathohistological examination, during which it is essential to make a differential diagnosis amongst PAES, estrogenin-induced changes and endometrial hyperplasia.

PAEC is characterized by a transgression of the glands location and structure under cystic expansion of their gap. Convoluted glands may predominate, sometimes scalloped, star-shaped, much corresponding to the secretory phase, but there are also single straight ones with a narrow gap. The cystic expansion of the gland may be surrounded by a "collar" of elongated stromal cells tightly arranged, and establishing periglandular "whirlpool"-type shapes. In the gap of many glands, including cystic expanded, liquid secret is accumulated.

In PAEC, the glandular epithelium looks inactive, with rare mitoses; features of the non-physiological stage of secretion is established. Although the structure of the glands corresponds much to the secretory phase, the glandular epithelium is usually flattened, cubic or prismatic, without signs or upon stratification of the nuclei weakly expressed, along with sporadic mitoses. Some epithelial cells contain basal vacuoles within the cytoplasm. There are cystic cell metaplasia of epithelium and secretory epithelium with signs of apocrine secretion, especially within cystic expanded glands. The apoptosis is expressed weakly or moderately, having a focal character.

For PAEC, a stroma with a dense cell arrangement, low proliferative activity, and typically no signs of perivascular deciduo-like reaction. The glandular-stromal ratio is not broken, but the glands are often distributed unevenly. There may be foci of stroma edema. Lipidcontaining foam cells are not detected. The areas of stroma disintegra- 
tion are not typical. PAEC is characterized by abnormal vascularization. The clusters of arteries are revealed with thickened walls upon smooth muscle cell hyperplasia, resembling tangles of spiral arteries, a minor-cell network of capillaries, thin-walled ectatically expanded vessels. Fibrin blood clots within the vessels are not detected.

Insufficient awareness of specialists on the morphological manifestations of PAEC may lead to an erroneous diagnosis of estrogeninduced changes within endometrium or its hyperplasia when examining the operating material past hysterectomy or endometrial biopsies in patients with uterine leiomyomas treated with SPRM. It is particularly important to indicate mandatory therapy with pharmaceuticals of SPRM group, in the forms of referrals for endometrial biopsies and surgical material past hysterectomy for pathohistological examination.

Antifibrinolytic Pharmaceuticals. Amongst all antifibrinolytics remedies to provide the treatment of heavy menstrual bleeding against the backdrop of uterine fibroids, the tranexamic acid is approved only.

Tranexamic acid is a synthetic inhibitor of fibrinolysis and is able to competitively block the plasminogen activation process, thus preventing clot cleavage and inhibiting fibrinolysis.

The optimal daily dose of the pharmaceutical is $4 \mathrm{~g}$, the duration of therapy is 4-5 days. Against the background of the use of tranexamic acid, there is a decrease in the volume of menstrual bleeding by $40 \%$.

Non-steroidal anti-inflammatory pharmaceuticals (NSAIPs) may be used in patients with metrorrhagia and dysmenorrhea.

The impact mechanism of all NSAI3s is a block of cyclooxygenase 2 activity and prostaglandin production. Currently, it has been proven that fibroids produce an increased amount of cyclooxygenase 2 and prostaglandins, which is clinically manifested by dysmenorrhea and abundant metrorrhagia.

NSAIPs may be used both systemically and locally (rectally). 
Antigonadotropins (danazol and gestrinone). Danazol is a 19-nortestosterone derivative. The mechanism of its impact is to inhibit the secretion of gonadotropin, direct inhibition of impact within foci of endometriosis and estrogen synthesis in the ovaries. In this regard, danazol is most effective upon the treatment of metrorrhagia and endometriosis and does not affect the extent of myomatous nodes. Side effects of pharmaceuticals are non-specific and include weight gain, muscle spasms, decreased breast extent, acne, hirsutism, increased skin fat, decreased levels of high-density lipoproteins, increased levels of liver enzymes, hot flushes, mood changes, depression.

Danazol is prescribed $200-400 \mathrm{mg}$ per day for 3-6 months.

Another androgenic steroid, gestrinone not only reduces the extent of fibroids but also cause amenorrhea. The advantage of this pharmaceutical is a persistent reduction in the extent of myomatous nodes and their continued reduction past the termination of administration. Gestrinon is prescribed $2.5 \mathrm{mg}$ twice a day per 3-6 months. When breakthrough bleeding occurs, the frequency of use of the drug increases.

\section{SURGICAL METHODS OF TREATMENT}

The surgery intervention is the main method of uterine fibroids treating. Medical indications for surgical treatment are abnormal uterine bleeding, infertility or miscarriage of pregnancy, rapid growth of nodes, violation of the function of adjacent organs, as well as the lack of conservative therapy effect.

Only radical hysterectomy (extirpation of the uterus) leads to a complete recovery of the patient. Subtotal hysterectomy (supravaginal amputation of the uterus) is not a completely radical intervention. Although recurrent fibroids in the stump of the cervix are developed infrequently, according to the recommendations of the American Congress of Obstetricians and Gynaecologists (2007), the method of choice shall be total surgery. 
Organ-preserving myomectomy is the method of choice for the patients of reproductive age who want to have more children. However, there is still a high risk of myomatous node growth from new clones of abnormal myocytes.

\section{Preoperative Preparation}

If the patient has moderate to severe iron-deficiency anemia (hemoglobin level less than $80 \mathrm{~g} / 1$ ), preoperative parenteral therapy with iron preparations is indicated per $2-3$ months.

The treatment shall be combined with the use of gonadotropinreleasing hormone agonists or progesterone receptor modulators (mifepristone, ulipristal acetate) to provide the development of persistent amenorrhea within 3 months. In addition to uterine bleeding ceasing against the background of the use of these pharmaceuticals, there is a significant decrease in the volume of myomatous nodes and the intensity of their blood supply reduction, which decreases the volume of intraoperative blood loss.

For hysterectomy, vaginal access is optimal, but its implementation is limited by the tumor extent (not above 16 weeks of conditional pregnancy) and the availability of adhesion process. The choice of laparoscopic or laparotomic access for hysterectomy shall be decided individually.

When performing an organ-preserving operation, submucosal myomatous nodes (type $0-11$ ) non exceeding $5-6 \mathrm{~cm}$ in their diametre are removed by hysteroresectoscopy using a mono- or bipolar resectoscope or an intrauterine morcellator.

Interstitial and subserous myomatous nodes may be removed by laparoscopic or laparotomic access with mandatory layer-by-layer suturing of the uterine wall. Conducting coagulation of the node bed due to the high risk of rupture of the uterus during pregnancy for an untenable scar shall be unacceptable.

Past total hysterectomy, patients shall be recommended to refrain from sexual activity within 1-2 months. 
Past organ-preserving myomectomy, women shall use contraception within 6 to 12 months. The onset of pregnancy is possible in 6 to 12 months.

\section{Leiomyoma}

The Technical Approach to Transcervical Surgery of

Prior to trans-cervical leiomyoma surgery performing, for at least 2 months, the therapy upon gonadotropin-releasing hormone agonists or ulipristal acetate shall be performed.

During the surgery, to reduce the risk of uterine perforation, forcibly dilate the cervical canal using hegar's dilators shall not be recommended. The opening of cervix may be performed using laminaria sticks, prostaglandins or intracervical administration of a diluted vasopressin solution.

\section{The Methods of Myomectomy}

There are three main methods for removing leiomyomas under hysteroscopic control as follows:

- morcellation (removal in parts);

- cutting with an electrosurgical loop;

- vaporization.

\section{CONSERVATIVE MYOMECTOMY}

Myomectomy may be performed upon hysteroscopy, laparoscopy, or classically during laparotomy.

There are indications for surgical treatment of uterine fibroids as following:

1. Uterine bleeding non-responding to conservative therapy.

2. The suspicion of a malignant process.

3. Rapid growth of myomatous nodes.

4. Growth of fibroids past menopause.

5. Uterine fibroids distorting the uterine cavity in patients with infertility or habitual miscarriage. 
6. Myomatous nodes non-deforming the uterine cavity, which extent exceeds $5 \mathrm{~cm}$ in patients with infertility or habitual miscarriage.

7. The location of myomatous nodes within isthmus and/or in the tubal corners of uterus in patients with infertility.

Main mechanisms of influence of uterine fibroids onto fertility are as follows:

1. The deformity of uterine cavity (submucous and intramural submucous nodes of fibroids), which leads to an obstacle to the entry of sperm into the uterine cavity and fallopian tubes. It was found that the availability of so-called isthmus myomatous nodes, which diametre did not exceed $4 \mathrm{~cm}$, did not affect the frequency of pregnancy within the IVF cycle. On the other hand, in patients with fibromyoma with a diametre of above $4 \mathrm{~cm}$, the effectiveness of IVF was significantly below. It is assumed that in patients with uterine fibroids, it is difficult to move spermatozoa into the uterine cavity, and past fertilization - the arrival of an embryo throughout fallopian tubes into the uterine cavity, and the implantation process is disrupted. The most unfavourable nodes are those as reaching a diametre of $5 \mathrm{~cm}$ or above, as well as those located within the area of one's isthmus and the mouth of fallopian tubes.

2. Increased or impaired contractile activity of myometrium, leading to sperm expulsions, impaired embryo transporting and implanting. It is believed that this is due to the deformation of one's uterus by a myomatous node, a transgression of physiological contractile activity of myometrium, or the availability of its abnormal contractions (primarily within submucous and intramural localization of the tumor).

3. Production of vasoactive proinflammatory cytokines by the endometrium of myomatous altered uterus, which prevent sperm to be transported and embryo to be implanted. Inflammatory changes in the endometrium may play a certain role in the implantation disorder, especially in case of submucous node localization. Some authors consider as possible causes of disorders of implanta- 
tion and early embryonic development in patients with uterine myoma the changes in endometrium of vasoactive substances, as well as violation of expression in the tumor tissue genes involved into these processes (insulin-like growth factor; factor regulating the synthesis of retinoids, etc.).

4. Changes in Blood Flow within Myometrium. Thus, the Bullet study revealed that in patients with uterine myoma, the vascularization of myo- and endometrium changes. It was found that in this disease there is a change in the activity of angiogenesis and a transgression of microcirculation in the intact myometrium and tumor tissue, which is accompanied by a decrease in blood flow resistance within myometrial and uterine arteries.

\section{Hysteroscopic Conservative Myomectomy}

The indications for hysteroscopic myomectomy shall be as follows:

1. Abnormal uterine bleeding.

2. Non-carrying of pregnancy.

3. Infertility.

4. The suspicion of a malignant process of endometrium.

The European Society of Hysteroscopy classifies submucous myomatous nodes according to the degree of germination within myometrium into three categories, which assists the specialist to plan a surgical approach. The TO category includes all submucous myomatous nodes onto stem. Submucous myomatous nodes germinating into the myometrium by below $50 \%$ are classified as T I, while those germinating by above $50 \%$ are classified as T II. Category T O and $\mathrm{T}$ I may be removed hysteroscopically by a surgeon with little experience, while category T II fibroids shall be resected abdominally, and hysteroscopic resection may be performed by a highly qualified specialist only. Reducing the volume of myomatous nodes upon preoperative aGn-RH may facilitate hysteroscopic resection of submu- 
cous myomatous nodes and reduce blood loss. However, the structure of fibroids tissue tends to become much fibrous and difficult to be separated past this type of treatment.

During hysteroscopy, it shall be possible to remove submucous and intramural-submucous myomatous nodes. This may be performed under general or regional anesthesia. In some cases, this operation may be performed onto an outpatient basis, depending on the type and the extent of fibroids nodes. Although this method is widely used, its effectiveness upon the treatment of uterine bleeding remains non-studied utterly. Conducted retrospective analysis of 105 patients underwent hysteroscopic myomectomy of submucosal nodes by van der Kooij et al., revealed complete absence of bleeding in $90 \%$ of cases within 17 months past surgery. The most common postoperative complications associated with hysteroscopic myomectomy are as follows: bleeding (2.4\%), uterine perforation (1.5\%), cervical ruptures (1-11\%), hyperhydration. Long-term consequences of hysteroscopic surgery are intrauterine adhesions and infertility. Repeated hysteroscopy reveals relapses in about $10 \%$ of cases.

Pritts et al. (2009) within their systematic review regarding the effects of surgery onto the influence of submucous and intramural nodes, deform-ating the uterine cavity, and impacting one's fertility, provide the data as following: the removal of submucous nodes led to a significant increase in the frequency of pregnancy (from $27.2 \%$ to $43.3 \%$ ) and a decrease in the percentage of non-pregnancy (from $50 \%$ to $38.5 \%$ ).

\section{Laparoscopic Conservative Myomectomy}

Laparoscopic myomectomy as a minimally invasive treatment method has long been the method of choice for symptomatic uterine myoma. This operation is still widely used for subserous localization of fibroids nodes, as well as for intramural, depending on the location of the nodes and a surgeon's skills.

For the first time, myomectomy along with laparoscopic access was performed by K. Zemm in 1979. Since then, the operation 
technique and surgical capabilities have undergone significant changes. Until recently, the main contraindications for laparoscopic myomectomy were as follows: large extent of myomatous nodes, low, isthmus location of one's tumor, multiple myoma. These factors establish technical difficulties, as a result of which there may be: the risk of damage to large vessels, necrotizing extensive myometrial surfaces with excessive use of electrosurgical hemostasis, incomplete restoration of myometrial defect, lengthening the duration of an operation, increasing the volume of blood loss, difficulties in evacuating the removed myomatous node from the abdominal cavity.

So, according to the data by V. Mais, the time of laparoscopic myomectomy upon removal of above 4 nodes or a node larger than $6 \mathrm{~cm}$ increased significantly compared to laparotomy. The main disadvantage of laparoscopic access to perform myomectomy in patients planning pregnancy, according to the literature, is the inability to apply a full-fledged reliable suture to the myometrial defect, which means the establishment of an incomplete scar onto uterus in the future. On the other hand, in recent years, the technical capabilities of endovideosurgery have made it possible to avoid these undesirable complications. According to the data by V.I. Kulakov, for this purpose it is necessary to observe the features of surgical technique as following:

1. The direction of myometrium incision shall be chosen according to the structure of anatomical layers of uterine wall, taking into account the convenience for subsequent application of endoscopes (the needle shall be entered the edge of the wound at an angle of $90^{\circ}$ ).

2. When suturing the uterus wound, there shall be captured a muscle layer of sufficient thickness to close the defect and hemostasis utterly.

To do this, layer-by-layer stitching of the myometrial defect into 1-2-3 rows with a absorbable suture material shall be performed using curved needles of large diametre and mandatory extracorporeal tying of knots using the Clark-Rich method. 
When conducting a comparative analysis regarding the effectiveness of myomectomy by various surgical approaches, a scope of boffins obtained their data on a relative decrease in blood loss and the duration of hospitalization past laparoscopic myomectomy compared with laparotomy. Reducing the duration of operation is facilitated by improving the operative technique of a surgeon.

The most important indicator regarding the effectiveness of myomectomy in patients with infertility is the risk of developing adhesive disease within one's postoperative period, which in itself may cause the infertility of this group of patients. Assessing the probability of developing adhesions within one's abdominal cavity and pelvis past performing myomectomy without using anti-adhesive barriers, according to the literature, in $92.2 \%$ of cases in the group of patients underwent laparotomic myomectomy, when performing repeated (secondlook) laparoscopy, the adhesive process was diagnosed. Amongst patients who underwent laparoscopic myomectomy, adhesions were found in $82.1 \%$ of cases. Herewith, the density of adhesions was estimated. This indicator was 3.2 points past laparotomic, and 2.6 points after laparoscopic access. The use of the "Interceed" anti-adhesive barrier past myomectomy, regardless surgical access, assists to reduce both the frequency of adhesions (from $73.3 \%$ in the control to $58.3 \%$ in the main group) and their density (from 1.84 to 0.94 points, respectively). Wherein, upon the laparoscopic access, the quantity of adhesions in both groups remained at the same level (about $55 \%$ ), but the density decreased significantly: from 2.81 to 0.9 points. Past myomectomy with laparotomic access, the barrier contributed to a decrease in the frequency of adhesions to $61.5 \%$ compared to $80.9 \%$ in the control group, with a significant decrease in their density to 0.98 points compared to the control -1.33 .

The results of general clinical examination within the early and late postoperative periods confirmed that myomectomy performed with endoscopic access revealed accelerated normalization of peripheral blood and body temperature indicators by above 2-3-fold, less expressed postoperative pain syndrome, a reduction in the quan- 
tity of stay in-bed days, the period of disability and abstinence from sexual activity past surgery. In a comparative analysis of the effectiveness of laparoscopic and laparotomic approaches for performing myomectomy, it was revealed that a specially developed technique of laparoscopic myomectomy in patients with infertility may reduce intraoperative blood loss by 3 -fold, decrease the time of hospitalization of patients by 2-fold and the duration of postoperative antibiotic therapy by 1.5 -fold compared with myomectomy performed upon laparotomy.

An important indicator of the results of myomectomy is the risk of such complications of pregnancy and childbirth, such as failure of a postoperative scar onto uterus. However, the incidence of this complication is only $1 \%$ amongst patients having laparoscopic myomectomy. According to the literature, there are the main risk factors for failure of the scar onto uterus past laparoscopic myomectomy as following: extensive electrosurgical coagulation in the bed of myomatous node removed, leading to necrosis of the intact myometrium, refusal to use a multi-row endoscope.

\section{Laparotomic Myomectomy}

The first laparotomic myomectomy was performed in 1840 . Amusat, which removed the myomatous node onto a stem. 4 years later W.L. Atlee performed successfully a vaginal access myomectomy. Myomectomy received its present development at the turn of the XIX-XX centuries. The technique of the operation was perfected by N.A. Kelly, S.R. Nble., T.S. Cullen,

W.J. Mauo, 1.C. Rubin, V. Bonney. Thanks to these researchers, laparotomic myomectomy has become a standardized and safe surgical intervention in gynaecology. According to the data by V. Bonney (1931), at first myomectomy consisted of removing nodes onto a stem in most cases. Later, the accumulated experience allowed gynaecologists to remove myomatous nodes onto short stems and, 
finally, intramural myomatous nodes. In connection with the difficulties of stopping the bleeding occurs when the removal of fibroids, surgeons gave preference to hysterectomy for a long time. However, the desire of patients to have a child later and the refusal to remove the uterus gradually contributed to the fact that myomectomy became a generally accepted method of surgical treatment of uterine fibroids.

In their survey, Bonney et al. identified the main stages of laparotomic myomectomy as following:

1. Access to the abdominal cavity. Most abdominal myomectomies are performed using a Pfannenstiel cross-section. In some cases, lower-middle laparotomy shall be used.

2. Incision of Myometrium. With intramural location of myomatous nodes, the incision onto uterus shall be performed in the most vascular-free area within vertical or horizontal direction. Over larger myomas carry out a linear or elliptic incision through the surface layer of myometrium, getting directly into the underlying myoma, without disturbing its capsules.

3. Enucleation of Myomatous Node. The myoma shall be captured with clips, a surgical corkscrew or bullet forceps and pulled back to establish tension and to pull the node out. Wherein, it shall be necessary to coagulate or to ligate the vascular stem of the node. In order to minimize blood loss and to prevent the development of hematomas, the free connective or vascular tissue between the node capsule and myometrium shall be subjected to ligation, coagulation with electricity, treatment with a $\mathrm{CO}_{2}$ laser or a harmonic scalpel.

4. Suturing myometrial defect shall be performed with separate stitches in several rows for a full comparison of myometrium edges.

Thin absorbable materials (vicryl, PDS 3-0 and 4-0) are used.

5. The abdominal cavity shall be sutured in layers in a typical way.

Special attention shall be paid when performing myomectomy laparotomy access to prevent adhesion establishing. For this purpose, anti-adhesive barriers and adhesive compositions shall be used. It shall be necessary to take care of the tissues, as minimizing the use of napkins, and intraoperative blood loss as well. 
According to Sawin et al., there were no significant differences in the incidence of postoperative complications in women underwent laparotomic myomectomy and laparotomic hysterectomy and $40 \%$. The incidence of massive bleeding is significantly lower within the group of patients having had myomectomy compared to hysterectomy. It shall be noted that laparotomic myomectomy is a longer operation, but is accompanied by significantly less blood loss. The average length of in-patient stay is significantly shorter in the group underwent myomectomy. In general, no significant clinical differences were found within the postoperative period of myomectomy and hysterectomy. Thus, myomectomy may be considered as a safe alternative to hysterectomy.

The study by Machupalli, Norkus, Mukherjee, Reilly revealed that after laparotomic myomectomy, the reproductive prognosis for patients with myoma is improved. According to these studies, pregnancy occurred much often in younger patients if they had had a history of pregnancies. The rate of miscarriage is significantly higher in patients with uterine fibroids having not undergone myomectomy.

\section{Vaginal Myomectomy}

Large myomatous nodes onto a thin base may deform one's vagina and cause intermenstrual bleeding, abnormal vaginal discharge, and urinary retention. In most cases, such nodes may be removed by vaginal access, and the node stem may be ligated. In rare cases, they may cause uterus turning over, especially upon the large nodes with a base within the area of uterus bottom.

In 1994, A. Magos et al. reported for the first time on vaginal myomectomy, which allows avoiding injury to the anterior abdominal wall within laparotomy and overcoming difficulties upon laparoscopy and hysteroscopy, especially under large intramural myomas. The idea of vaginal myomectomy was born within a vaginal hysterectomy in a patient with her uterine myoma of the extent corresponding to 14 weeks of pregnancy. The surgeon had techni- 
cal difficulties performing a posterior colpotomy, but the uterus was too large to remove it through the anterior colpotomic opening due to a large intramural myomatous node located within the isthmus area along the anterior wall of uterus. In an attempt to avoid conversion to laparotomy, an anterior colpotomy and subsequent enucleation of the myomatous node were performed, which led to a significant reduction in the extent of uterus and allowed the completion of the vaginal hysterectomy. Past the operation, the idea of performing conservative myomectomy via vaginal access as a separate operation arose.

Later A. Davies et al. (1999) described the technique of vaginal myomectomy through the posterior colpotomic opening, which was successfully performed in $91.4 \%$ cases.

French gynaecologists also published information on their experience of performing vaginal myomectomy via posterior colpotomy and confirmed their high efficiency and reproducibility of these techniques along with the ability to restrict vaginal access in above $80 \%$ of cases.

Currently the Ministry of Healthcare of the Russian Federation regulates the conditions to perform vaginal myomectomy as following:

1) the extent of uterus below 16 weeks of pregnancy;

2) adequate mobility of uterus;

3) the absence of expressed adhesions, diseases of uterus appendages and vaginal stenosis expressed;

4) the patient's desire to preserve her uterus.

\section{MAIN STAGES OF VAGINAL MYOMECTOMY}

1. Bladder emptying.

2. Bimanual examination of the patient past her introduction to anesthesia in order to clarify the localization and extent of nodes, as well as the mobility of uterus and the adequacy of operative access.

\section{Uterotonics.}


4. Infiltrating the cervix with a solution with a local anesthetic and vasoconstrictor.

5. Posterior or anterior colpotomy (cross section, the length of $4-5 \mathrm{~cm})$.

6. If necessary, the intersection of sacro-uterine ligaments for posterior colpotomy or cervical-vesicular ligaments for anterior colpotomy with their reposition at the end of the intervention.

7. The installation of front and rear retractors of adequate extent.

8. The capture of dominant node with bullet forceps, the uterus shall be removed to the intersection of the vaginal wall.

9. A longitudinal sectional view to an adequate exposition of the tissue site.

10. Upon larger extent of node, the morchellaceae shall be performed.

11. Probing the uterus to check the cavity integrity.

12. Layer-by-layer suturing of uterine wall.

13. ReturnING uterus to its original physiological position.

14. Draining abdominal cavity.

15. Colpotomy incision suturing.

The advantages of vaginal access upon conservative myomectomy are as follows: optimal rehabilitation, minimal postoperative pain, cosmetic effect, minimal likelihood of intra-abdominal adhesions, and etc.

In addition, a rupture of uterus along the line of postoperative scar may be considered as a potential complication of any myomectomy, but manual suture performed with vaginal access is a much reliable measure for preventing possible rupture.

\section{HYSTERECTOMY}

The first successful hysterectomy was performed by vaginal access in 1813 by Conrad Langenbeck, and today, past almost two centuries, this operation is the second most frequently performed in women of reproductive age after cesarean section. Approximately 
55,000 vaginal hysterectomies are performed annually in the UK and above 600,000 in the US. In Russia, the frequency of hysterectomies for uterine fibroids is $40-42 \%$ of the total quantity of hysterectomies. The indications for this operation are menorrhagia $(21 \%)$, uterine fibroids (33\%), pelvic pain (3\%) and pelvic organ prolapse $(28 \%)$.

Hysterectomy is the only radical method of treating uterine fibroids and guarantees complete absence of relapses of the disease. Hysterectomy may be performed using vaginal access, upon laparotomy, or laparoscopy (full or vaginal-associated access). Each method has its advantages and disadvantages. The traditional surgical approach to hysterectomy requires a larger incision, a 2-5-day of in-patient stay, and the need for longer use of pain medications. The laparoscopic method has many advantages in comparison with laparotomy: reduced severity of postoperative pain, shorter in-patient stays, good cosmetic effects, and brief rehabilitation periods.

The British National Institute for Clinical Excellence (NICE) states that removal of uterus shall be considered as a method of treatment only in cases where other methods of treatment are not effective, are contraindicated, or upon the absence of reproductive plans in the patient. The most serious complications of hysterectomy are as follows: bowel, bladder, and ureter injuries requiring relaparotomy, bleeding requiring hemotransfusion, pelvic abscesses, venous thrombosis, and PE. About $61.4 \%$ of women over 45 year old underwent hysterectomy for uterine fibroids also exposed concomitant bilateral ovariectomy. To date, the issue of removing unchanged ovaries upon hysterectomy remains controversial. At least in women under 45 year old, unchanged ovaries shall be preserved.

We will consider in detail two main and commonly used options for hysterectomy: laparoscopic hysterectomy of uterus and vaginal hysterectomy. 


\section{Laparoscopic Hysterectomy}

Since 1989 H. Rich performed laparoscopic hysterectomy for the first time, a technique that has been replicated by many operating gynaecologists around the world. It is proved that the majority of hysterectomies requiring glandular surgery may be performed laparoscopically partially or completely. Despite this, a number of boffins believe that laparoscopic access to remove one's uterus increases the risk of various complications, primarily urological: injury to the ureters, bladder. On the other hand, it has been proved that laparoscopic hysterectomy has a scope of undeniable advantages over its laparotomic counterpart. These advantages include as follows: minimal intraoperative blood loss, less expressed postoperative pain, brief in-patient periods, cosmetic effects, etc.

In Russia, removal of one's uterus by laparoscopic access has been performed since 1993 (V.I. Karnaukh).

In recent years, laparoscopic hysterectomy has become firmly established in everyday gynaecological practice. According to various data, the share of laparoscopic hysterectomy in the total scope of hysterectomies in European countries varies widely. So, in France, it is $13.5 \%$; in the UK-36.5\%, and in the US is $75 \%$.

The indications for choosing laparoscopic rather than traditional laparotomic access are as follows:

1. Anatomical obstacles (narrow pubic arch, narrow vagina, expressed arthritis as prevents a patient from being positioned for lithotomy).

2. Severe obesity.

3. The need for surgery onto uterine appendages or their removal.

4. A revision of abdominal cavity, subphrenic space, lymph nodes.

5. Laparotomic operations with the expected pronounced adhesive process undergone previously.

6 . The extent of uterus above 12 weeks of pregnancy (in an unborn woman).

The indications for laparoscopic hysterectomy are as follows: 
1. Multiple fibroids in combination with cervical pathology (scarring, cervical hypertrophy, eroded ectropion, precancerous diseases of one's cervix).

2. Malignant endometrial lesion of stage I.

3. Adenomyosis.

4. Endometrial pathology: polyposis, recurrent and atypical hyperplasia.

5. The combination of endometrium and uterus pathology along with common external endometriosis.

Contraindications to laparoscopic hysterectomy are as follows:

1. Uterine prolapse. In these cases, it is easier to perform removal of one's uterus by vaginal access.

2. Significant extent of uterus (above 16 weeks of pregnancy past preoperative treatment with Gn-RH analogues) shall be a relative contraindication for laparoscopic access, since experienced surgeons perform laparoscopic removal of one's uterus larger than 20 weeks of pregnancy.

3. Cystic volume formation of appendages, which extent do not allow them to be removed intact, i.e. this formation may not be located in an accessible extent bag prior to decompression, implemented from the outside with a needle.

\section{VAGINAL HYSTERECTOMY}

Vaginal hysterectomy was performed many centuries prior to an attempt was made to remove the uterus by abdominal access. The physician Soranus of Ephesus is said to have amputated a gangrenous uterus through the vagina in the second century BC. In 1517, the Italian J. Bernario performed a hysterectomy with vaginal access, and in 1560, Adrea della Croce from Spain also implemented this surgical intervention. In 1600 Scheck of Granberg described 26 cases of performing a vaginal hysterectomy, usually for one's uterus prolapse. In most cases, specialists noticing a twisted or prolapsed uterus, removed this organ, sometimes without even recognizing its origin. 
First reports of a hysterectomy performed by a professional surgeons belong to the XIX century. The first successful hysterectomy was implemented with vaginal access upon uterine cancer in 1813 in Germany. In 1889, Simson described a technique for safely ligating the uterine and ovarian arteries.

In Russia, the first vaginal hysterectomy was successfully performed by A.A. Kiter in 1846 in Kazan, and the first supravaginal amputations of uterus by V.F. Grubev in Kharkov in 1866 and N.V. Sklifosovsky in 1867 in Odessa.

An outstanding Russian obstetrician-gynaecologist, professor D.O. Ott, made his invaluable contribution to the development of vaginal access upon surgical interventions.

\section{The Main Stages of the Operation:}

1. Opening of anterior and posterior vaults of one's vagina, allocation of broad uterine ligaments.

2. Sequential ligation and intersection of sacro-uterine, cardinal ligaments, fallopian tubes, fallopian vessels, own ovarian ligaments, round ligaments of uterus.

3. Removal of one's uterus with its cervix (upon the uterus cut above 12 weeks of gestation, mainly through marcillation).

4. Fixation of the stump due to sacro-uterine, cardinal ligaments, round ligaments and ligamentous apparatus of uterus appendages.

5. Peritonization with a circular pouch suture with extraperitoneal ligament fixation.

6. Establishing the stump of vagina.

Main complications of the operation are as follows:

1. Infiltrated changes within the stump area of one's vagina.

2. Intraoperative blood loss of above $600 \mathrm{ml}$.

3. Injury to the bladder.

4. Lesion to the rectum in patients with severe adhesions of their pelvic organs.

5. The bleeding from the stump of one's vagina within the postoperative period with the imposition of provisional stitches. 

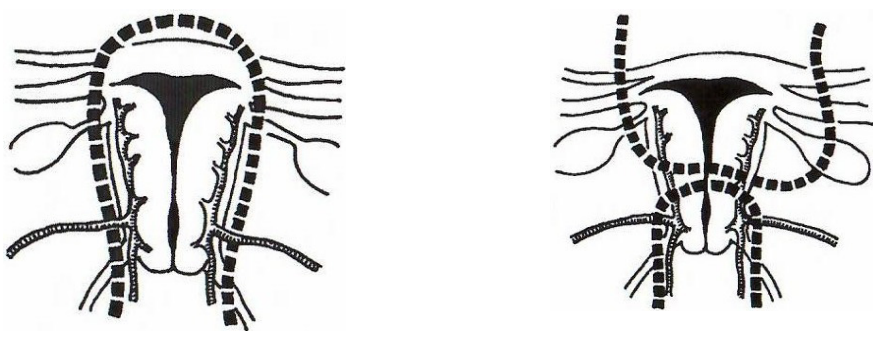

$a$

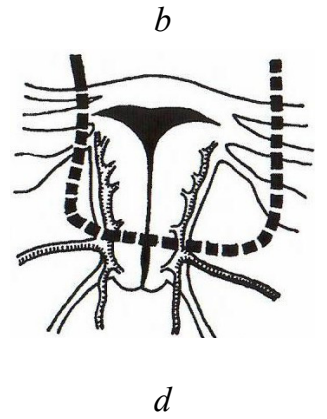

$c$

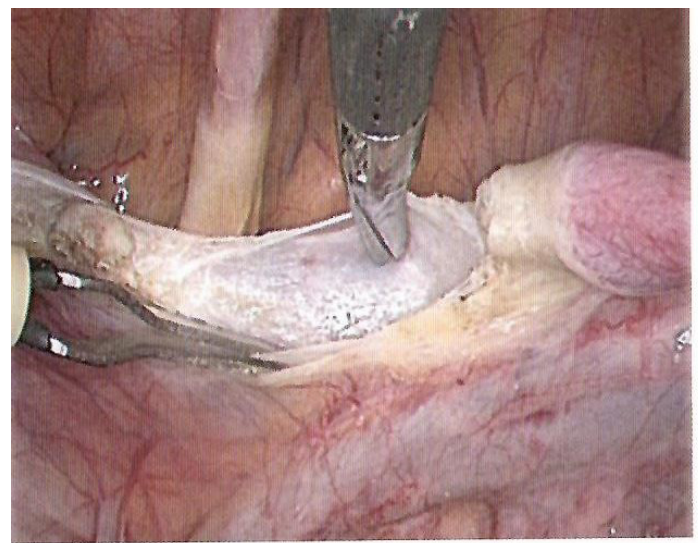

e

Fig. 23. Laparoscopic Hysterectomy: $a$ - Diagnostic Laparoscopy with Vaginal Hysterectomy; $b$ - Laparoscopically Assisted Vaginal Hysterectomy; $c$-Total

Laparoscopic Hysterectomy; $d$ - Subtotal Laparoscopic Hysterectomy; $e$-Intersections of Round Uterine Ligaments; $f$-Dissection of the Broad Uterine Ligament; $g$ - Establishing a "Window" in the Back leaf of the Broad Uterine Ligament; $h$ - The Bladder Is Separated from the Isthmus of Uterus; $i$ - The Uterine Artery Was Crossed on the Left 

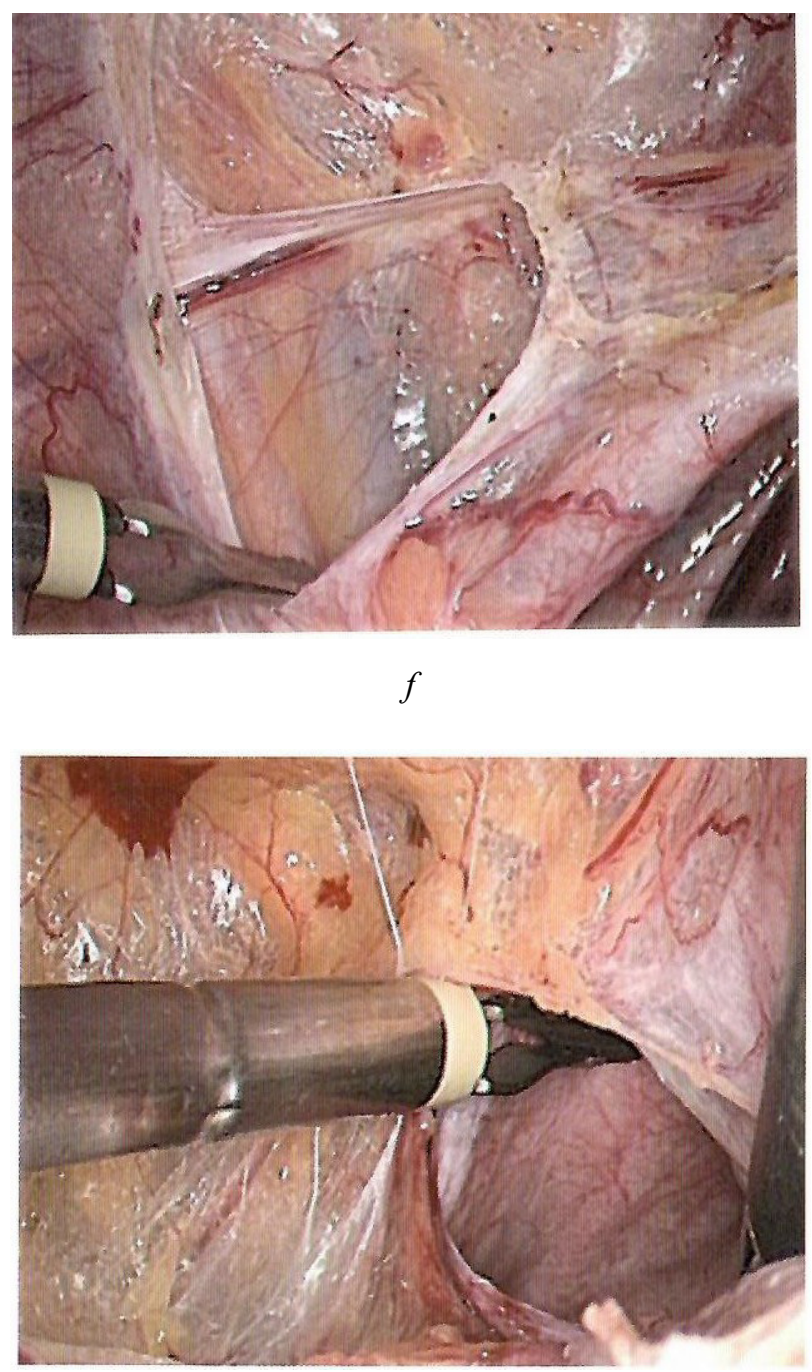

$g$

Fig. 23. Continuation of the figure 


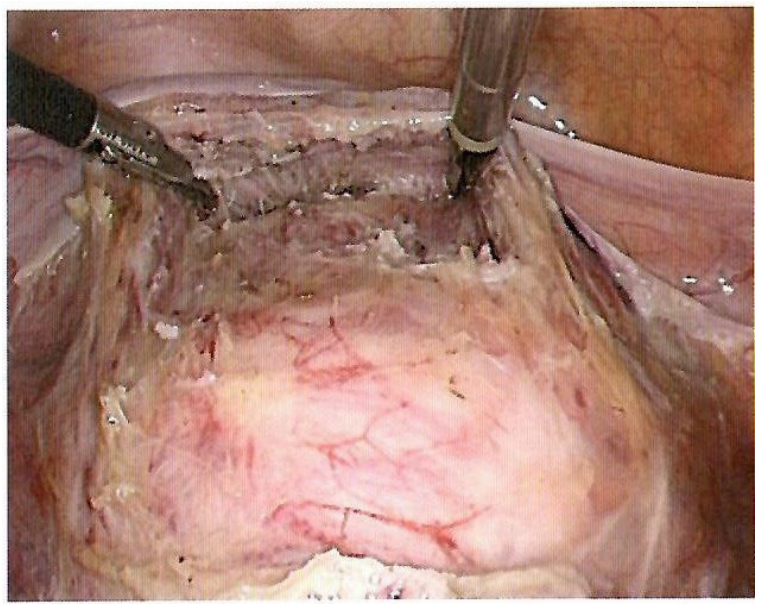

$h$

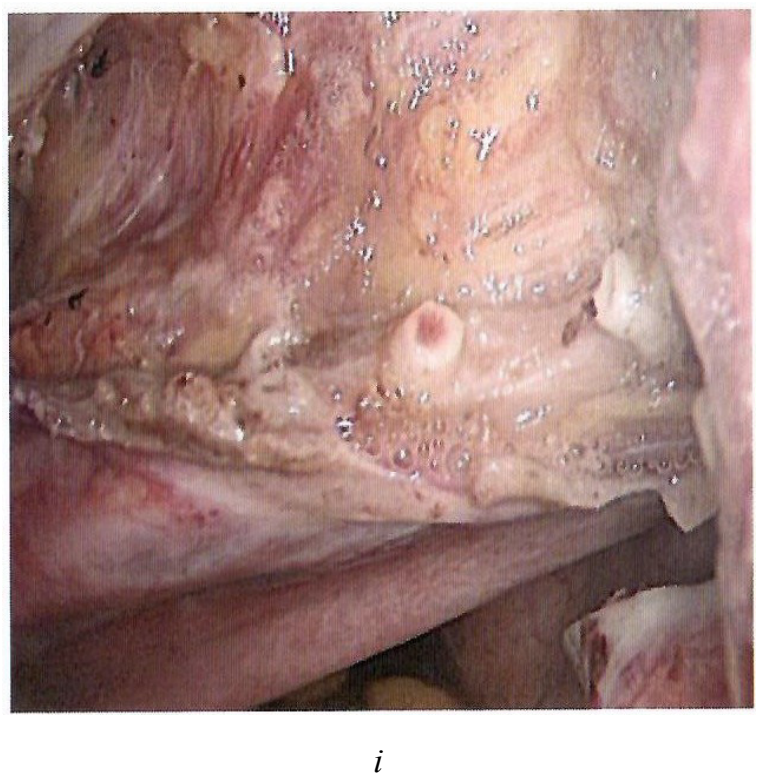

Fig. 23. Ending of the figure 


\section{Minimally InVASIVE TREATMENT Methods}

Despite the fact that hysterectomy is the only radical method of treatment, many patients and doctors are looking for the possibility to use minimally invasive alternative methods of treating uterine fibroids (144), such as uterine artery embolization (EMA), magnetic resonance upon focused ultrasonic ablation (MRgFUS) and ultrasonic-controlled ablation (VizABlate ${ }^{\mathrm{TM}}$ and Acessa ${ }^{\mathrm{TM}}$, USA).

\section{Uterine Artery Embolization}

Uterine artery embolization (EMA) is a percutaneous invasive procedure performed by a radiologist. For the first time, EMA was used to stop massive pelvic bleeding. Only since 1995 has EMA been considered as a possible treatment for menorrhagia associated with uterine fibroids. In its essence, the method consists of passing an angiographic catheter throughout the femoral into the uterine arteries and inserting embolic agents (in most cases, polyvinyl alcohol particles or gelatin microspheres) into both uterine arteries until arterial blood flow indicators decrease. The proposed mechanism of EMA impact is reduced to complete occlusion or a significant decrease in the indicators of uterine blood flow at the level of arterioles, leading to irreversible ischemic disorders in myomatous nodes with subsequent necrosis, while normal myometrial tissue is able to recover after ischemia. This procedure is usually performed under local or intravenous anesthesia and usually takes 1 hour. The radiation dose upon EMA is comparable to the dose received within a normal radiological examination.

Past the procedure, most patients report ischemic pain of varying severity, lasting per 8-12 hours, usually requiring parenteral analgesia (narcotic analgesics, non-steroidal anti-inflammatory drugs). The intensity of pain gradually decreases over an average of 12 hours. Within 4-5 days, there may be recurrent pulling pains in the lower abdomen due to uterine contractions, and symptoms such as malaise, 
fatigue, nausea and subfebrile temperature. As a rule, patients return to their normal activity within 8-14 days.

This method allows to level the symptoms of disease, to reduce the extent of myomatous nodes, and in some cases cause their expansion from one's uterus.

Complications of EMA may be divided into intraoperative, early (within the first 30 days past the surgery) and late (occurring past 30 days of the postoperative period). Intraoperative complications include the establishment of a hematoma as a result of catheterization of the artery, thrombosis or pseudo-aneurysm of the artery, an allergic reaction to contrast agents. Technical impossibility of catheterization of one's uterine artery occurs in a very minor percentage of patients. Early complications: post-embolization syndrome, including pain, nausea, febrilitet, the availability of inflammation markers in the peripheral blood. If this symptom persists for a long time or the patient's condition worsens, infectious complications shall be excluded.

\section{Ligation of Uterine Arteries}

Uterine artery ligation may be performed by vaginal or laparoscopic access. As a result, the blood supply to the uterus decreases. This procedure is based on the same principle as EMA ones, but is relatively easier to be performed. Akinola et al. revealed that the method of uterine arteries ligation is as effective as EMA, while Hald et al. found the opposite. Attempts have also been made to perform this procedure in conjunction with myomectomy in order to reduce intraoperative blood loss. The combination of uterine artery embolization and simultaneous blocking of anastomosis amongst uterine and ovarian vessels may be much effective than EMA only in terms of long-term control of symptoms and relapses of the disease. However, in this category of patients, the level of FSH in the peripheral blood is significantly higher within the postoperative period, which means that the ovarian reserve is reduced. 


\section{Magnetic Resonance Fcused Ultrasonic (FUS) Ablation}

Magnetic resonance upon focused ultrasonic ablation (MRgFUS) is a relatively new method of thermal ablation of uterine fibroids, which uses focused high-intensity ultrasonic to pass through the anterior abdominal wall and to reach a specific point of one's leiomyoma. Wherein, within a few seconds, the temperature of the tissues increases $\left(55-90^{\circ} \mathrm{C}\right)$, leading to coagulation necrosis of the tumor. MRI monitoring allows to orientate the ultrasonic beam accurately and to monitor the temperature in real time. The effectiveness of this procedure in different patients shall not be the same. Thus, it was proved that the effectiveness of this method correlates with the signal intensity in T2-weighted magnetic resonance images. That is, in patients whose signal intensity in T2-weighted magnetic resonance images was lower prior to the treatment, the effect of FUS-ablation will be much effective. Thus, myomatous nodes of type 1 (low signal intensity) and type 2 (intermediate signal intensity) are suitable for this treatment method, while nodes of type 3 (high signal intensity) are not applicable. In patients with their myomatous node volume of above $500 \mathrm{~cm}^{3}$, it shall be advisable to conduct a preparatory course of treatment upon aGn-RH drugs per 3 months, in order to reduce the extent of the tumor, which in turn improves the effectiveness of thermal radiation. It has been suggested in the literature that the use of aGn-RH potentiates the thermal effects of MRgFUS, especially in women with a myomatous node diametre of $10 \mathrm{~cm}$ or above.

The advantages of MRgFUS are complete noninvasiveness of the procedure, as well as constant visualization of fibroids and adjacent structures, which prevents injuries to neighboring tissues. The main drawback of this procedure is strictly limited indications for its implementation. This method of treatment is suitable only for those patients whose fibroids are located directly under the anterior abdominal wall, i.e. along the anterior wall of one's uterus, as well as upon the unavailability of abdominal cavity and pelvis adhesions. 
The average time of the procedure is quite long, and the patient shall lie still within the entire manipulation.

The therapeutic effect of this procedure as reducing the severity of symptoms of uterine fibroids continues for an average of 2 years, but in the future, $16-20 \%$ may require other methods of treatment of fibroids, including surgery. The results of a prospective survey of pregnancy outcomes past MRgFUS revealed that the percentage of miscarriage was $26 \%$, which is comparable to that of women of the same age without uterine fibroids. The share of deliveries was $41 \%$ of all pregnancies, and $64 \%$ of deliveries via natural birth canal. Currently, only a minor percentage of women with uterine fibroids meet the inclusion criteria for this new treatment. Due to the lack of randomized data at the moment, MRgFUS shall be considered as an experimental treatment method. 


\title{
PREVENTION OF UTERINE MYOMAS
}

\author{
Shall be known: the opportunities for preventing uterine \\ fibroids
}

Recommendations for preventing the development of uterine fibroids and for patients with a tumor already diagnosed.

1. Timely onset of pregnancy and childbirth in relation to age: the first birth is recommended at 22 year old, the second is at 25 , the third and above - up to 35 year old. It is important to give birth to one or two children up to 27-30 years, which prevents premature aging of myocytes.

2. It shall be remembered that uterine fibroids are often developed at the age of 33-35. Taking into account the fact that prior to the availability of a node determined macroscopically, the uterine fibroids grow 3-5 years, the effect of damaged factors (inflammatory gynaecological diseases, interruption of involuntary pregnancy, psychoemotional stress) is 30 year old, so in this age period, one shall avoid adverse effects especially.

3 . When pregnancy occurs, it shall be kept (taking into account the contraindications), since abortion causes a growth spur of the tumor from its microscopically active germ.

4. Excessive insolation and gradual temperature effects shall be avoided, especially past 30 year old.

5. Past the age of 30 and upon the absence of birth, the structure of myocytes is changed. There is an aging of uterine muscle observed, as well as predominance of large myocytes upon reduced extensibility and contractile activity. Timely pregnancy and childbirth prevent premature aging of one's uterus.

6. Upon the availability of hereditary uterine fibroids, the latter is developed 5-10 years earlier (the age of 20-25), so such women are recommended to maintain pregnancy and first birth at 19-20 year 
old and then to repeat birth until they are 30-35. Breastfeeding a child for at least 6 months prevents further development of uterine fibroids, stops its growth (proliferative activity).

7. To prevent the stimulating effect of large uterine fibroids onto the development of atypical endometrial hyperplastic processes, timely treatment (including surgery) is necessary prior to the onset of menopause.

8. If within the first 2 years of menopause myomatous nodes practically do not disappear, they shall be removed surgically.

9. Uterine fibroids are the result of somatic cell mutation due to numerous damaging factors, so prevention shall be based on a healthy lifestyle and the preservation of a woman's reproductive health. 


\section{UTERINE FIBROIDS AND PREGNANCY}

Due to the development of assisted reproductive technologies, there is a steady increase in the quantity of age-related prepregnancies with various obstetric and gynaecological pathologies, including uterine fibroids. The frequency of uterine fibroids detection during pregnancy reaches up to $10 \%$. In most cases, against the background of minor uterine fibroids, the course of pregnancy is not complicated. With large node sizes, the risk of miscarriage, placental insufficiency, premature placental abruption, abnormal fetal positions and labour dysfunction increases. The rate of cesarean section in women with uterine fibroids is 4-fold above in the population.

The extent of myomatous nodes upon pregnancy may increase both due to true growth (hypertrophy and hyperplasia of cells), and due to false enlarging as a result of nutritional disorders within the node.

A hemorrhagic infarction may be developed along with extensive hemorrhages in the myoma, which leads to its rapid increase.

During pregnancy, most often there is an increase in the nodes extent, which occurs predominantly in the first trimestre, and in the postpartum period, especially with preserved lactation, node regression are developed. The most susceptible to growth are large nodes (above $5 \mathrm{~cm}$ in their diametre).

To assess the prognosis of pregnancy complications in patients with uterine fibroids, it shall be necessary to take into account the extent of nodes, their quantity, growth pattern, clinical and morphological type (simple or proliferating fibroids), localization relative to the placenta, and the availability of secondary changes in them. 


\section{TEST TASKS}

Select one or above correct points

1. METHODS FOR UTERINE FIBROIDS DIAGNOSING

1) ultrasonic examination

2) magnetic resonance imaging

3) hysteroscopy

4) laparoscopy

2. CLINICAL MANIFESTATIONS OF SUBMUCOUS UTERINE FIBROIDS

1) dysmenorrhea

2) menorrhagia

3) secondary infertility

4) iron-deficiency anemia

3. MAIN METHODS OF SUBMUCOUS UTERINE FIBROIDS DIAGNOSTICS

Gynaecological examination

1) ultrasonic examination

2) hysterography

3) hysteroscopy

4) laparoscopy

4. ABSOLUTE INDICATION TO PROVIDE SURGICAL TREATMENT (uterine extent)

1) uterine fibroids 8 weeks

2) uterine fibroids 5 weeks

3) uterine fibroids 10 weeks

4) uterine fibroids above 14 weeks 
5. PREOPERATIVE HORMONE THERAPY OF UTERINE FIBROIDS SHALL BE PERFORMED UPON AS FOLLOWS

1) cervical uterine fibroids

2) the growth of fibroids within postmenopause

3) upon uterine myoma with submucous location of the node

4) upon uterine fibroids with subserous location of the node

6. THE METHOD OF SURGICAL TREATMENT OF SUBSEROUS UTERINE FIBROIDS

1) transcervical myomectomy

2) laparotomy upon supravaginal amputation of uterus

3) laparoscopy, myomectomy

4) laparotomy, myomectomy

7. POSSIBLE COMPLICATIONS UPON THE "NASCENT" NODE

1) establishment of a decubital ulcer

2) infection of the node

3) profuse uterine bleeding

4) extroversion of uterus

8. THE VOLUME OF SURGICAL TREATMENT FOR CERVICAL NODE LOCATION

1) supravaginal amputation of uterus

2) myomectomy using vaginal access

3) extirpation of uterus

4) surgical treatment of uterine fibroids of this localization shall not be implemented

9. THE MAIN METHOD OF DIAGNOSTICS REGARDING THE "NASCENT" NODE

1) transvaginal echography

2) examination of cervix in mirrors

3) hysteroscopy

4) laparoscopy 
10. FOR THE DIAGNOSIS OF SUBMUCOUS UTERINE FIBROIDS ARE INFORMATIVE AS FOLLOWS
1) transvaginal echography
2) hysterography
3) hysteroscopy
4) laparoscopy

11. EXTRAGENITAL COMPLICATIONS IN LARGE UTERINE FIBROIDS
1) hydronephrosis
2) intestinal obstruction
3) acute urinary retention
4) peptic ulcer of 12 duodenal ulcer

12. CONSERVATIVE MANAGEMENT IS POSSIBLE AS FOLLOWS

1) upon uterine fibroids per 7 weeks

2) upon the growth of fibroids in postmenopause

3) upon uterine fibroids per 5 weeks, metrorrhagia

4) upon cervical fibroids

13. THE METHOD OF SURGICAL TREATMENT UPON THE "BORN" MYOMATOUS NODE

1) extirpation of uterus

2) transcervical myomectomy

3) supravaginal amputation of uterus

4) laparoscopy, myomectomy

14. COMPLICATIONS UPON SUBSEROUS NODE LOCALIZATION
1) uterine bleeding
2) twisting the node stem
3) endometritis
4) node necrosis 


\section{DIFFERENTIAL DIAGNOSIS OF A SPORADIC SUBSEROUS NODE SHALL BE PERFORMED}

1) upon a bowel tumor

2) upon an ovarian tumor

3) upon a kidney ptosis

4) upon ectopic pregnancy

\section{Response Standards}

\begin{tabular}{|l|l|}
\hline \multicolumn{1}{|c|}{ Question No. } & \multicolumn{1}{c|}{ Correct answer } \\
\hline 1 & $1,2,3,4$ \\
\hline 2 & $1,2,3,4$ \\
\hline 3 & $1,2,3$ \\
\hline 4 & 4 \\
\hline 5 & $1,3,4$ \\
\hline 6 & 3,4 \\
\hline 7 & $1,2,3,4$ \\
\hline 8 & 2,3 \\
\hline 9 & 2 \\
\hline 10 & $1,2,3$ \\
\hline 11 & 1,3 \\
\hline 12 & 1,4 \\
\hline 13 & 2 \\
\hline 14 & 2,4 \\
\hline 15 & $1,2,3,4$ \\
\hline & \\
\hline
\end{tabular}




\section{SUGGESTED READING}

Adamyan L. V., Zayratyants O. V., Manukhin I. B., Tikhomirov A. L., Sonova M. M., Opalenov K. V., Kazenashev V. V., Kosheleva O. K., Ganeeva Zh. L. et al. The Suppression of Angiogenesis and Production of Growth Factors in Combination with the Induction of Metalloproteinase Activity within Uterine Leiomyomas past a Course of Ulipristal Therapy // Problems of Reproduction. 2014. № 4. P. 28-34.

Adamyan L. V., Zayratyants O. V., Tikhomirov A. L., Manukhin I. B., Opalino K. V.,Kazansev V. V.,Aliev, etc. Propotions and Antiproliferative Impact of Selective Modulator of Progesterone Ulipristal Receptors to Uterine Leiomyoma // Problems of Reproduction. 2014. № 3. P. 41-44.

Adamyan L. V., Andreeva E. N., Artymuk N. V., Belotserkovtseva L. D., refugee V. F., Gevorkyan M. A., Glukhov E. Yu., Gus A. I., Dobrokhotova E. A., Zhordania K. I., Zayratyants O. V. et al. Uterine Fibroids: Diagnosis, Treatment and Rehabilitation. Clinical Recommendations on Patients Management. M.: Scientific Centre of Obstetrics, Gynaecology and Perinatology named after Academician V. I. Kulakov, 2015.

Obstetrics and Gynaecology: The National Guide / Ed. by E.K. Aylamazyan, V.I. Kulakova, V.E. Radzinsky, G.M. Savelyeva. M.: GEOTAR-Media, 2009. 1218 p.

Vikhlyaeva E. M. The Guide to the Diagnosis and Treatment of Uterine Leiomyoma. M.: MEDpress-inform, 2004. 399 p.

Vikhlyaeva E. M., Zheleznov B. I., Zaporozhan V. N. et al. The Guide to the Endocrine Gynaecology. M.: Medical Information Agency, 1997. $768 \mathrm{p}$.

Zairatyants O. V., Sidorova I. S., Levakov S. A., Levin E. M., K. V. Palenov The Features of Morphogenesis and Angiogenesis of Uterine Leiomyomas // Archive of pathology. 2005. № 3. P. 29-31. 
Zayratyants $O$. V. PAEC (Progesterone receptor modulator Associated Endometrial Changes). Endometrial changes associated with progesterone receptor modulator. A new type of reversible morphological changes in the endometrium in the treatment of uterine leiomyoma with Esmia ${ }^{\circledR}$ (ulipristal acetate, pharmaceutical company $<<$ Gideon Richter $>$ ): The Guidelines for Pathologists and Obstetricians-Gynaecologists. M., 2013. 30 p.

Kondrikov N. I. The Pathology of Uterus: The Illustrated Guide. M.: Practical Medicine, 2008. 344 p.

Kondrikov N. I., Barinova I. V. Pathology of Uterus: The Guide for Physicians. 2nd ed. M.: Practical medicine, 2019. 352 p.

Levakov $S$. A. Options for the Development of Uterine Fibroids (Simple and Proliferating): Diss. Ph.D. in Med. Sc. M., 2001.

Levakov S. A., Zayratyants O. V., Borovkova E. I. The Efficacy and Safety of Selective Progesterone Receptor Modulators upon the Treatment of Patients with Simple and Proliferating Uterine Myoma // Obstetrics and Gynaecology. 2015. № 3. P. 94-99.

Uterine Fibroids: Diagnosis, Treatment and Rehabilitation: Clinical Recommendations Regarding the Patients Management / ed. by L. V. Adamyan. M., 2014. $30 \mathrm{p}$.

Savitsky G. A., Savitsky A. G. The Uterine Fibroids (Problems of Pathogenesis and Pathogenetic Therapy). 3rd Ed. SPb.: ALBI-SPb., 2003. $236 \mathrm{p}$.

Samoylova T. E. The Medication of Uterine Leiomyoma with Antigestagens: The Opportunities and Orospects // Gynaecology. 2011. Vol. 13, № 3. P. 62-68.

Serov V. V., Vasilevskaya L. N. The Uterine Fibroids. Some Issues of Pathogenesis, Clinics and Treatment. M.: Med., 1970. P. 11-18.

Sidorova I. S., Levakov S. A., Kapustiia I. N., Mametbekova R. B. The Materials of the II Russian Forum "Mother and Child". M., 2000. P. 294.

Sidorova I. C. Uterine Fibroids (Modern Problems of Etiology, Pathogenesis, Diagnosis and Treatment). M.: MIL, 2003. 256 p. 
Tikhomirov A. L. Fibroids, Gathogenetic Grounds of Organ Preserving Treatment. M., 2013. $319 \mathrm{p}$.

Tikhomirov A. L., Kazenashev V. V., Zayratyants O. V., Manukhin I. B. The First Clinical and Morphological Results of Patients Treatment with Uterine Myoma Using Ulipristal Acetate // Gynaecology. 2014. Vol. 16, № 2. P. 29-33.

Tikhomirov A. L., Zayratyants $O$. V. The Clinical and Morphological Characteristics of Uterine Fibroids past the Use of a Selective Receptors Modulator of Ulipristal Progesterone // The Issues of Gynecology, Obstetrics and Perinatology. 2014. Vol. 13, № 1. P. 67-73.

Tikhomirov A. L., Zayratyants $O$. V. The Clinical and Morphological Trend of Uterine Fibroids Treatment with Ulipristal Acetate // The Archive of Obstetrics and Gynaecology named after V.F. Snegireva. 2015. Vol. 2, № 4. P. 52-54.

Chmielnicki O. K. Cytological and Histological Diagnostics of Diseases of Cervix and Uterus Body. SPB: SOTIS, 1999.

Yakovlev I. A., Kukute B. G. The Morphological Diagnosis of Precancerous Processes and Cancer of Uterine under Biopsies and Swabs. Kishinev: STIINCA, № 1979.

Baird D. D., Hill M. C., Schectman J. M., Hollis V. W. Vitamin D and the risk of uterine fibroids // Epidemiology. 2013. Vol. 24. P. 447.

Vitamin D and the risk of uterine fibroids A. The impact of uterine leiomyomas: a national survey of affected women // Am J Obstet Gynecol. 2013. Vol. 209. P. 319.

Chabbert-Buffet N., Mesuri G., Bouchard P., Spitz M. Selective progesterone receptor modulatois and progesterone antagonists: mechanisms of action and clinical applications // Hum. Reprod. Up-dated. 2005. Vol. 11. P. 293-307.

Donnez J., Tatarchuk T.F., Bouchard P. et al. Ulipristal acetate versus placebo for fibroid treatment before surgery // N. En-gl.J. Med. 2012. Vol. 366. P. 409-4020.

Donnez J., Tomaszewski., Vazquez F. et al. Ulipristal acetate versus leuprolide acetate for uterine fibroids // N. Engl. J. Med. 2012. Vol. 366. P. 421-32. 
Donnez J., Vazquez F., Tomaszewski. et al. Longterm treatment of uterine fibroids with uli pristal acetate. Efficacy and safety of repeated use of ulipristal acetate in uterine fibroids. (PEARL IV) // Fertility and Sterilit y. 2014. Vol. 103 (2). P. 519-27.

Donnez J., Vazquez F., Tomaszewski. et al. Longterm medical management of uterine fibroids with ulipristal acetate // Fertility and Sterility. 2016. Vol. 105. P. 165-73.

Eggert S.L., Huyck K.L., Somasundaram P. et al. Genome-wide linkage and association analyses implicate FASN in predisposition to Uterine Leiomyomata // Am J Hum Genet. 2012. Vol. 91. P. 621.

Kurman R.J., Carcangiu M.L., Herrington C.S., Young R.H. (eds.). WHO Classification of Tumours of Female Reproductive Organs (4th edition). IARC: Lyon, 2014.

Laughlin S.K.,Hartmann K.E.,Baird D.D. Postpartum factors and natural fibroid regression // Am J Obstet Gynecol. 2011. Vol. 204. P. 496.e1.

Miikinen N., Vahteristo P., Bytzow R. et al. Exomic landscape of MED12 mutation-negative and -positive uterine leiomyomas // Int J Cancer. 2014. Vol. 134. P. 1008.

Marsh E.E., Ekpo G.E., Cardozo E.R. et al. Racial differences in fibroid prevalence and ultrasound findings in asymptomatic young women (18-30 years old): a pilot study // Fertil Steril. 2013. Vol. 99. P. 1951.

Mehine M., Kaasinen E., Mdkinen N. et al. Characterization o $\mathrm{f}$ uterine leiomyomas by whole-genome sequencing // N Engl J Med. 2013. Vol. 369. P. 43.

Puri K., Famuyide A.O., Erwin P.]. et al. Submucosa 1 fibroids and the relation to heavy menstrual bleeding and anemia // Ат $J$ Obstet Gупесol. 2014. Vol. 210. P. 38.

Radin R.G., Palmer J.R., Rosenberg L. et al. Dietary glycemic index and load in relation to risk of uterine leiomyomata in the Black Women's Health Study // Ат J Clin Nutr. 2010. Vol. 91. P. 1281.

Seth S., Goel N., Singh E., Mathur A.S., Gupta G. Effect of mifepristone $(25 \mathrm{mg})$ in treatment of uterine myoma in peri- 
menopausal woman // Journal of Mid-Life Health. 2013. Vol. 4 (1). P. 22-6. DOI: 10.4103/ 0976-7800.109630.

Wechter M.E.,Stewart E.A.,Myers E. R. et al. Leiomyoma-related hospitalization and surgery: prevalence and predicted growth based on population trends // Am J Obstet Gyнecol. 2011. Vol. 205. P. 492.e1.

Williams A., Glant M. PRM-Associated Endometrial Changes (PAEC). ESMYA"' (ulipristal acetate). Pathologist's guide. Medical Information Service Preglem S.A. Geneva: Switzerland, 2012.

Wise L. A.,Radin R.G.,Palmer J.R. et al. A prospective study of dairy intake and risk of uterine leiomyomata // Am J Epidemiol. 2010. Vol. 171. P. 221.

Wise L.A., Radin R.G., Palmer. R et al. Intake of fruit, vegetables, and carotenoids in relation to risk of uterine leiomyomata // Am J Clin Nutr. 2011. Vol. 94. P. 1620. 


\section{LIST OF ABBREVIATIONS}

AGn-RH - the agonists of gonadotropin-releasing hormone IUD - intrauterine device

HSG - hysterosalpingography

$\mathrm{GnRH}$ - gonadotropin-releasing hormone

IHC - immunohistochemical (reaction)

ICI - isthmic-cervical insufficiency

$\mathrm{COC}$ - combined oral contraceptives

CT - computer tomography

LDH - lactate dehydrogenase

MSCT - multispiral computed tomography

PRM - progesterone receptor modulators

MRI - magnet-resonance imaging

NSAIPs - non-steroidal anti-inflammatory pharmaceuticals

SPRM - selective progesterone receptor modulators

PI - placental insufficiency

USE - ultrasonic examination

CDM - color Doppler mapping

ALKALINE PHOSPHATASE / AP - alkaline phosphatase

MRgFUS - magnetic resonance focal ultrasonic surgery 


\section{CONTENTS}

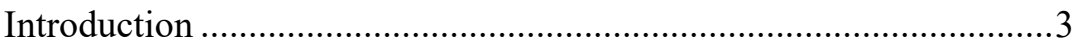

Terminology, Epidemiology, and Risk Factors ...............................4

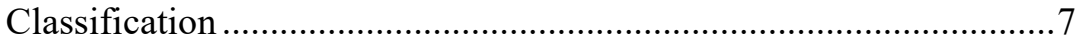

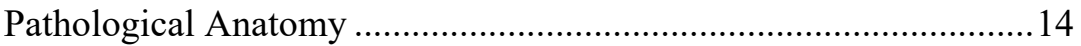

Etiology, Pathogenesis and Morphogenesis

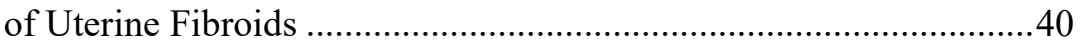

Clinics of Uterine Fibroids ..............................................................51

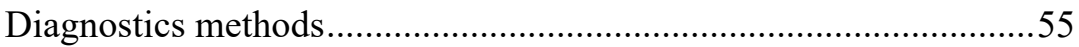

Treatment of Patients with Uterine Fibroids ....................................63

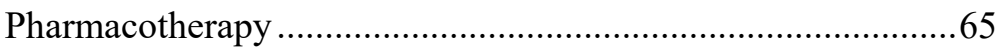

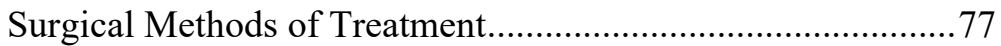

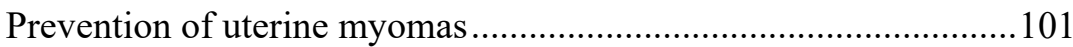

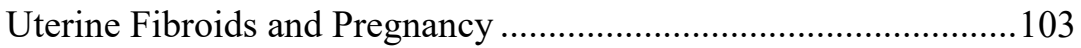

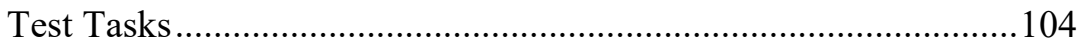

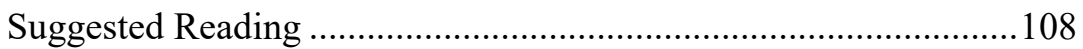

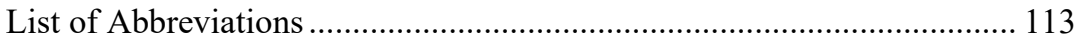


Educational edition

Statnykh N.V., Padrul M.M., Olina A.A., Sadykova G.K., Chugaeva T.N., Shirinkina E.V.

\section{UTERINE MYOMA GUIDELINES}

Study guide for students of the medical faculty

Technical editor M.N. Afanaseva

Подписано в печать 22.03.2021. Формат 60×90/16.

Усл. печ. л. 7,25. Тираж 50 экз. Заказ № 48/2021.

ИП Серегина О.Н.

Адрес: 614107, г. Пермь, ул. Металлистов, д. 21, кв. 174. 